\title{
Melastoma malabathricum (L.) Smith Ethnomedicinal Uses, Chemical Constituents, and Pharmacological Properties: A Review
}

\author{
S. Mohd. Joffry, ${ }^{1}$ N. J. Yob, ${ }^{1}$ M. S. Rofiee, ${ }^{1}$ M. M. R. Meor Mohd. Affandi, ${ }^{1}$ \\ Z. Suhaili, ${ }^{2}$ F. Othman, ${ }^{3}$ A. Md. Akim, ${ }^{3}$ M. N. M. Desa, ${ }^{3,4}$ and Z. A. Zakaria ${ }^{3}$ \\ ${ }^{1}$ Departments of Pharmaceutics and Pharmaceutical Sciences, Faculty of Pharmacy, Universiti Teknologi MARA, \\ Puncak Alam Campus, Selangor, 42300 Bandar Puncak Alam, Malaysia \\ ${ }^{2}$ Faculty of Agriculture and Biotechnology, Universiti Sultan Zainal Abidin, Kampus Kota, Jalan Sultan Mahmud, \\ 20400 Kuala Terengganu, Malaysia \\ ${ }^{3}$ Department of Biomedical Science, Faculty of Medicine and Health Sciences, Universiti Putra Malaysia, Selangor, \\ 43400 UPM Serdang, Malaysia \\ ${ }^{4}$ Halal Products Research Institute, Universiti Putra Malaysia, Selangor, 43400 UPM Serdang, Malaysia
}

Correspondence should be addressed to Z. A. Zakaria, dr_zaz@yahoo.com

Received 26 July 2011; Accepted 4 September 2011

Academic Editor: Angelo Antonio Izzo

Copyright () 2012 S. Mohd. Joffry et al. This is an open access article distributed under the Creative Commons Attribution License, which permits unrestricted use, distribution, and reproduction in any medium, provided the original work is properly cited.

\begin{abstract}
Melastoma malabathricum L. (Melastomataceae) is one of the 22 species found in the Southeast Asian region, including Malaysia. Considered as native to tropical and temperate Asia and the Pacific Islands, this commonly found small shrub has gained herbal status in the Malay folklore belief as well as the Indian, Chinese, and Indonesian folk medicines. Ethnopharmacologically, the leaves, shoots, barks, seeds, and roots of M. malabathricum have been used to treat diarrhoea, dysentery, hemorrhoids, cuts and wounds, toothache, and stomachache. Scientific findings also revealed the wide pharmacological actions of various parts of $M$. malabthricum, such as antinociceptive, anti-inflammatory, wound healing, antidiarrheal, cytotoxic, and antioxidant activities. Various types of phytochemical constituents have also been isolated and identifed from different parts of M. malabathricum. Thus, the aim of the present review is to present comprehensive information on ethnomedicinal uses, phytochemical constituents, and pharmacological activities of M. malabathricum.
\end{abstract}

\section{Introduction}

Melastomataceae plants originate in the tropic and subtropic regions, with a total of more than 4000 species in the world. In the Southeast Asian region alone, the genus Melastoma comprises 22 species, 2 subspecies, and 3 varieties [1]. Malaysia, particularly, with a tropical climate, is home to at least 12 species, many of which are used by natives in folk medicine. One of the plants within the Melastomataceae family that have gained herbs status in the Malay folklore belief is Melastoma malabathricum Linn., which has been known to comprise two subspecies, namely, M. malabathricum L. ssp. malabathricum and M. malabathricum Linn ssp. normale [2].

In general, M. malabathricum is a small shrub commonly found in previously cleared land, waste places, and road- side throughout the Southeast Asian countries, including Malaysia [3]. It is native to tropical and temperate Asia and the Pacific Islands [4]. The plant is one of the most common weeds that grow wildly and abundantly throughout the tropics, especially in the moist areas, and can be found in the Indian Ocean Islands, throughout South and South-East Asia, China, Taiwan, Australia, and the South Pacific Ocean [5]. Throughout Malaysia, particularly, the plant is very common in the lowland and mountain forests, chiefly in open places. M. malabathricum has different vernacular names depending on the location (e.g., Malaysia, Indonesia, China, and India) where the plant was found and the communities or tribes (e.g., Malay, Chinese, and Indian) that used them traditionally for medicinal purposes [4, 6-20] (Table 1). 
TABLE 1: The vernacular name of $M$. malabthricum.

\begin{tabular}{|c|c|c|c|c|}
\hline No. & Vernacular names & Language & Country & References \\
\hline 1 & $\begin{array}{l}\text { Senduduk, Sekeduduk, } \\
\text { Kenduduk }\end{array}$ & Malay & Malaysia & $\begin{array}{l}\text { Abdul Majid and Ting [6] } \\
\text { Fazlin et al. [7] }\end{array}$ \\
\hline \multirow{3}{*}{2} & Kendudu, Pucuk Kenduduk & Riau & \multirow{3}{*}{ Indonesia } & Grosvenor et al. [8] \\
\hline & Harendong & Sunda & & Abdul Majid and Ting [6] \\
\hline & Kluruk, Senggani & Jawa & & Fazlin et al. [7] \\
\hline \multirow{2}{*}{3} & Singapore rhododendron & \multirow{2}{*}{ English } & Singapore, Britain & Ling et al. [4] \\
\hline & Malabar melastome & & Britain & $\begin{array}{l}\text { Umali-Stuart and } \\
\text { Stiuart-Santiago [9] }\end{array}$ \\
\hline 4 & $\begin{array}{l}\text { Mang kre, Mang re, Bre, } \\
\text { Kadu-da }\end{array}$ & Thais & Thailand & Fazlin et al. [7] \\
\hline \multirow{3}{*}{5} & Malatungau, Malatungaw & Ibanag & \multirow{3}{*}{ Philippine } & \\
\hline & Bubtoi & Sambali & & $\begin{array}{l}\text { Umali-Stuart and } \\
\text { Stiuart-Santiago [9] }\end{array}$ \\
\hline & Yagomyum & Cebu Bisaya & & \\
\hline 6 & Ye mu dan & Chinese & China & Zhengyi et al. [10] \\
\hline \multirow{7}{*}{7} & Builukhampa & Mizoram & \multirow{7}{*}{ India } & Sharma et al. [11] \\
\hline & Yachubi & Manipur (Meitei tribe) & & Khumbongmayum et al. [12] \\
\hline & Longumpo, Bobuchunmei & Manipur (Naga tribe) & & Ringmichon et al. [15] \\
\hline & Karali & Malkangiri & & Pattanaik et al. [13] \\
\hline & Chuthuksuru & Wokha (Loga-Naga tribes) & & Jamir et al. [17] \\
\hline & Kechi-yaying & Arunachal Pradesh (Adi tribes) & & Kagyung et al. [16] \\
\hline & Koroli & Mayurbhanj & & Thatoi et al. [14] \\
\hline \multirow{3}{*}{8} & Koiam-pay-bang & Bandarban (Marma tribe) & \multirow{3}{*}{ Bangladesh } & Rahmatullah et al. [18] \\
\hline & Kakkhu & Netrakona (Garo tribe) & & Rahmatullah et al. [19] \\
\hline & Aksio & $\begin{array}{l}\text { Chittaggong (Chakma, Murong, } \\
\text { Tonchonga tribes) }\end{array}$ & & Rahmatullah et al. [20] \\
\hline
\end{tabular}

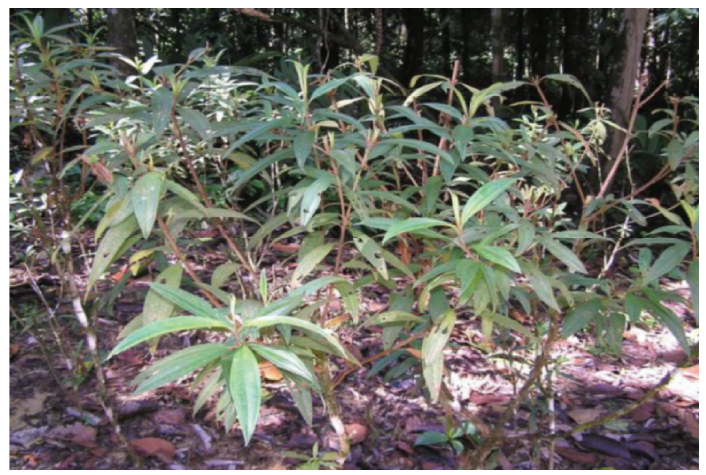

Figure 1: The shrubs of Melastoma malabathricum L. (adapted from http://www.google.com/).

This showy bush of small trees rapidly colonises wastelands as their seeds are dispersed by birds. The characteristics of $M$. malabathricum include its average height of 0.5-1(-5) $\mathrm{m}$ high but may occasionally grow up to $5 \mathrm{~m}$ long (Figure 1). The stems are 4-sided to subterete, generally bristly, covered with small rough scales, and reddish. Branchlets are numerous, procumbent, densely covered with appressed scales. The petiole is approximately $0.5-1.9 \mathrm{~cm}$ while the leaves are blade ovate, elliptic, or elliptic-lanceolate, 4-14

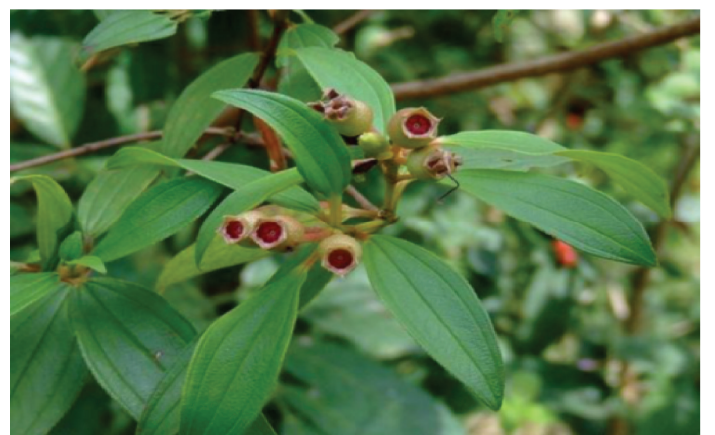

FIGURE 2: The leaves and fruits of M. malabathricum L. (adapted from http://www.google.com/).

$\times 1.7-3.5(-6) \mathrm{cm}$, stiffly papery, abaxially densely strigose and puberulous, adaxially densely strigose, secondary veins 2 (or 3) on each side of midvein, tertiary veins numerous and parallel, base rounded to subcordate, margin entire, apex acuminate (Figure 2). Inflorescences subcapitate corymbose, terminal, 3-7-flowered, with 2 leaflike bracts at base. Pedicel 2-8(-10) mm, strigose, apically 2-bracteolate, bracteoles lanceolate to subulate, $2-5 \mathrm{~mm}$, abaxially densely strigose, margin ciliate. Hypanthium 5-9 mm, densely compressed 


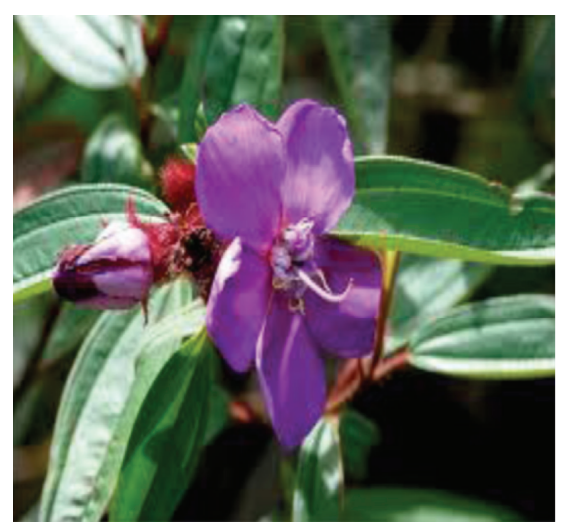

(a)

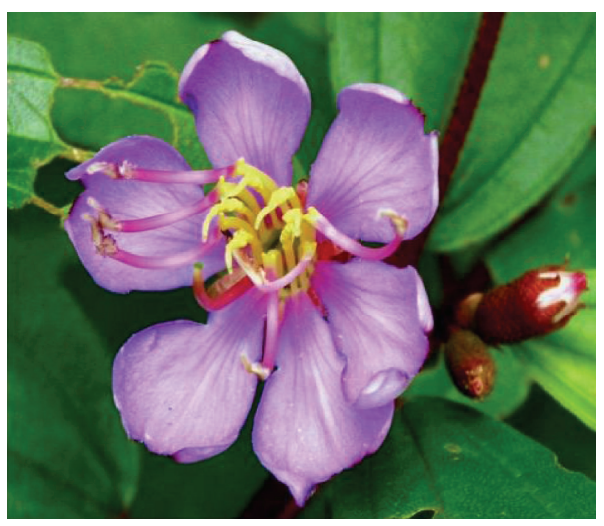

(b)

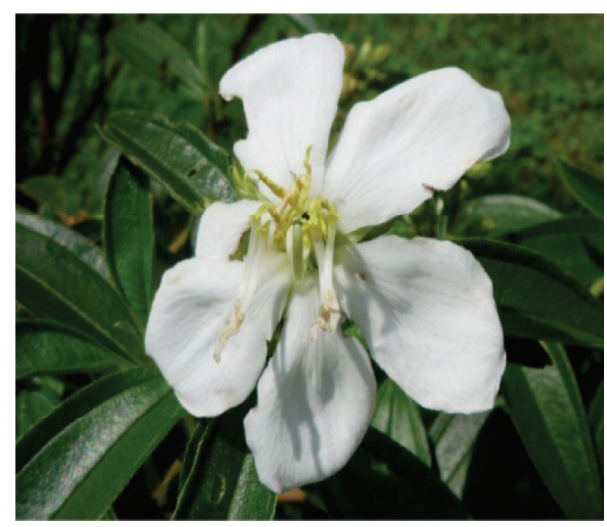

(c)

FIGURE 3: Melastoma malabathricum flowers with different petal colour. (a) Dark purple-magenta petals, (b) light pink-magenta petals, and (c) white petals (adapted from http://www.google.com/).

strigose, margin fimbriate. Calyx lobes lanceolate to ovatelanceolate, apex acuminate, on both sides and along their margin squamosly strigose and pubescent. Petals reddish purple, $2-3(-4) \mathrm{cm}$, margin only ciliate, apex rounded. The flowers, which are short-lived and last only a day, grow in 5 to 10 clusters and have 5 petals [21]. The flower has ten stamens of two different kinds: five larger ones with yellow filaments and purple curved upper parts including the anther and five smaller ones with yellow and straight filaments and yellow anthers. On rare occasions, M. malabathricum consists of three varieties, having large-, medium- and small-size flowers with dark purple-magenta petals (Figure 3(a)), light pink-magenta petals (Figure 3(b)), and (the rare variety) white petals (Figure 3(c)) [22]. The calyx closely set with short chaffy and silky or silvery scale. Longer stamens with connective long extended at base, curved, apex bifid. Shorter stamens with anthers 2-tuberculate at base; connective not extended. Ovary half inferior, densely strigose, apically with a ring of setae. Fruit urceolate-globular, 6-15 $\times 6-12 \mathrm{~mm}$, succulent, densely squamose strigose [10]. The fruits are technically classified as berries, and, when they are ripe, they break open irregularly to reveal the soft, dark purple, sweet but rather astringent-tasting pulp and numerous orange seeds (Figures 4(a) and 4(b)). The seeds are dimorphic: with or without embryos. Fertile seeds are folded or spiral, tri- angular to $\mathrm{D}$-shaped in outline, $0.45-0.8 \mathrm{~mm}$ long, $0.35-$ $0.6 \mathrm{~mm}$ wide, $0.17-0.3 \mathrm{~mm}$ thick, with light yellow or pale to dark cream-coloured testa. Seeds without embryo are similar to the fertile seeds but smaller, $0.3-0.5 \mathrm{~mm}$ long, $0.2-0.3 \mathrm{~mm}$ wide, $0.2 \mathrm{~mm}$ thick, appear collapsed, dented, or wrinkled and with completely black or reddish-black testa. The seeds are tasteless and can be eaten, and they stain the tongue black. The name "melastoma" is Greek for "black mouth," a name appreciated by generations of children who have eaten the berries. M. malabathricum has evergreens and flowers throughout the year [23].

M. malabathricum has been claimed to possess various medicinal values according to the communities/tribes traditional beliefs and, interestingly, the whole plant could be used as herbal medicine. It is also a well-known herb in Malaysia, particularly, where its leaves, shoots, and roots are prepared in various ways for treatment of different diseases and ailments (Table 2(a)). Many reviews have appeared in the literature regarding $M$. malabathricum medicinal uses. However, none have described the complete chemical and pharmacological properties of this important ethnomedicinal plant. Therefore, we aimed to compile an up-to-date and comprehensive review of M. malabthricum that covers its ethnomedicinal uses, phytochemical contents, and scientifically proven pharmacological properties. 


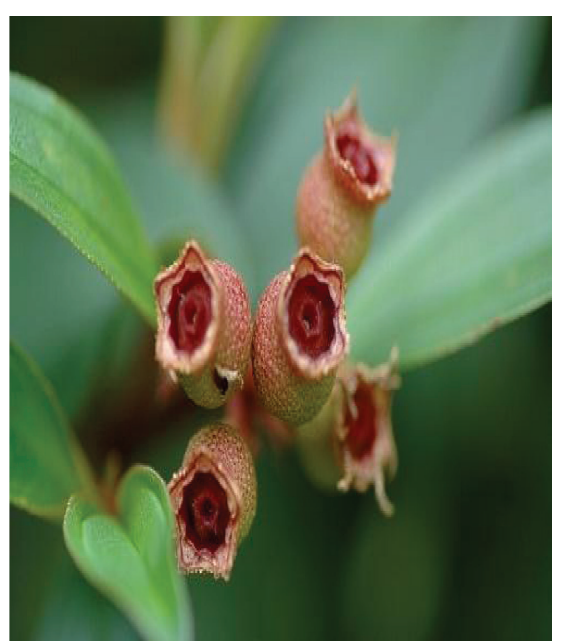

(a)

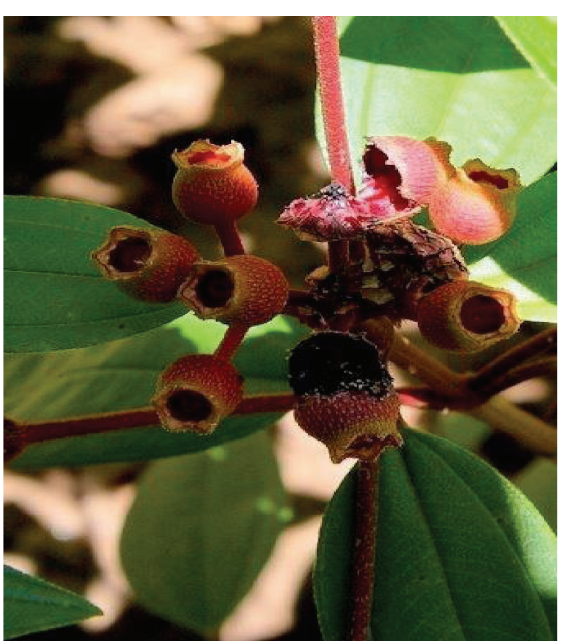

(b)

Figure 4: The fruits of Melastoma malabathricum. (a) Unripe fruits, and (b) ripe fruits revealing the soft, dark purple, sweet pulp, and numerous orange seeds (adapted from http://www.google.com/).

\section{Ethnomedicinal Uses}

There are a lot of uses for M. malabathricum reported in folk medicine, but not supported by clinical data [23-25]. Generally, various parts (e.g., leaf, roots, and/or barks) of the plant are used in Malay, Indian, and Indonesian folk medicines to treat various types of ailments and diseases, for example, diarrhoea, dysentery, leucorrhoea, hemorrhoids, cuts and wounds, infection during confinement, toothache, stomachache, flatulence, sore legs, and thrush [23, 26, 27] (Table 2). There is also report on the use of M. malabathricum seeds in the famous "poh chi" pills to treat diarrhea in traditional Chinese medicine [28].

2.1. Reports on Traditional Uses of Various Parts of M. malabathricum. The leaves are chewed up, pounded, and applied as paste on cuts or wounds or finely chopped up and squeezed to apply the juice onto the wound to stop bleeding $[29,30]$. According to Sharma et al. [11] the leaves can also be used to prevent scarring from smallpox, to treat dysentery, diarrhoea, and piles, and as a tonic. The young leaves are eaten to treat diarrhea while the young premature leaves are consumed raw to cure dysentery [23, 31]. The shoots can be ingested to treat puerperal infections, high blood pressure, and diabetes $[23,24]$ while the shoots juice can also be used as a mouthwash to relieve a toothache or to treat leukorrhea. Other than those mentioned above, the leaves are also medicinally useful to treat ulcers, gastric ulcers, scar, pimple, and black spot at skin [32]. The roots can also be used as mouthwash to relieve a toothache and to treat epilepsy $[24,25,32]$, given to postpartum women to aid healing and womb strengthening $[7,25,30]$ or to alleviate rheumatism, arthritis, and tenderness in the legs [23, 24]. The decoction of the roots is used to treat diarrhea [33]. In addition, the roots' liquid can be applied to lessen the soreness due to thrush in children $[23,24]$. The barks are medicinally useful for the treatment of various skin diseases [34]. The flowers are also used in India to treat cancer [35].
Other than that, the powdered leaves and roots can be applied to wounds and pox scars to aid the healing process [7, 24] or used to relieve the discomfort of hemorrhoids [7] with the former also used as astringent for dysentery [9]. The juice of leaves and roots is used as a digestive aid [9]. Furthermore, the leaves and flowers are useful for the treatment of cholera, diarrhoea, prolonged fever, dysentery, leucorrhoea, wounds, and skin diseases and for the preparation of gargles [11, 23, $24,36]$. The decoction of roots and leaves or roots alone are also traditionally used to tone up the uterus after childbirth in order to strengthen the womb and accelerate wound healing. Other than that, women also use this herb for excessive menstrual bleeding and cramps, to relieve postmenstrual syndrome, stomach ache, and white discharge, and to enhance fertility [23]. Its flowers, seeds, and leaves are used to reduce white vaginal discharge and indigestion [9]. The flowers of $M$. malabathricum are also used as a nervous sedative and for hemorrhoidal bleeding [9]. The combination of leaves and flowers is used as astringent in leukorrhea and chronic diarrhea [9]. Despite being a traditional medicinal herb that is widely used, particularly, in Malay culture, there is not much scientific study carried out on M. malabathricum.

2.2. Reports on the Uses of M. malabathricum by Various Communities/Tribes. The list of medicinal uses of M. malabathricum according to the different communities or tribes reported around the world is shown in Table 2(b). According to Elliott and Brimacombe [37] the cold infusion of $M$. malabthricum flowers is an optional ingredient added to an oral remedy for anaemia associated with gastrointestinal bleeding and epigastric pain. The Talang Mamak peoples of Riau province, Sumatra, Indonesia, used the ground leaf and applied it as a compress to cuts and wounds [8]. A survey of the Malay ethnomedico botany in the Machang district, Kelantan, Malaysia, revealed the application of $M$. malabathricum fruits juice on dry lip [38] while in the Gemenceh 
TABle 2: (a) Medicinal uses of M. malabathricum according to its part. (b) Medicinal uses of M. malabathricum according to several communities/tribes reported around the world.

(a)

\begin{tabular}{|c|c|c|}
\hline Plant parts & Medicinal uses & Reference \\
\hline \multirow{10}{*}{ Leaves } & $\begin{array}{l}\text { Leaves are chewed up, pounded, and applied as paste on cuts or } \\
\text { wounds or finely chopped up and squeezed to apply the juice onto } \\
\text { the wound to stop bleeding }\end{array}$ & $\begin{array}{l}\text { Latiff and Zakri [29]; } \\
\text { Jaganath and } \mathrm{Ng}[25] \\
\text { Zakaria et al. }[30]\end{array}$ \\
\hline & $\begin{array}{l}\text { Leaves are used to prevent scarring from smallpox, to treat dysentery, } \\
\text { diarrhoea, piles, and as a tonic }\end{array}$ & Sharma et al. [11] \\
\hline & Young leaves are eaten to treat diarrhea & Jaganath and Ng [25] \\
\hline & Young premature leaves are consumed raw to cure dysentery & Sajem and Gosai [31] \\
\hline & $\begin{array}{l}\text { Leaves are also useful to treat ulcers, gastric ulcers, scar, pimple, and } \\
\text { black spot at skin }\end{array}$ & Lohézic-Le Dévéhat et al. [32] \\
\hline & $\begin{array}{l}\text { Combination of leaves and roots in powder form is applied to } \\
\text { wounds and pox scars to aid the healing process or used to relieve the } \\
\text { discomfort of hemorrhoids }\end{array}$ & Burkill [24]; Fazlin et al. [7] \\
\hline & Powdered leaves alone is used as astringent for dysentery & $\begin{array}{l}\text { Umali-Stuart and } \\
\text { Stiuart-Santiago [9] }\end{array}$ \\
\hline & Juice of leaves and roots is used as a digestive aid & $\begin{array}{l}\text { Umali-Stuart and } \\
\text { Stiuart-Santiago [9] }\end{array}$ \\
\hline & $\begin{array}{l}\text { Combination of leaves and flowers is used in the treatment of cholera, } \\
\text { diarrhoea, prolonged fever, dysentery, leucorrhoea, wounds, and skin } \\
\text { diseases and for the preparation of gargles }\end{array}$ & $\begin{array}{l}\text { Perry [36]; Burkill [24]; } \\
\text { Koay [23]; Sharma et al. [11] }\end{array}$ \\
\hline & $\begin{array}{l}\text { Combination of leaves and flowers is used as astringent in leukorrhea } \\
\text { and chronic diarrhea }\end{array}$ & $\begin{array}{l}\text { Umali-Stuart and } \\
\text { Stiuart-Santiago [9] }\end{array}$ \\
\hline \multirow[t]{2}{*}{ Shoots } & $\begin{array}{l}\text { Shoots are ingested to treat puerperal infections, high blood pressure, } \\
\text { and diabetes }\end{array}$ & Burkill [24]; Koay [23] \\
\hline & $\begin{array}{l}\text { Juice of shoots is used as a mouthwash to relieve a toothache or to } \\
\text { treat leukorrhea }\end{array}$ & \\
\hline \multirow{6}{*}{ Roots } & $\begin{array}{l}\text { Roots are used as mouthwash to relieve a toothache and to treat } \\
\text { epilepsy }\end{array}$ & $\begin{array}{l}\text { Burkill [24]; } \\
\text { Jaganath and Ng [25]; } \\
\text { Lohézic-Le Dévéhat et al. [32] }\end{array}$ \\
\hline & $\begin{array}{l}\text { Roots are given to postpartum women to aid healing and womb } \\
\text { strengthening }\end{array}$ & $\begin{array}{l}\text { Fazlin et al. [7]; Jaganath and } \\
\mathrm{Ng} \text { [25]; Zakaria et al. [30] }\end{array}$ \\
\hline & $\begin{array}{l}\text { Roots are used to alleviate rheumatism, arthritis, and tenderness in } \\
\text { the legs }\end{array}$ & Burkill [24]; Koay [23] \\
\hline & Decoction of roots is used to treat diarrhea & $\operatorname{Lin}[33]$ \\
\hline & $\begin{array}{l}\text { Juice of roots is applied to lessen the soreness due to thrush in } \\
\text { children }\end{array}$ & Burkill [24]; Koay [23] \\
\hline & $\begin{array}{l}\text { Combination of roots and leaves in a form of decoction or roots } \\
\text { alone are used to tone up the uterus after childbirth in order to } \\
\text { strengthen the womb and accelerate wound healing, reduce excessive } \\
\text { menstrual bleeding and cramps, relieve postmenstrual syndrome, } \\
\text { stomach ache, and white discharge, and enhance fertility }\end{array}$ & Koay $[23]$ \\
\hline Barks & Barks are useful for the treatment of various skin diseases & Jain and De Filipps [34] \\
\hline \multirow{3}{*}{ Flowers } & Flowers are used to treat cancer & $\begin{array}{l}\text { Mohandoss and Ravindran } \\
\text { [35] }\end{array}$ \\
\hline & Flowers are used as a nervous sedative and for hemorrhoidal bleeding & $\begin{array}{l}\text { Umali-Stuart and } \\
\text { Stiuart-Santiago [9] }\end{array}$ \\
\hline & $\begin{array}{l}\text { Combination of flowers, seeds, and leaves is used to reduce white } \\
\text { vaginal discharge and indigestion }\end{array}$ & Jaganath and $\mathrm{Ng}$ [25] \\
\hline
\end{tabular}


(b)

\begin{tabular}{|c|c|c|c|}
\hline Communities/tribes & Country & Medicinal uses & Reference \\
\hline Gayo and Alas & Aceh, Sumatra, Indonesia & $\begin{array}{l}\text { The cold infusion of } M \text {. malabthricum flowers is } \\
\text { an optional ingredient added to an oral remedy } \\
\text { for anaemia associated with gastrointestinal } \\
\text { bleeding and epigastric pain }\end{array}$ & $\begin{array}{l}\text { Elliott and Brimacombe } \\
\text { [37] }\end{array}$ \\
\hline Talang Mamak & Riau, Sumatra, Indonesia & $\begin{array}{l}\text { The ground leaves are applied as a compress to } \\
\text { cuts and wounds }\end{array}$ & Grosvenor et al. [8] \\
\hline \multirow[t]{2}{*}{ Malay } & $\begin{array}{l}\text { Machang, Kelantan, } \\
\text { Malaysia }\end{array}$ & The fruit juice is applied on dry lips & Ong and Nordiana [38] \\
\hline & $\begin{array}{l}\text { Gemenceh, Negri } \\
\text { Sembilan, Malaysia }\end{array}$ & $\begin{array}{l}\text { The pounded leaves are applied onto wounds to } \\
\text { accelerate healing }\end{array}$ & Ong and Nordiana [39] \\
\hline Jah Hut & Jerantut, Pahang, Malaysia & $\begin{array}{l}\text { The roots are applied as decoction to treat } \\
\text { diarrhea }\end{array}$ & $\operatorname{Lin}[33]$ \\
\hline Lakher and Pawi & Mizoram, India & $\begin{array}{l}\text { The decoction of the leaves or its juice is taken } \\
\text { orally to treat diarrhoea and dysentery }\end{array}$ & Sharma et al. [11] \\
\hline Meitei & $\begin{array}{l}\text { Manipur and Mayurbhanj, } \\
\text { Orissa, India }\end{array}$ & $\begin{array}{l}\text { The bark and leaves are used for treating skin } \\
\text { troubles, leukorrhea, diarrhea, and dysentry }\end{array}$ & Thatoi et al. [14] \\
\hline Didayi & Malkangiri, Orissa, India & $\begin{array}{l}\text { The leaves are applied externally as paste to treat } \\
\text { cuts and wounds }\end{array}$ & Pattanaik et al. [13] \\
\hline Sundanese & Bogor, West Java, Indonesia & $\begin{array}{l}\text { The leaves is used as topical application or oral } \\
\text { ingestion to treat toothache and for postpartum } \\
\text { remedy }\end{array}$ & Roosita et al. [40] \\
\hline Marmas & Bandarban, Bangladesh & The root juice is used to treat jaundice & Rahmatullah et al. [18] \\
\hline Garo & Netrakona, Bangaldesh & $\begin{array}{l}\text { The leaf juice is used as a diuretic and to treat } \\
\text { various urinary problems }\end{array}$ & Rahmatullah et al. [19] \\
\hline Murong & Rangamati, Bangladesh & $\begin{array}{l}\text { The root juice or water extract of boiled roots are } \\
\text { used orally to treat leukorrhea }\end{array}$ & Rahmatullah et al. [20] \\
\hline \multirow[t]{2}{*}{ Naga } & Manipur, India & $\begin{array}{l}\text { The fresh and dry leaves are used to treat cuts and } \\
\text { wounds, stomach disorder, and fever }\end{array}$ & Ringmichon et al. [15] \\
\hline & Tahiti & $\begin{array}{l}\text { The plant is used to treat diarrhea and dysentery } \\
\text { with its bark decoction used as gargle }\end{array}$ & $\begin{array}{l}\text { Umali-Stuart and } \\
\text { Stiuart-Santiago [9] }\end{array}$ \\
\hline
\end{tabular}

district, Negri Sembilan, Malaysia, the Malays applied $M$. malabathricum pounded leaves onto wounds to accelerate healing [39]. The Jah Hut tribe in Jerantut district, Pahang, Peninsular, Malaysia, used the roots of M. malabathricum as decoction to treat diarrhea [33]. The native peoples of Mizoram, India, used the decoction of the leaf or its juice, which is taken orally, in the treatment of diarrhoea and dysentery [11]. The Meitei community living in Manipur district in India and other tribes living in the Similipal Biosphere Reserve, situated in Mayurbhanj district of Orissa, India, used the bark and leaves of M. malabathricum for treating skin troubles, leukorrhea, diarrhea, and dysentery [14] while the Didayi tribe of Malkangiri district of Orissa, India, used the leaf externally as paste to treat cuts and wounds [13]. The Sundanese community of the West Java, Indonesia, uses the leaf of M. malabathricum as topical application or oral ingestion to treat toothache and for postpartum remedy [40]. The Marmas community of Naikhongcharri, Bandarban district, Bangladesh, used the root juice to treat jaundice [18]. The Garo tribal community living in Netrakona district, Bangladesh, used the leaf juice as diuretic and to treat various urinary problems [19]. The Murong tribes residing in the Rangamati district in the Chittagong Hill Tracts region, Bangladesh, used the squeezed juice from the roots or water extract of the boiled roots orally to treat leukorrhea [20]. In Tahiti, M. malabathricum is used to treat diarrhea and dysentery with its bark decoction used as gargle [9]. The Naga tribe of Manipur district, India, used the fresh and dry leaves of $M$. malabathricum to treat cuts and wounds, stomach disorder, and fever [15].

\section{Phytochemical Constituents}

Various phytochemical groups and constituents have been identified in M. malabathricum since 1968 and are strongly associated with its ethnomedicinal values (Tables 3(a) and 3(b)). Earlier study by Lowry [41] showed the presence of ellagic acid and anthocyanin (e.g., malvidin-3,5-diglucoside) in the methanol extract of $M$. malabathricum barks (MMMBk) and aqueous extract of M. malabathricum flowers (AMMFw), respectively. Meanwhile, Lowry [42] also reported the presence of anthocyanins (e.g., cyanidin- (Cy-) 3-glucoside and Cy-3,5-diglucoside) in the water extract of M. malabathricum fruits (WMMFr). Manzoor-I-Khuda et al. [43] reported the isolation of $\beta$-sitosterol and a triterpenoid designated as melastomic acid (5-hydroxylup-20(29) -en-28-oic acid) from the ethanolic extract of $M$. malabathricum roots (EMMR). Dinda and Saha [44] reported 


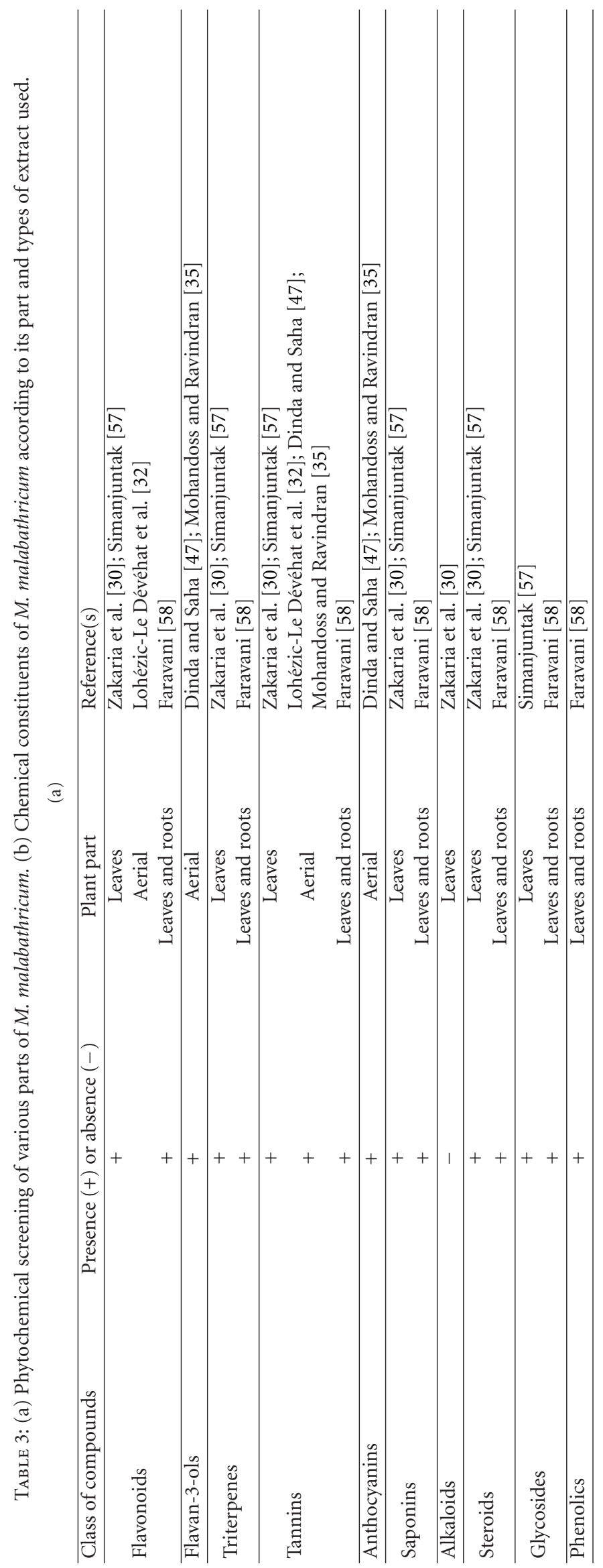




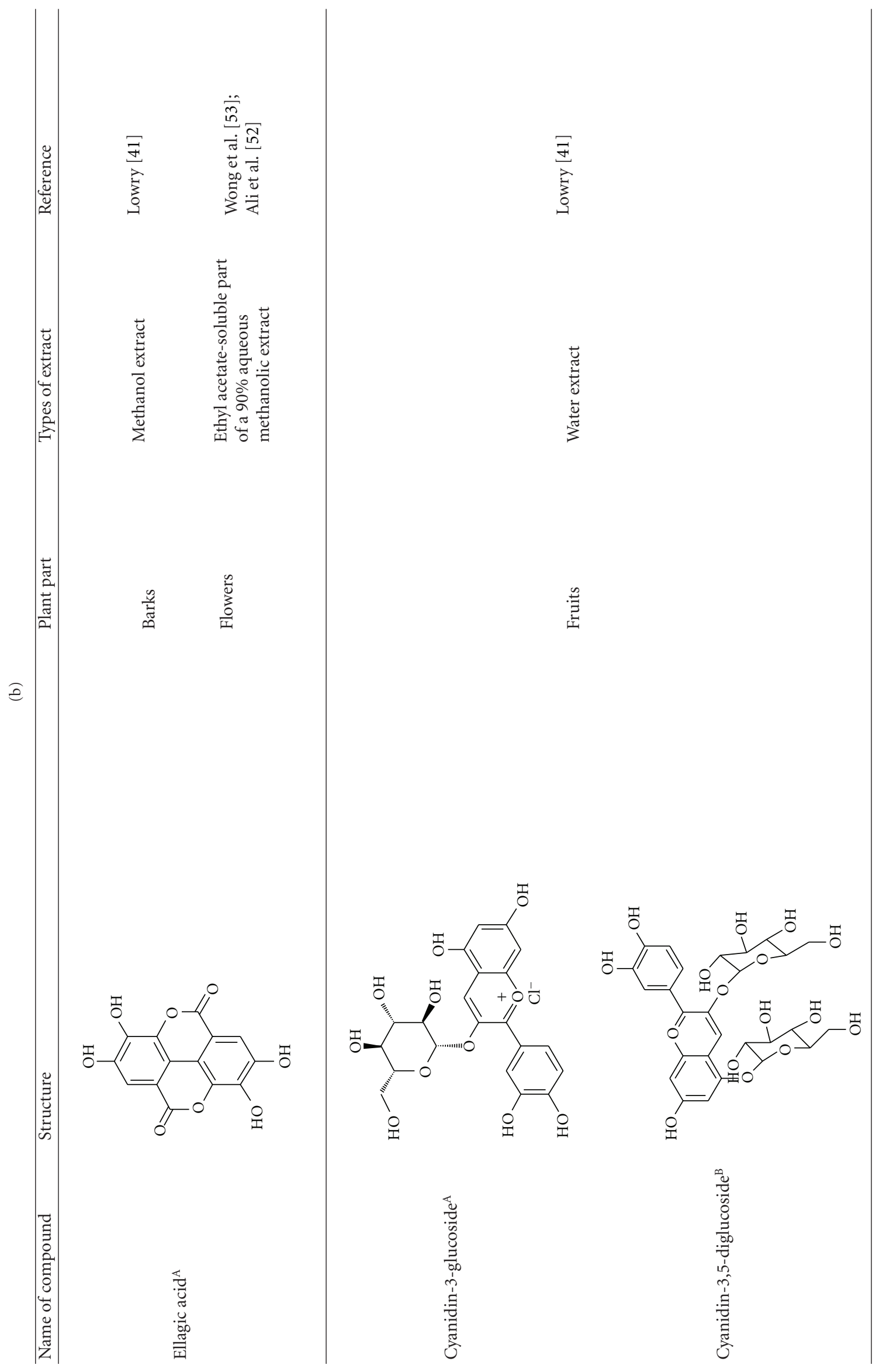




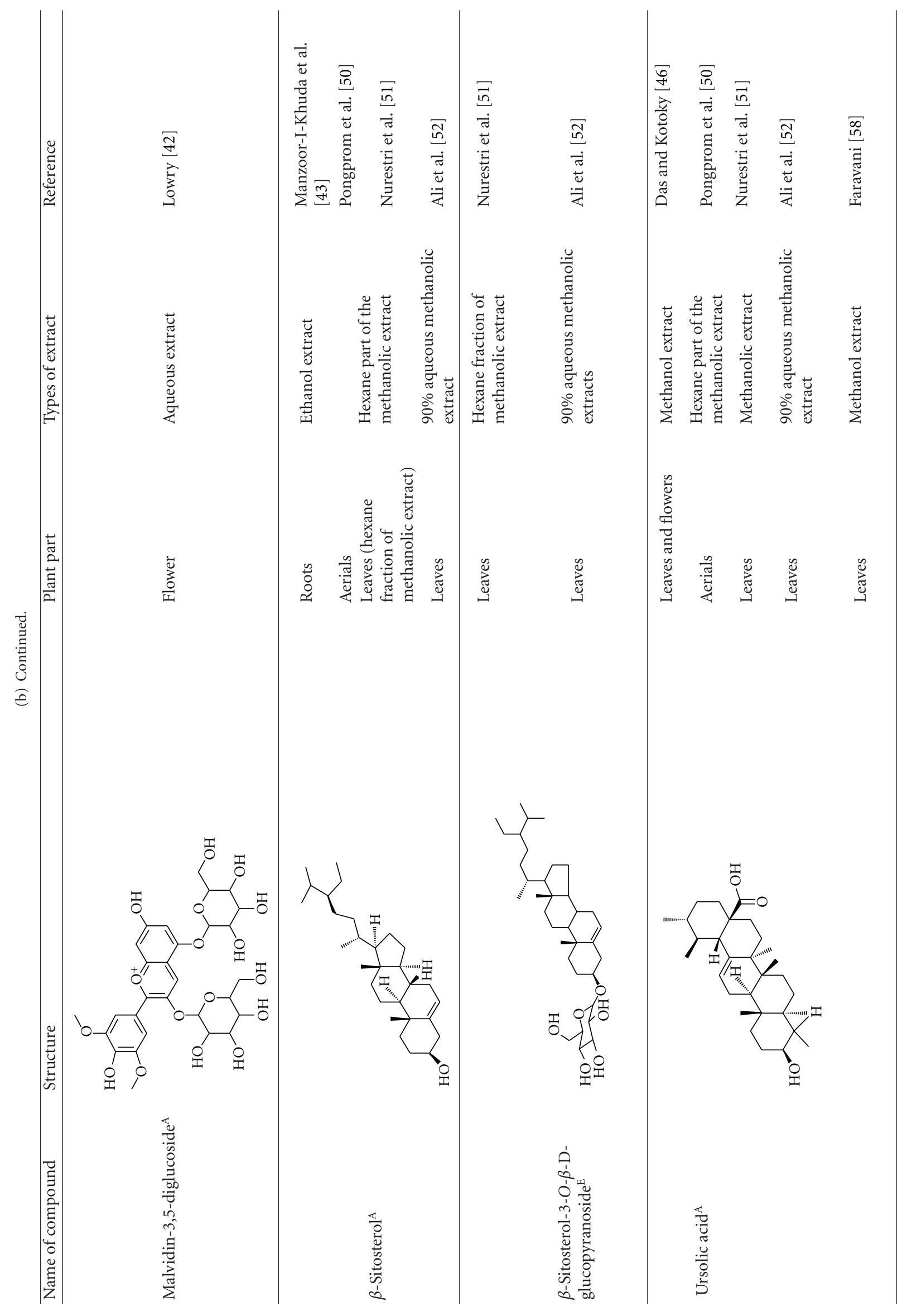




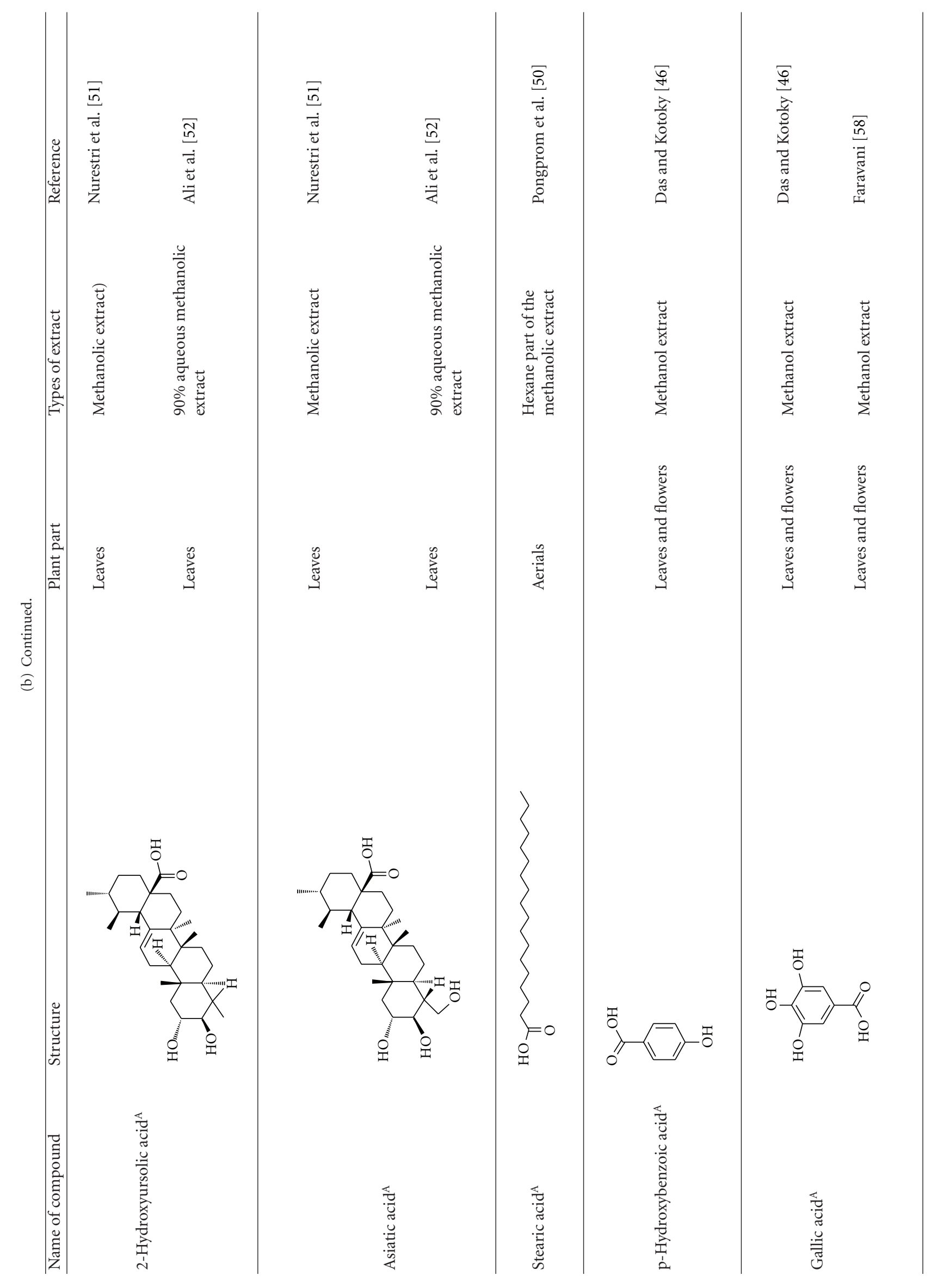




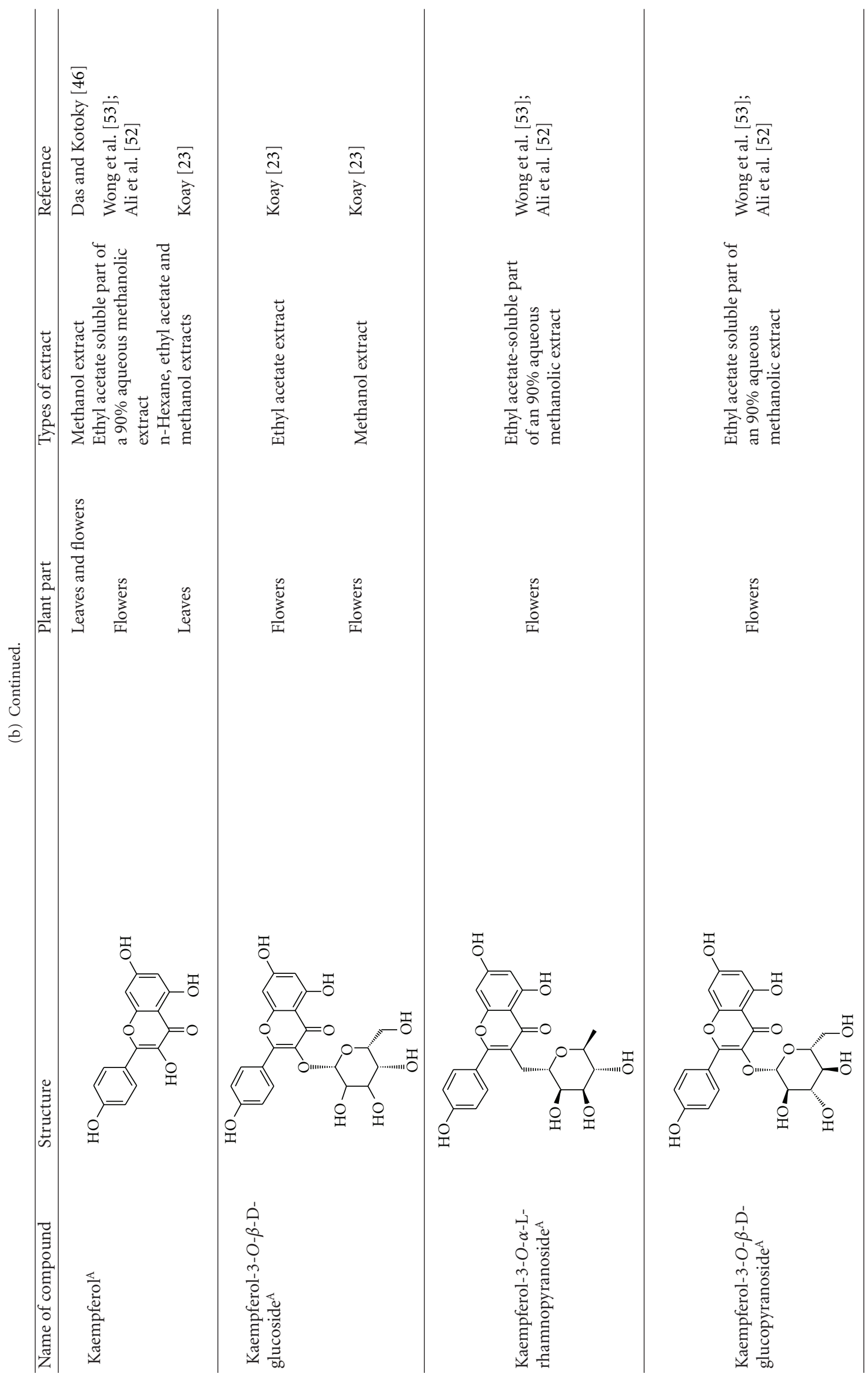




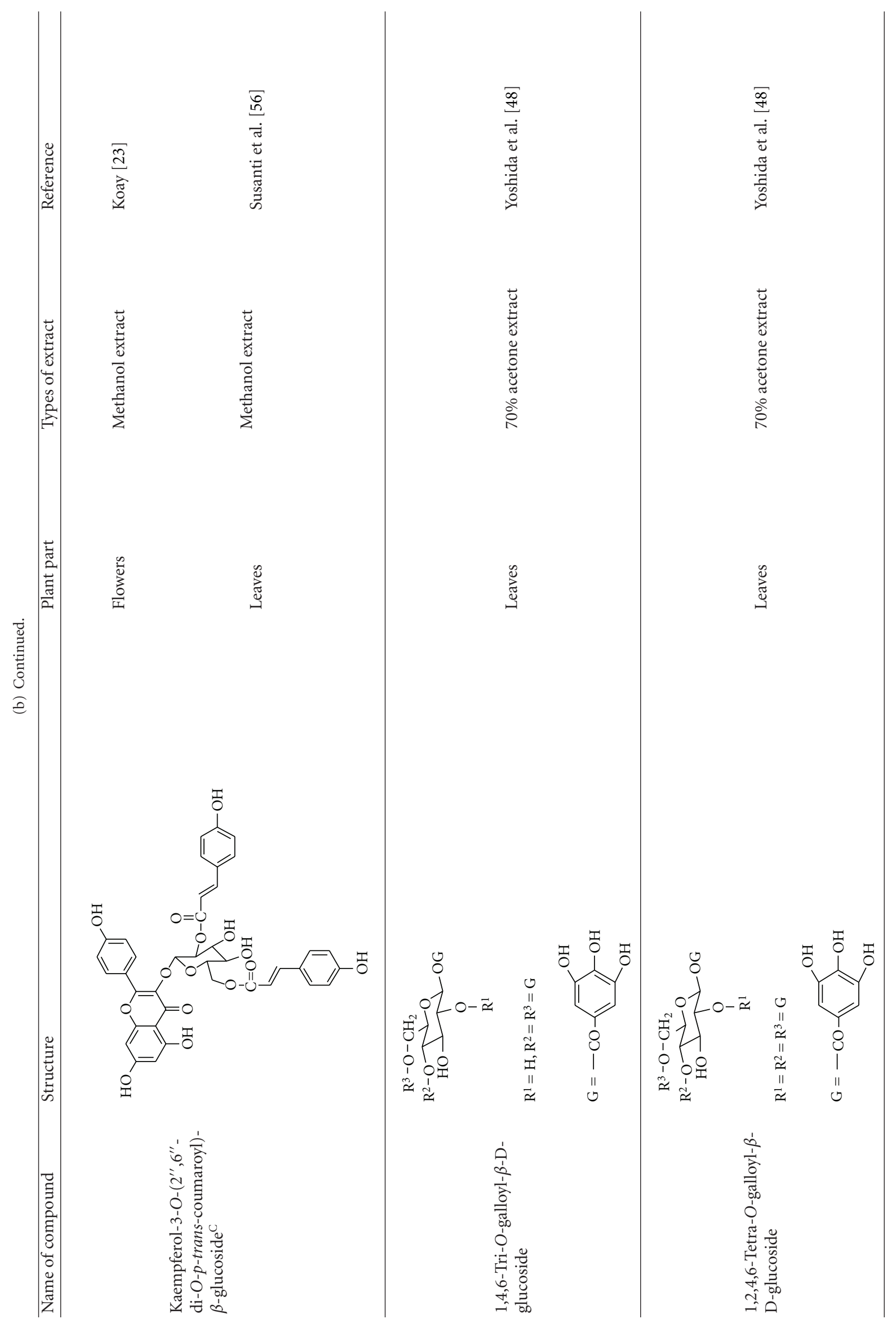




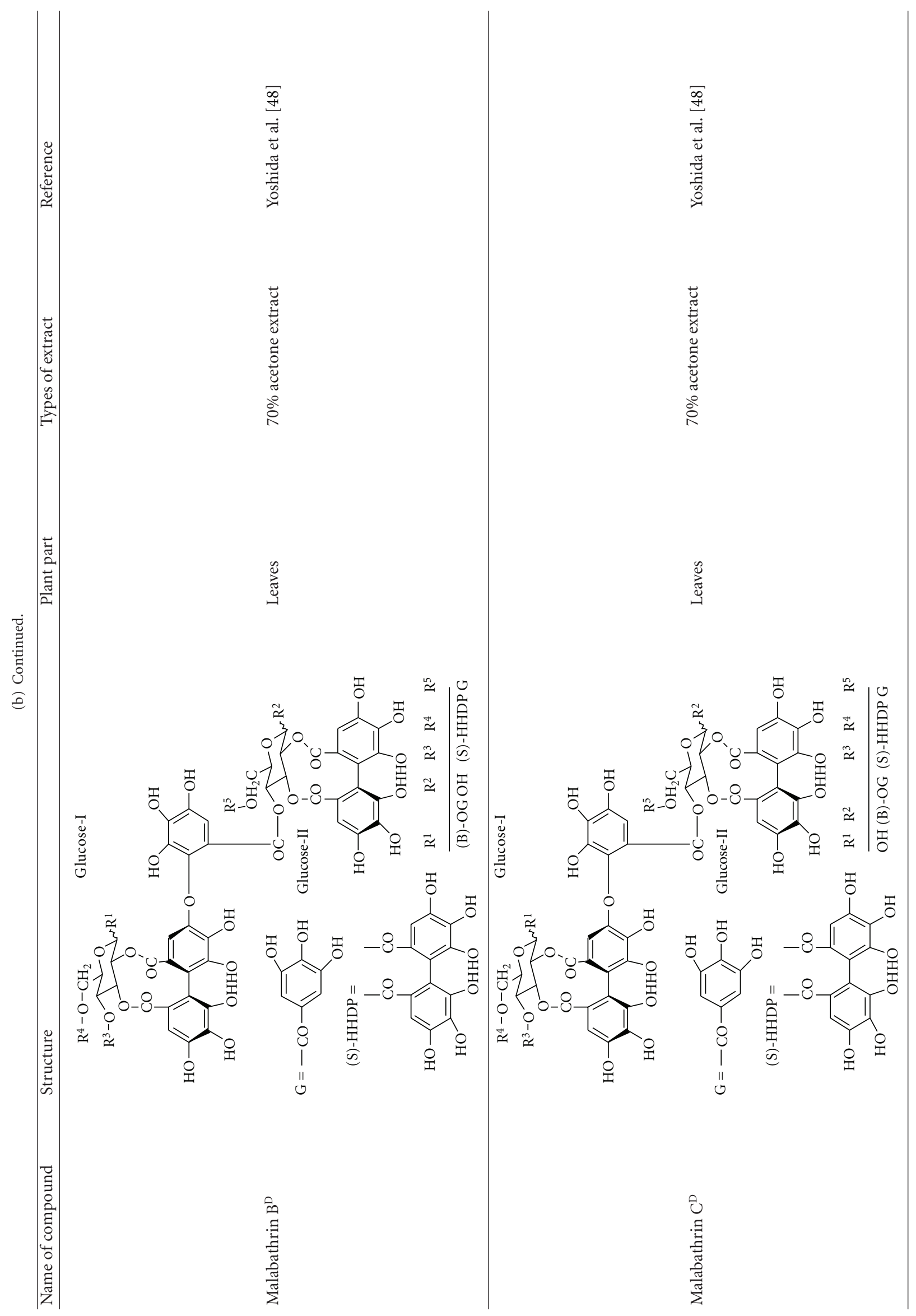




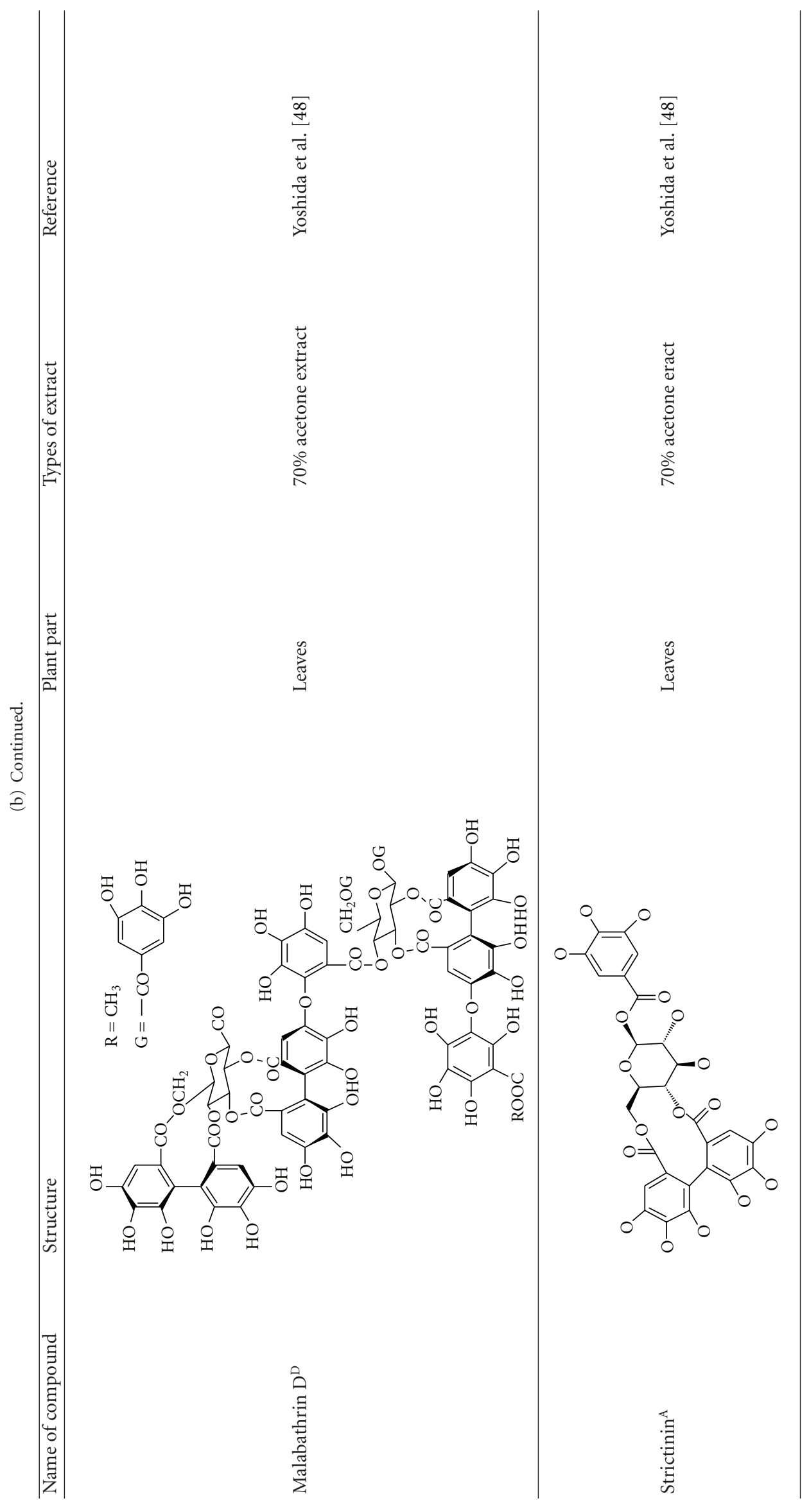




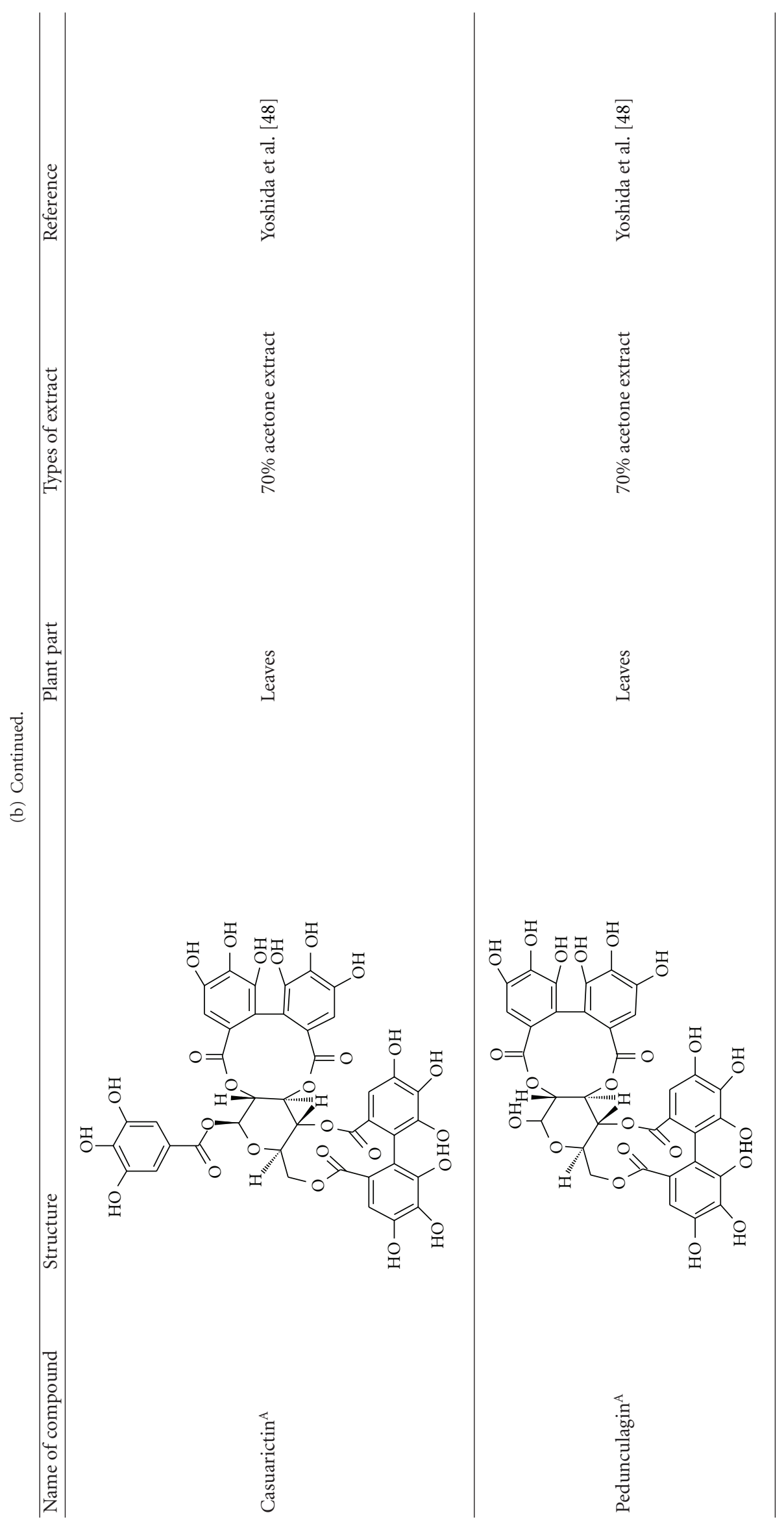




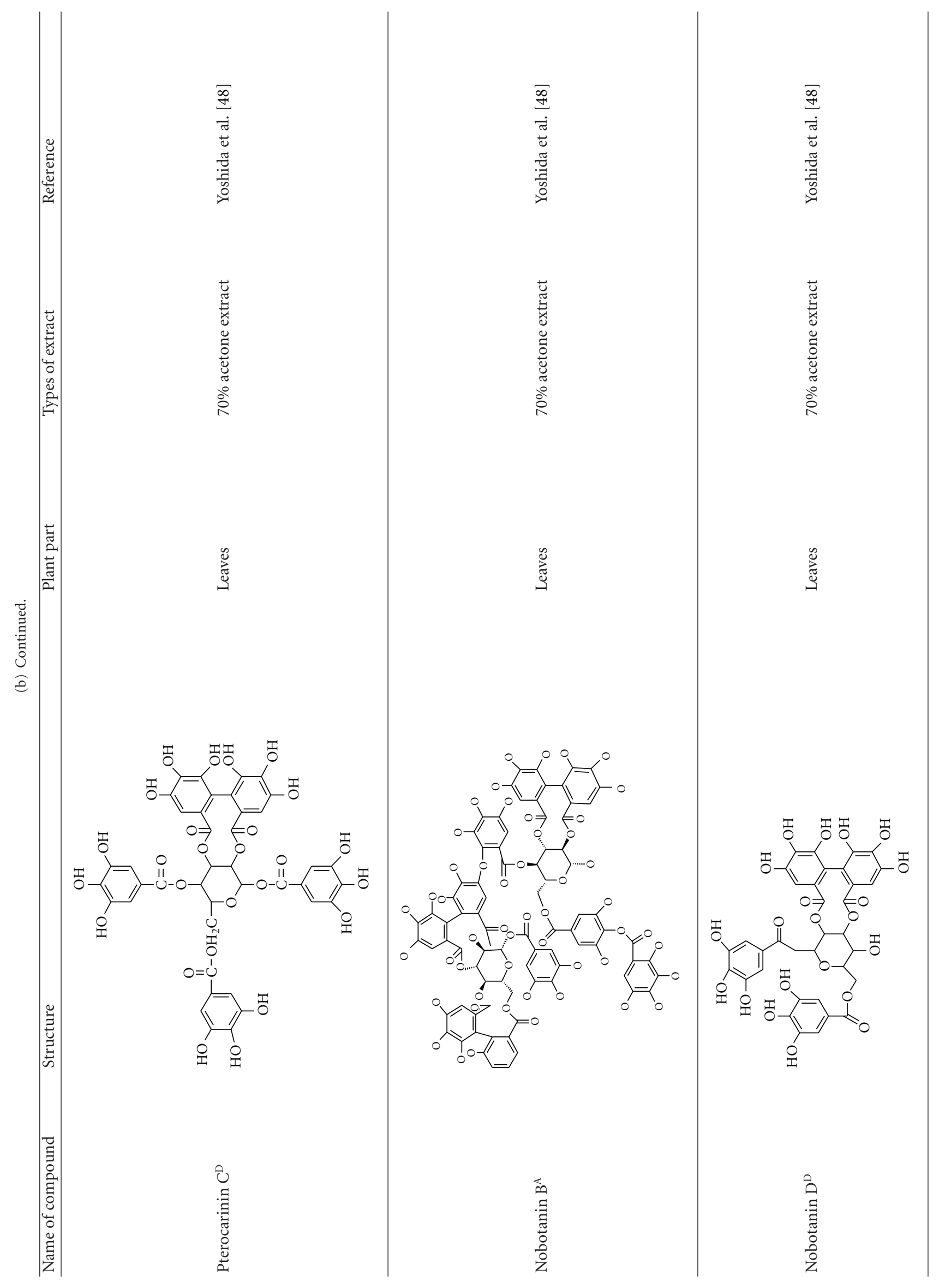




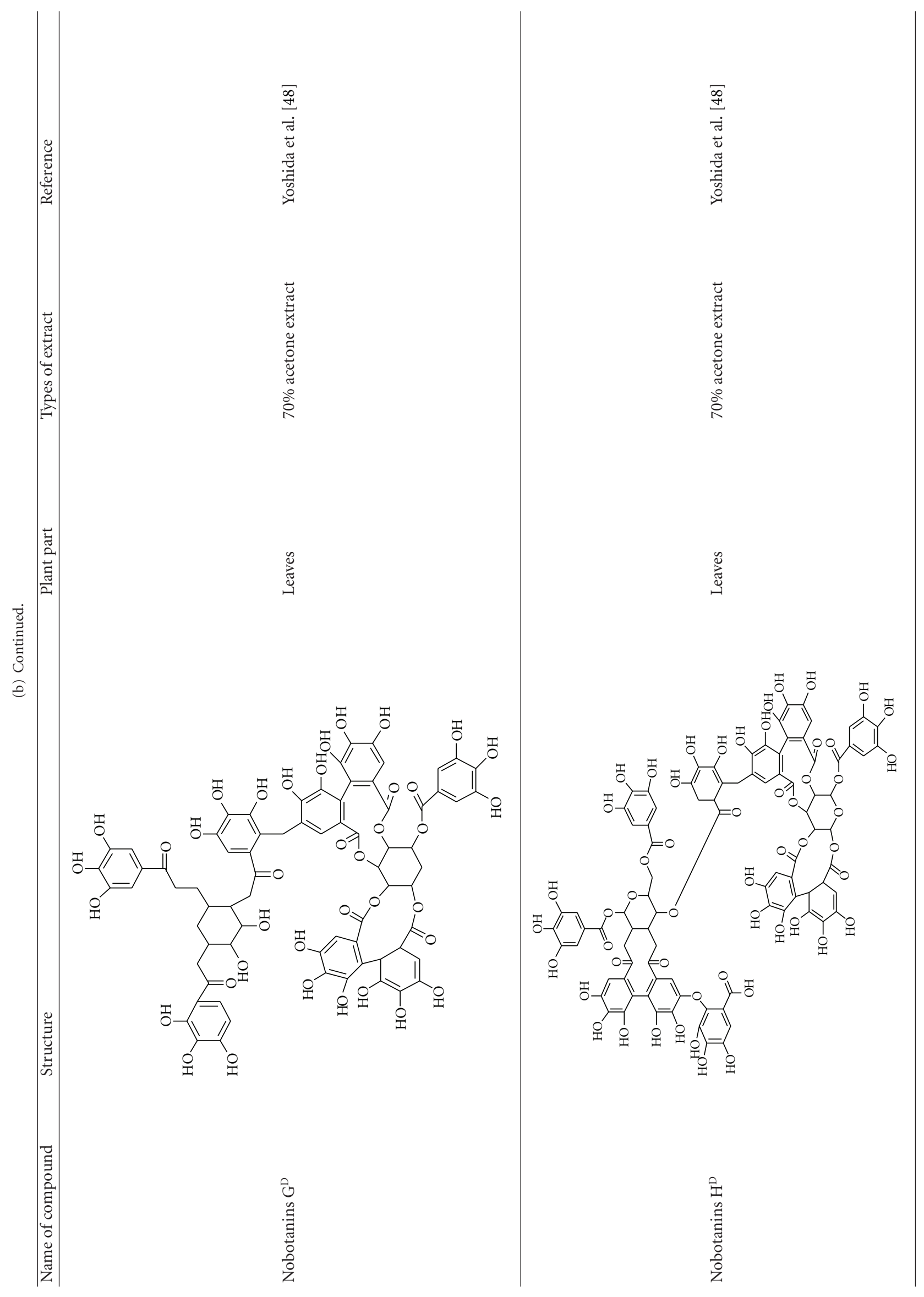




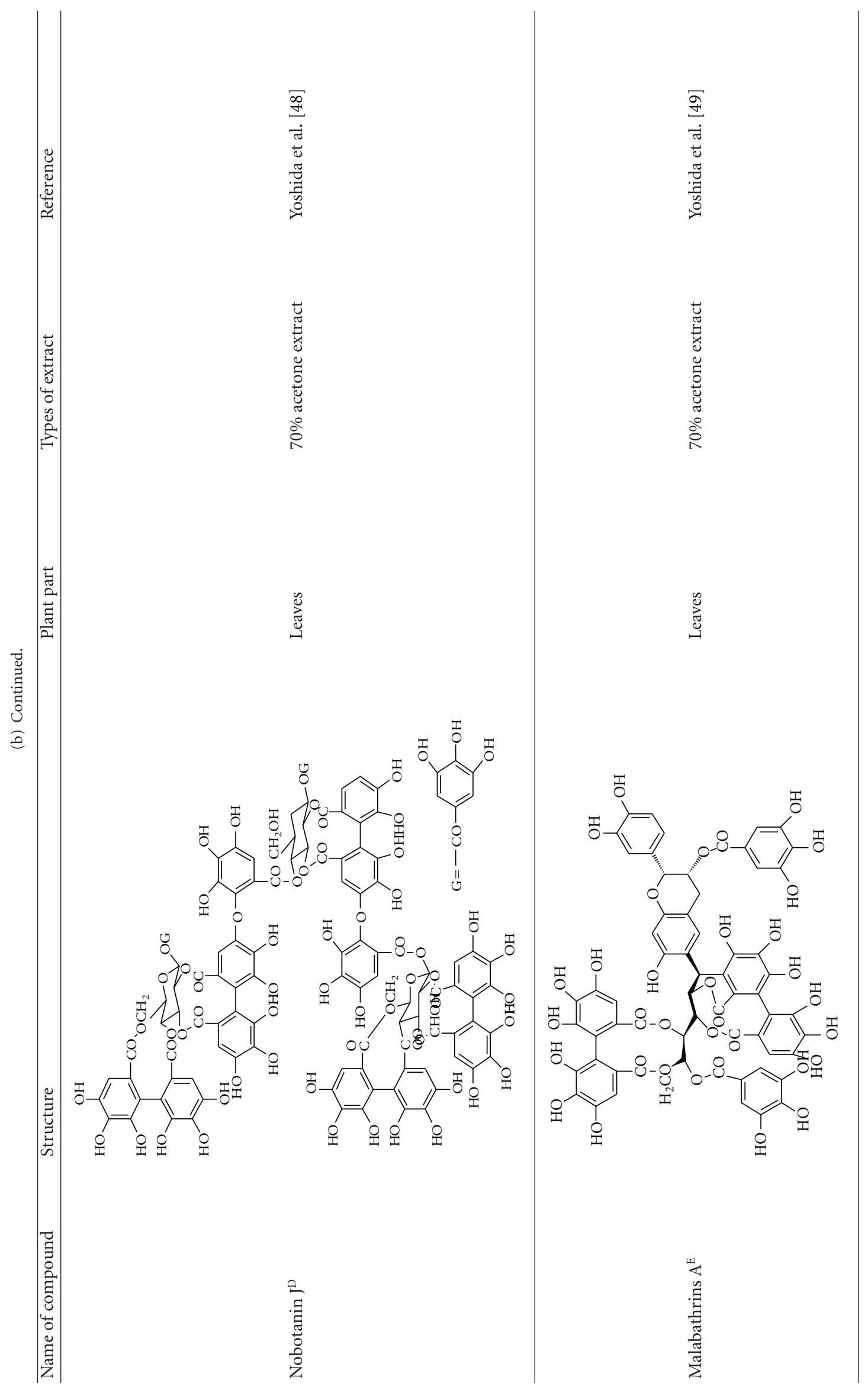




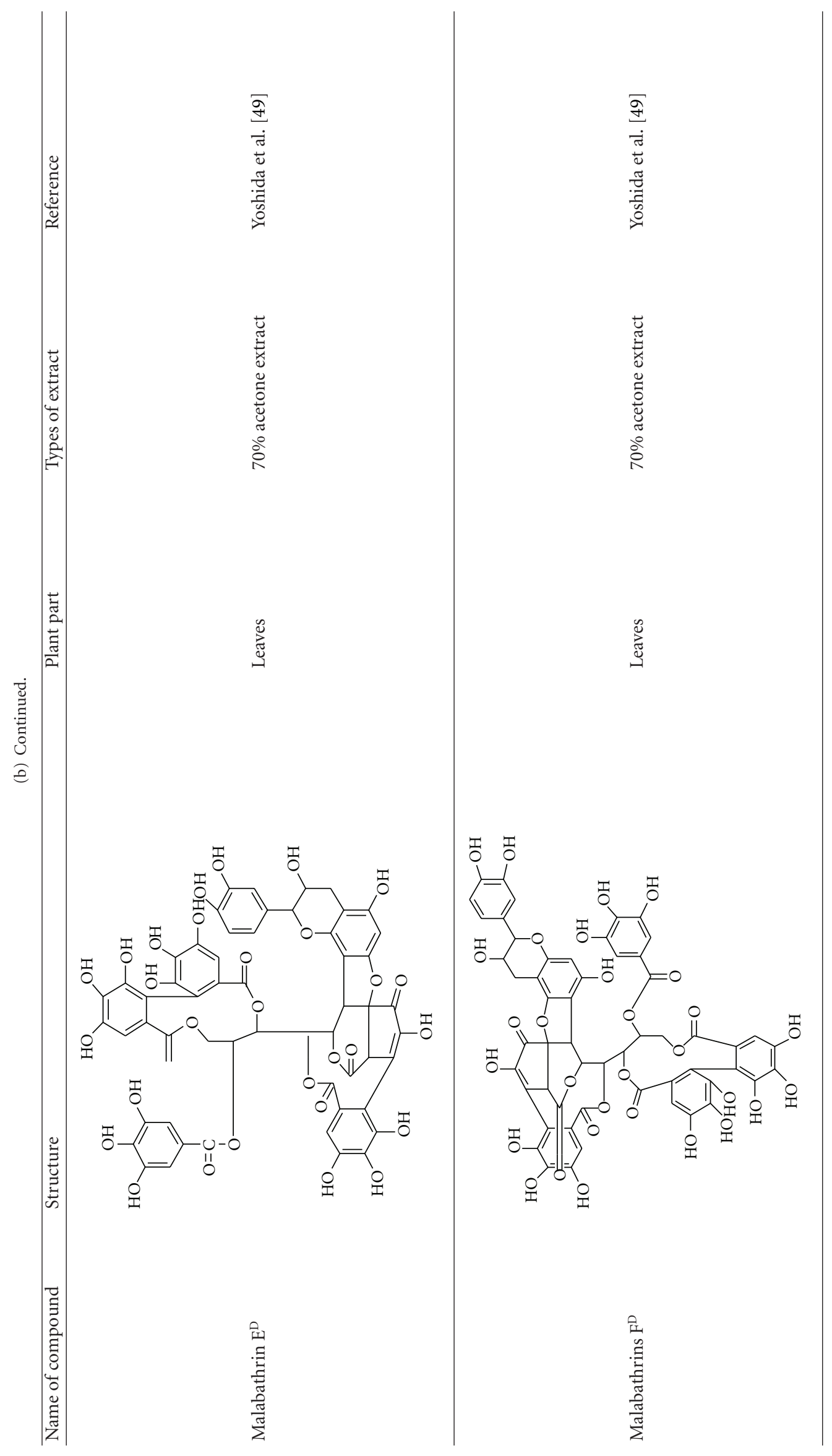




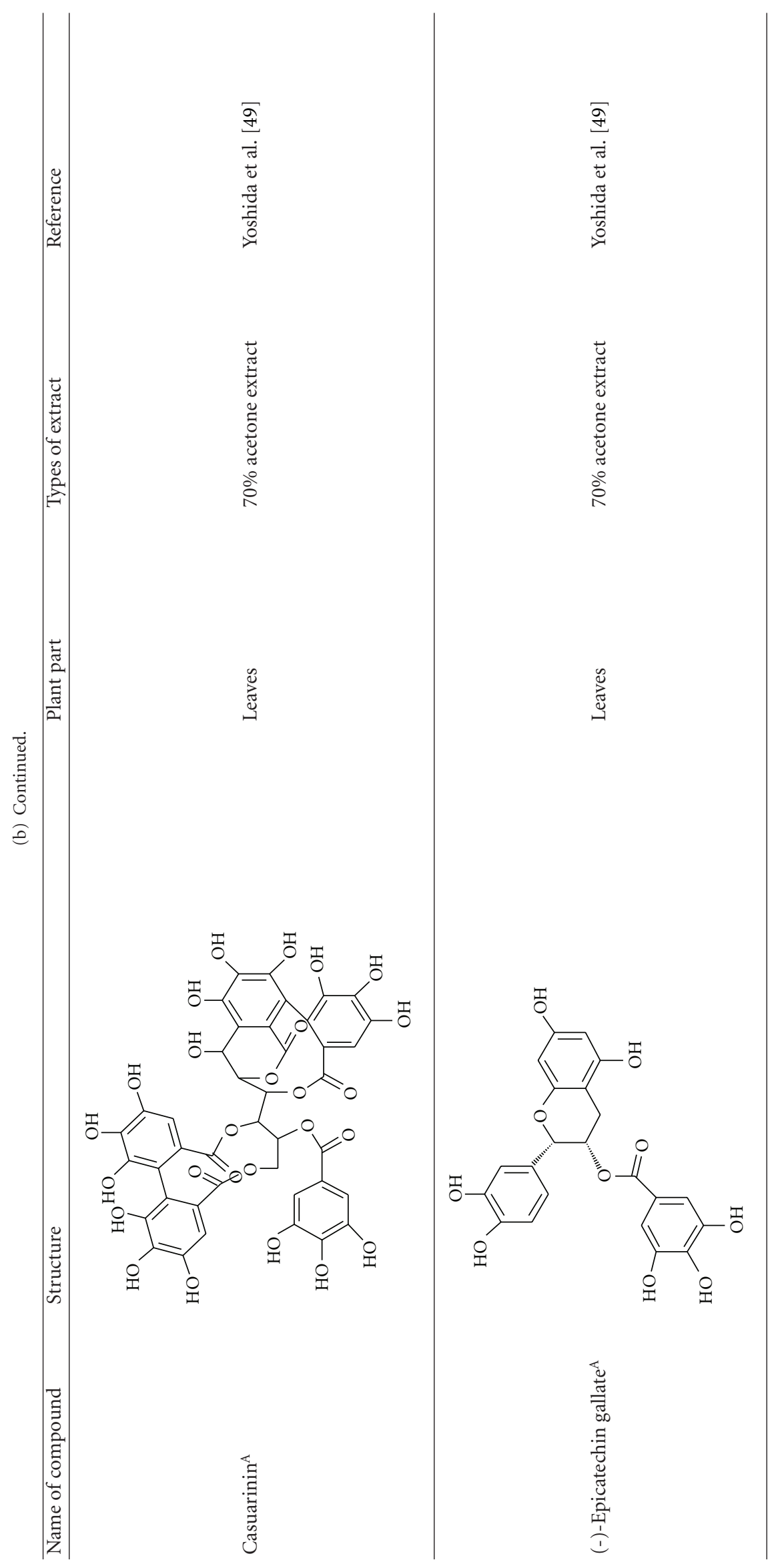




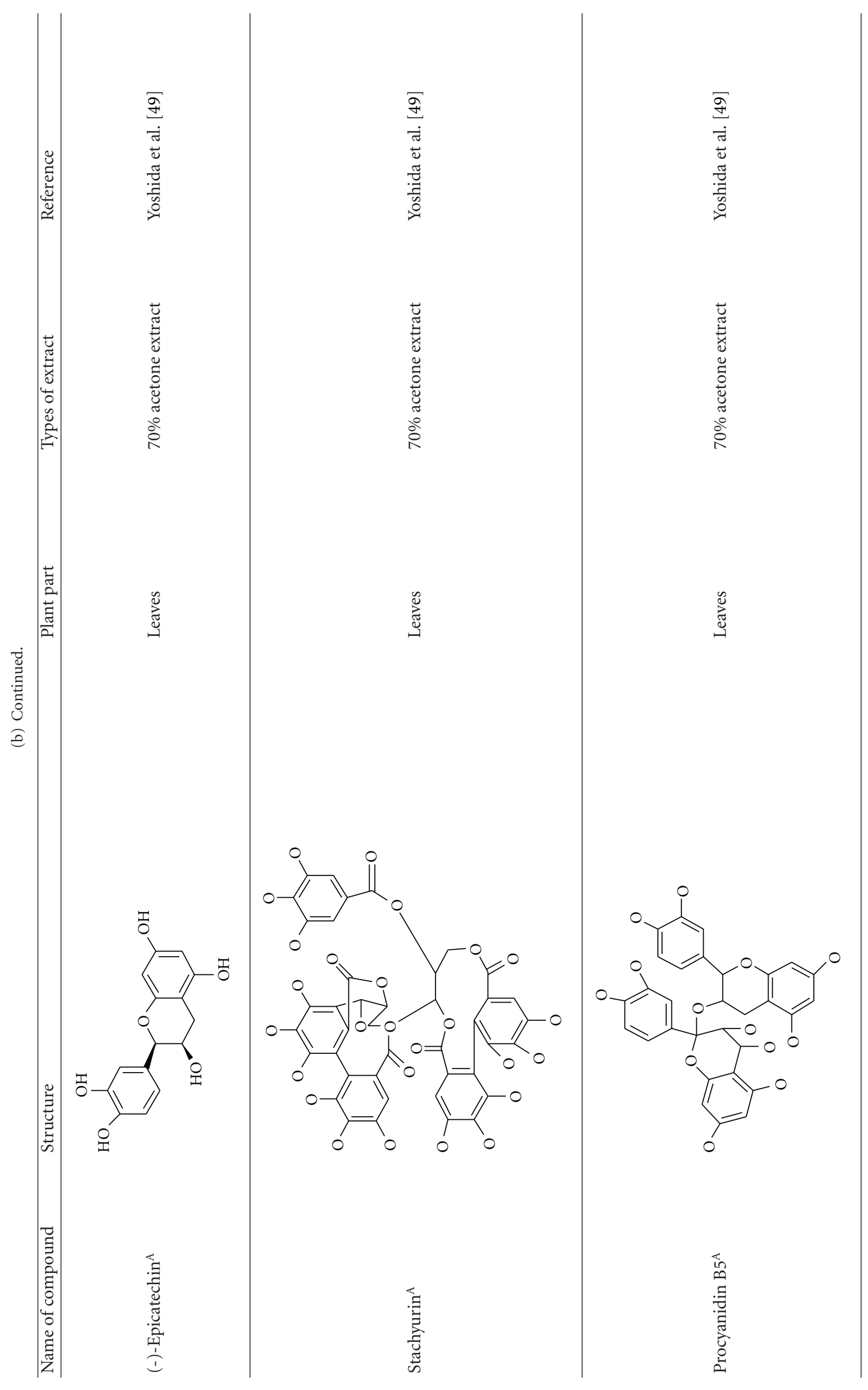




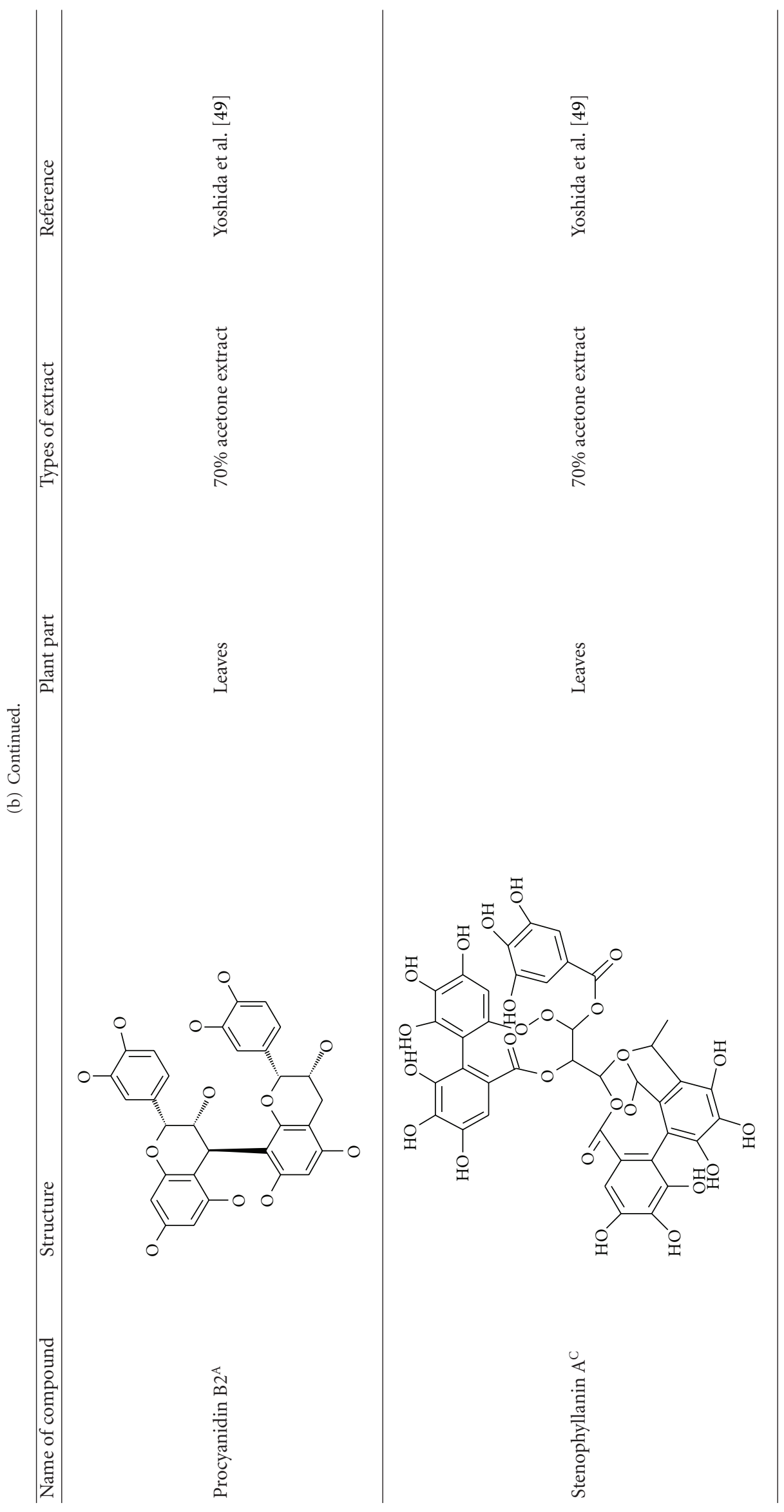




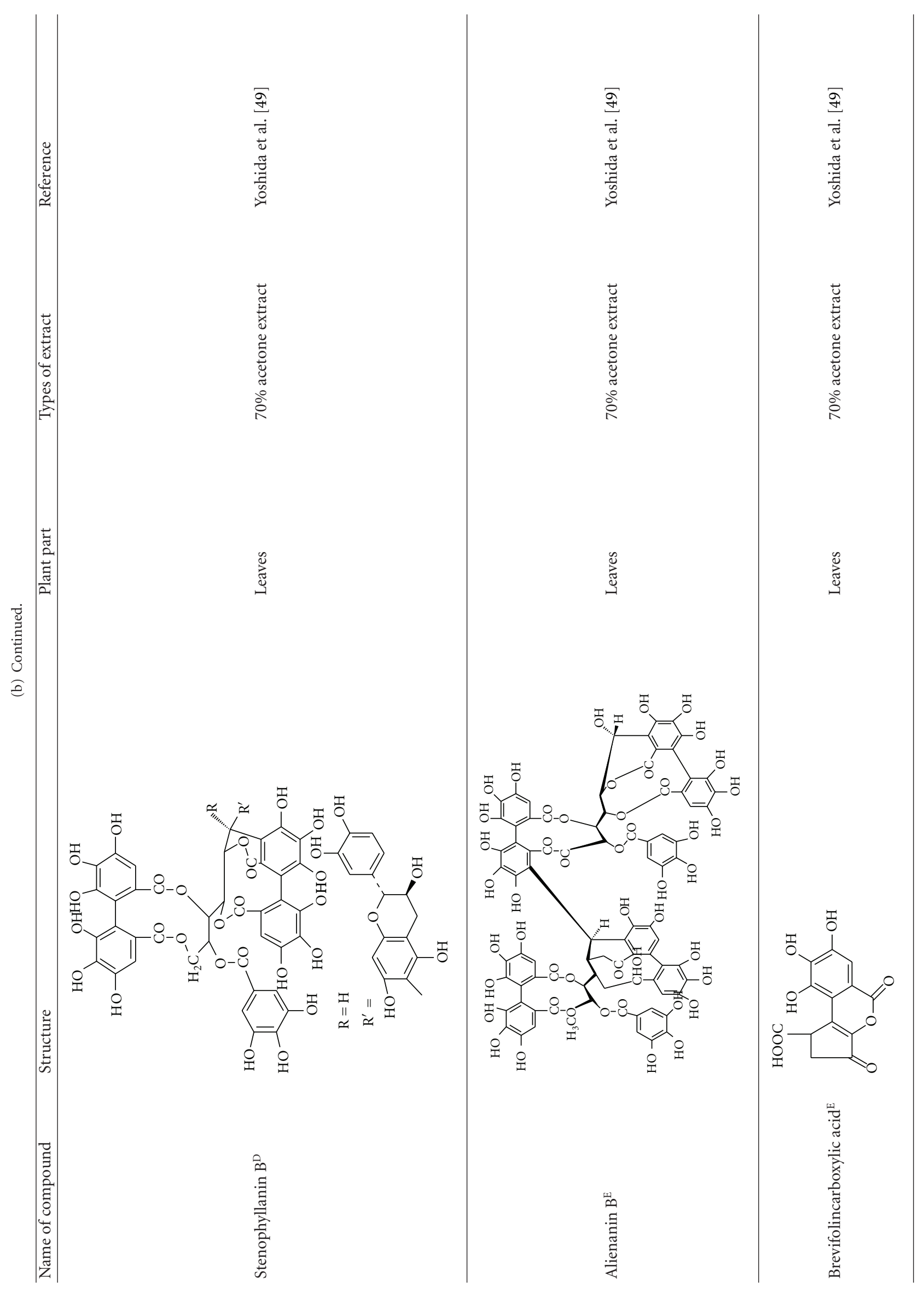




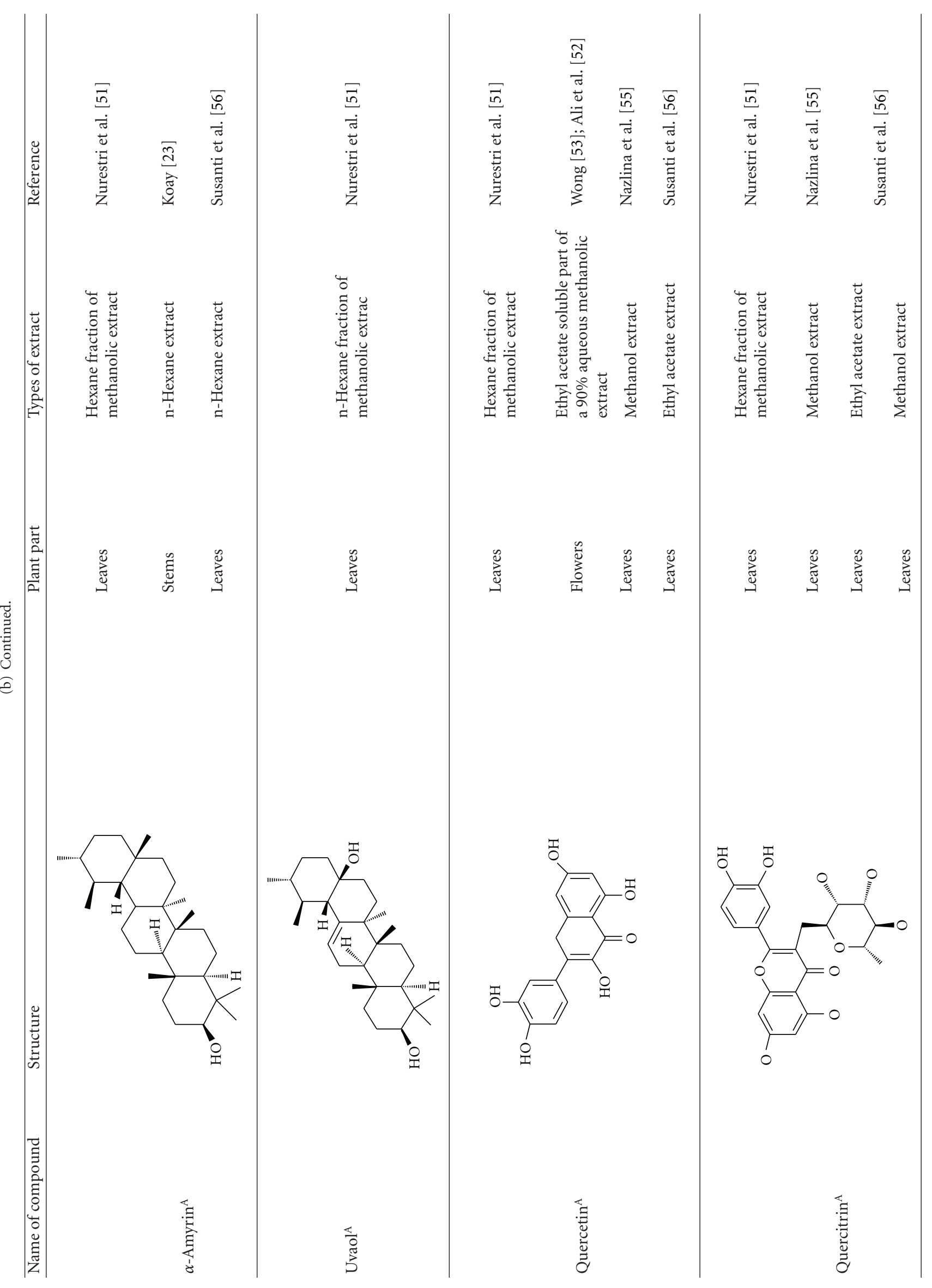




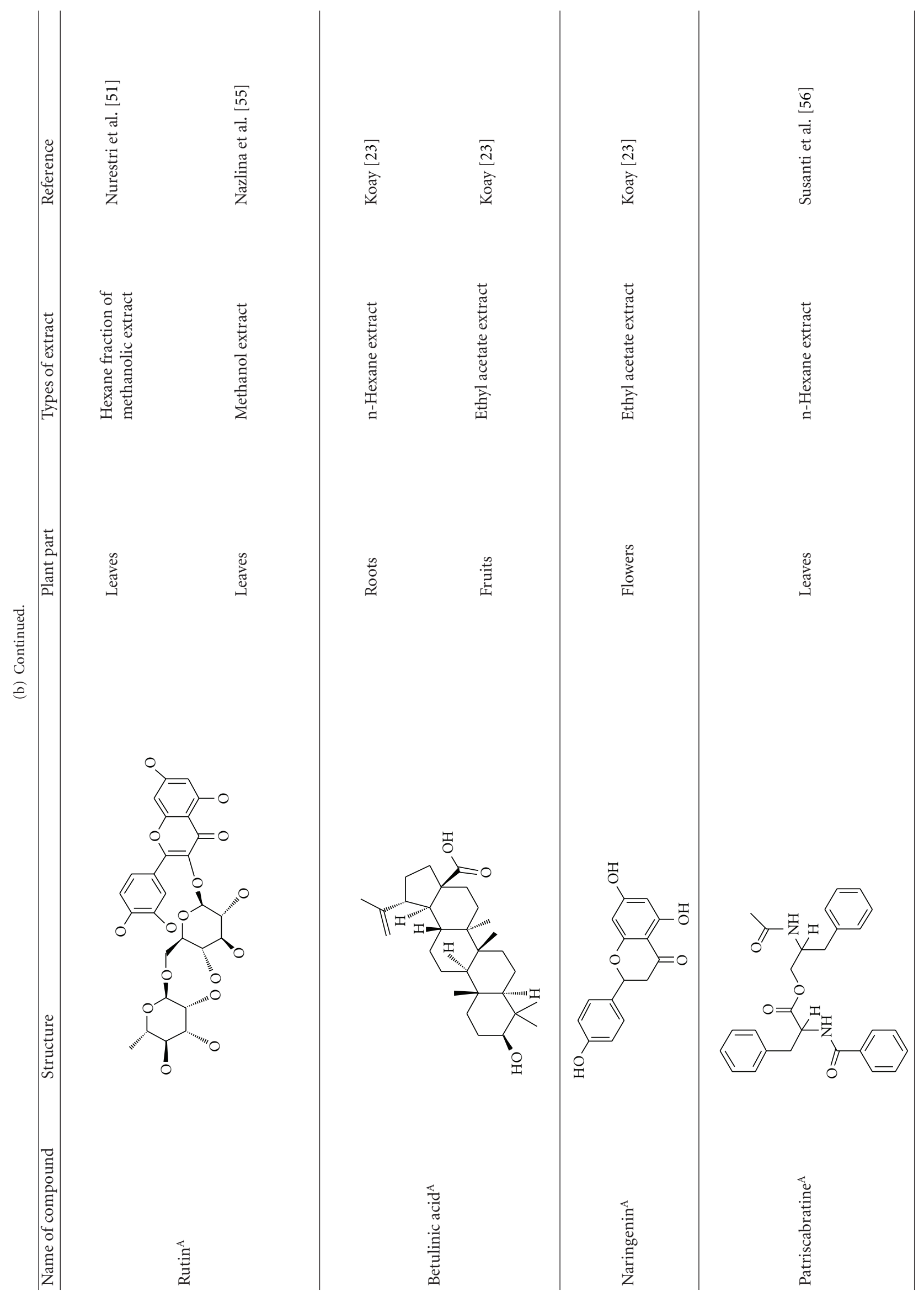




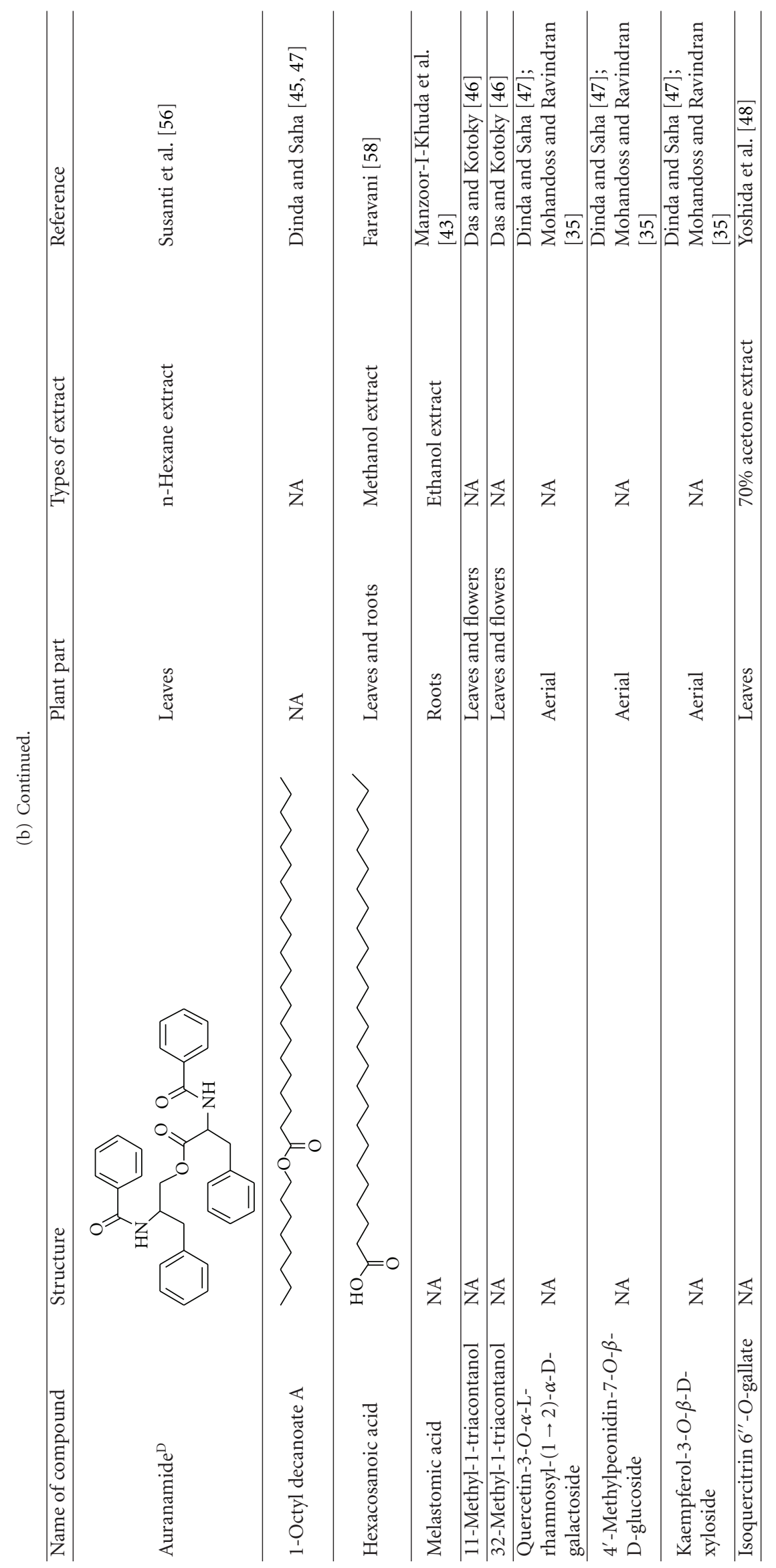




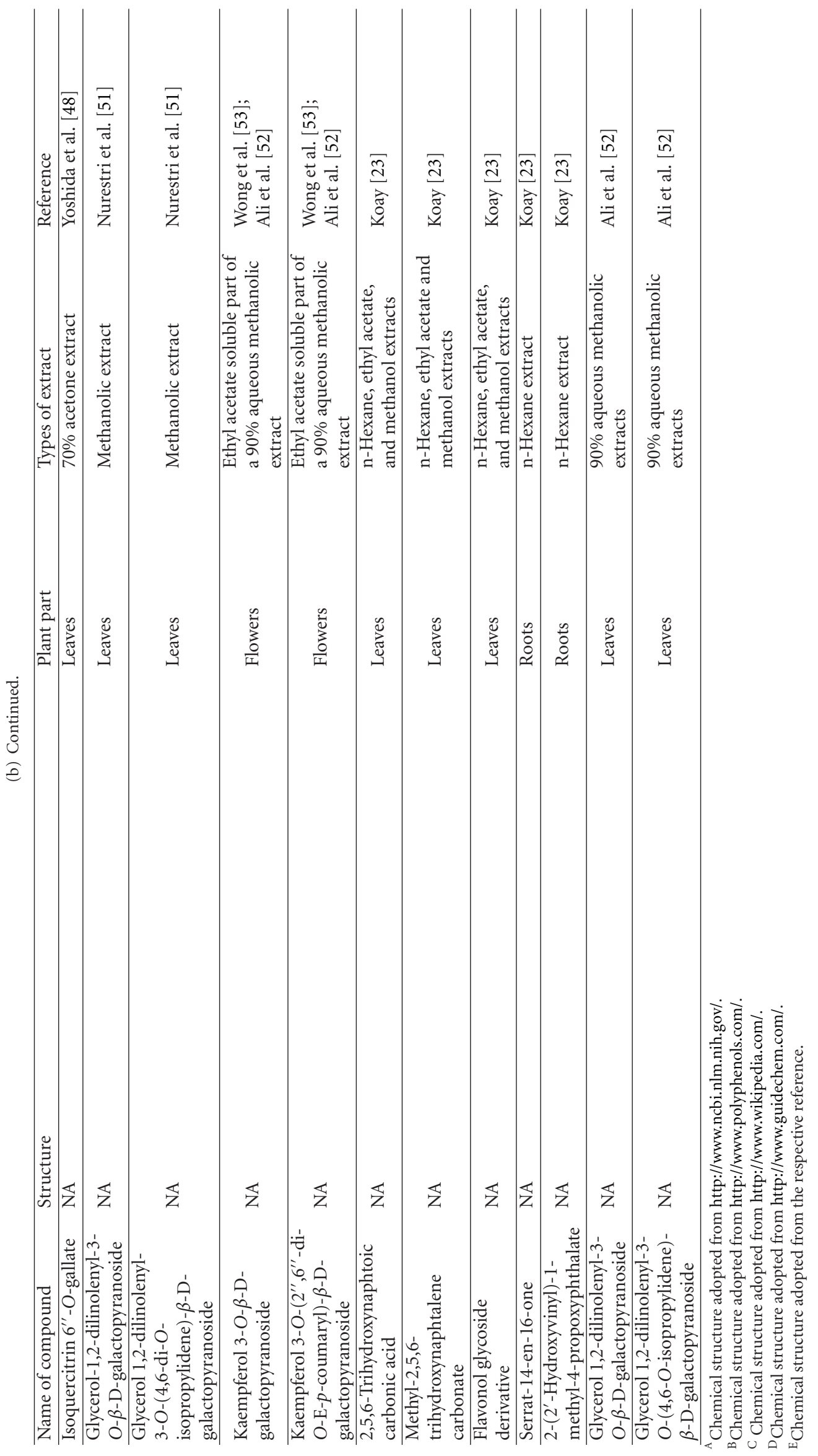


the isolation of 1-octyl docosanoate and 11-methyl-1tricontanol while Dinda and Saha [45] reported the presence of fatty acids and sterols. Das and Kotoky [46] reported the isolation of a new aliphatic constituent, namely, 32methyl-1-tritriacontanol, together with ursolic acid, p-hydroxybenzoic acid and gallic acid, and kaempferol from the leaves and flowers of M. malabathricum. Compounds like kaempferol-3-O- $\beta$-D-xyloside, quercetin-3-O- $\alpha$-L-rhamnosyl- $(1 \rightarrow 2)$ - $\beta$-D-galactoside, flavan-3-ol, $4^{\prime}$-methylpeonidin -7-O- $\beta$-D-glucoside, anthocyanins, and tannins have also been isolated from the aerial part of M. malabathricum [35, 47].

Yoshida et al. [48] reported the isolation of isoquercitrin $6^{\prime \prime}$-0-gallate, a flavonoid glycoside, three new dimeric hydrolysable tannins, namely, malabathrins $\mathrm{B}, \mathrm{C}$, and $\mathrm{D}$, and the eleven known hydrolysable tannins from the 70\% acetone extract of M. malabathricum leaves (AcMML). Among the eleven known tannins, seven were monomeric hydrolysable tannins, namely, 1,4,6-tri-O-galloyl- $\beta$-D-glucoside, $1,2,4,6$ tetra- $O$-galloyl- $\beta$-D-glucoside, strictinin, casuarictin, pedunculagin, nobotanin $\mathrm{D}$, and pterocarinin $\mathrm{C}$ while the other four were hydrolysable tannin oligomers which were identified as nobotanins $\mathrm{B}, \mathrm{G}$, and $\mathrm{H}$ (dimers) and nobotanin J (trimer). In the same year, Yoshida et al. [49] successfully isolated malabathrins $\mathrm{A}, \mathrm{E}$, and $\mathrm{F}$, new complex tannins in which an ellagitannin and a flavan-3-ol are bound by a C-glycosidic linkage belonging to type II+ tannins, and other tannins, namely, casuarinin, (-)-epicatechin gallate, (-)-epicatechin, stachyurin, procyanidin B-5 and B-2, stenophyllanins $\mathrm{A}$ and $\mathrm{B}$, alienanin $\mathrm{B}$, and brevifolincarboxylic acid. The chromatographic separation of the hexane part of the methanolic extract of $M$. malabathricum aerial parts (MMMAp) led to the identification of stearic acid, $\beta$-sitosterol and ursolic acid [50]. On the other hand, Nurestri et al. [51] have successfully isolated three pentacyclic triterpenoids, namely, ursolic acid, 2-hydroxyursolic acid and asiatic acid, as well as glycerol-1,2-dilinolenyl-3-O- $\beta$-Dgalactopyranoside and glycerol 1,2-dilinolenyl- 3-O-(4,6-di$O$-isopropylidene)- $\beta$-D-galactopyranoside from the methanolic extract of $M$. malabathricum leaves (MMML) with light pink-magenta petals [51]. Nurestri et al. [51] also isolated $\beta$-sitosterol, $\alpha$-amyrin, uvaol, quercetin, quercitrin, rutin, and sitosterol-3-O- $\beta$-D-glucopyranoside from the hexane fraction of MMML. Ali et al. [52] isolated three urs12 -ene pentacyclic triterpenoids, namely, ursolic acid, $2 \alpha$ hydroxyursolic acid and asiatic acid, $\beta$-sitosterol 3- $O-\beta$ Dglucopyranoside, glycerol 1,2-dilinolenyl-3-O- $\beta$-D-galactopyranoside and glycerol 1,2-dilinolenyl-3-O-(4,6-O-isopropylidene)- $\beta$-D-galactopyranoside from the $90 \%$ aqueous methanolic extracts of $M$. malabathricum fresh leaves (AMMML). In addition, subjection of the ethyl acetatesoluble part of an $90 \%$ aqueous methanolic extract of $M$. malabathricum flowers (AMMMFw) to isolation and identification of bioactive compounds yielded ellagic acid and six flavonoids which were identified as quercetin, kaempferol, kaempferol 3-O- $\alpha$-L-rhamnopyranoside, kaempferol 3-O- $\beta$-D-glucopyranoside, kaempferol 3-O- $\beta$-D-galactopyranoside, and kaempferol 3-O- $\left(2^{\prime \prime}, 6^{\prime \prime}-\right.$ di-O-E- $p$-coumaryl $)$ $\beta$-D-galactopyranoside $[53,54]$. Koay $[23]$ also cited that the n-hexane (HMML), ethyl acetate (EAMML), and MMML extracts of $M$. malabathricum leaves yielded three new compounds, 2,5,6-trihydroxynaphtoic carbonic acid, methyl-2,5,6-trihydroxynaphtalene carbonate, and flavonol glycoside derivative. The $\mathrm{n}$-hexane extract of $M$. malabathricum roots (HMMR) contained betulinic acid, serrat14-en-16-one, and 2-(2'-hydroxyvinyl)-1-methyl-4-propoxyphthalate. The ethyl acetate extract of $M$. malabathricum flowers (EAMMFw) yielded three compounds, kaempferol3-O- $\beta$-D-glucoside, kaempferol, and naringenin, while the methanol extract of $M$. malabathricum flowers (MMMFw) was found to contain kaempferol-3-O- $\left(2^{\prime \prime}, 6^{\prime \prime}\right.$-di-O-p-transcoumaroyl)-glucoside and kaempferol-3-O- $\beta$-D-glucoside. The ethyl acetate extract of $M$. malabathricum fruits (EAMMFr) afforded betulinic acid, while the n-hexane extract of the stems produced $\alpha$-amyrin. Nazlina et al. [55] successfully isolated rutin, quercitrin, and quercetin from the MMML using TLC assay. In addition, Susanti et al. [56] also reported the isolation of a triterpene ( $\alpha$-amyrin) and two amides (patriscabatrine and auranamide) from the HMML, two flavonoids (quercetin and quercitrin) from the EAMML, and two flavonoids (quercitrin and kaempferol3-O-( $2^{\prime \prime}, 6^{\prime \prime}$-di-O-p-trans-coumaroyl $)-\beta$-glucoside $)$ from the MMML after successive extraction of the leaves of M. malabathricum with white petals. Zakaria et al. [30] reported the presence of flavonoids, triterpenes, tannins, saponins, and steroids, but no alkaloids in the leaves of M. malabathricum found in Malaysia. Simanjuntak [57] also reported the presence of flavonoids, saponins, tannins, glycosides, and steroids/triterpenoids in the leaves of $M$. malabathricum collected in Sumatera, Indonesia. Faravani [58] identified several secondary metabolites from the MMML and methanol extract of $M$. malabathricum roots (MMMR), such as hexacosanoic acid, gallic acid, flavonoids and flavonoids glycosides, phenolics, triterpenes, tannins, saponins, and steroids. Further analyses of the MMML yielded 3 urs-12-ene pentacyclic triterpenoids, namely, ursolic acid, $2 \alpha$-hydroxyursolic acid and asiatic acid, $\beta$-sitosterol 3-O- $\beta$-D-glucopyranoside, glycerol 1,2-dilinolenyl-3-O- $\beta$-D-galactopyranoside, and glycerol 1,2-dilinolenyl-3-O-(4,6-O-isopropylidene)- $\beta$-D-galactopyranoside. On the other hand, ethyl acetate soluble part of AMMMFw contains a host of compounds, namely, ellagic acid and 6 flavonoids, namely, quercetin, kaempferol, kaempferol 3-O- $\alpha$-Lrhamnopyranoside, kaempferol 3-O- $\beta$-D-glucopyranoside, kaempferol 3$O-\beta$-D-galactopyranoside, and kaempferol 3-O- $\left(2^{\prime \prime}, 6^{\prime \prime}\right.$-di$O$-E-p-coumaryl)- $\beta$-D-galactopyranoside $[53,54]$. LohézicLe Dévéhat et al. [32] have reported the presence of flavonoids and hydrolysable tannins in the aerial parts of M. malabathricum following the preliminary phytochemical screening.

In addition, Dinda and Saha [59] and Yeoh et al. [60] have also reported on the presence and total leaf amino acid compositions of M. malabathricum. The leaf of M. malabathricum was found to contain all important amino acids, namely, Asp, Thr, Ser, Glu, Pro, Gly, Ala, Val, Met, lie, Leu, Tyr, Phe, His, Lys, Trp, and Arg with their respective percentage of total amino acids of $11.5,5.5,5.1,13.5,6.2,5.4,6.4$, $4.9,2.3,3.6,9.9,5.2,6.2,2.3,6.9,0.1,4.9$, and 4.24. 


\section{Pharmacological Activities}

Various parts of M. malabathricum have been claimed to possess medicinal values, which is supported particularly by the Malay and Indian traditional uses of the plants in the treatment of a number of diseases as described earlier. Scientifically, M. malabathricum, prepared as extracts using different types of solvents and tested using a range of in vitro and in vivo test models, demonstrated various pharmacological potentials that required in-depth studies (Table 4). The plant, regardless of the parts used, has been shown to exert antibacterial, antiviral, antiparasitic, antioxidant, cytotoxicity, anticoagulant, platelet-activating factor inhibitory, wound healing, antiulcer, antidiarrheal, antivenom, anti-inflammatory, antinociceptive, and antipyretic activities at different doses/concentrations. The following subchapters will discuss in detail those scientific findings related to pharmacological properties of M. malabathricum.

4.1. Acute Toxicity Study. Sunilson et al. [61] have determined the acute toxicity $\mathrm{LD}_{50}$ level of water extract of $M$. malabathricum leaves (WMML) collected in the State of Selangor, Malaysia. The extract, in the doses of 62.5, 125, 250, 500,1000 , and $2000 \mathrm{mg} / \mathrm{kg}$, was administered orally in mice. The authors recorded general signs and symptoms of toxicity, intake of food and water, and mortality for $48 \mathrm{~h}$. The acute toxicity study showed that the WMML administered up to $2000 \mathrm{mg} / \mathrm{kg}$ dose to the mice showed neither mortality nor any visible clinical signs of general weakness in the animals. This indicates that the WMML is safe for consumption even at the highest dosage $(2000 \mathrm{mg} / \mathrm{kg})$ tested.

4.2. Antibacterial Activity. Grosvenor et al. [62] studied the antimicrobial property of $70 \%$ methanol extract of combined M. malabathricum leaf, stem, and flower (MMMClsf), collected from the Riau province, Sumatra, Indonesia, against Escherichia coli, Staphylococcus aureus, Saccharomyces cerevisiae, and Fusarium oxysporum using the agar diffusion assay. The extract was effective only against $S$. aureus, $S$. cerevisiae, and F. oxysporum. Standard antimicrobial references used were $1 \mathrm{mg} / \mathrm{mL}$ chloramphenicol, $1 \mathrm{mg} / \mathrm{mL}$ tetracycline, and 10000 units/mL nystatin suspensions. The chloramphenicol and tetracycline exerted antimicrobial activity against $S$. aureus and E. coli, while nystatin suspension exhibited antimicrobial activity against $S$. cerevisiae and F. oxysporum.

Wiart et al. [63] studied the antibacterial and antifungal properties of MMML, collected from Kuala Kangsar in the State of Perak, Malaysia, against Bacillus cereus, B. subtilis, Escherichia coli, Pseudomonas aeruginosa and Candida albicans using the disc diffusion method. Standard antibiotics used were $10 \mu \mathrm{g}$ gentamycin and $20 \mu \mathrm{g}$ nystatin for antibacterial and antifungal comparison, respectively. The $1000 \mu \mathrm{g}$ MMML exerted poor antimicrobial activity with zone of growth inhibition recorded at $7 \mathrm{~mm}$ only against B. subtilis. In comparison, gentamycin was effective against all microorganisms tested, except $C$. albicans, with zone of inhibition ranging between 14 and $20 \mathrm{~mm}$ while nystatin was effective against $C$. albicans with zone of inhibition recorded at $11 \mathrm{~mm}$.
Thatoi et al. [14] reported the antimicrobial activity of the aqueous extract of different parts of $M$. malabathricum (e.g., AMML, stem (AMMS), bark (AMMBk), bulb $(\mathrm{AMMBb})$, fruit (AMMFr), and root (AMMR)), collected from Simlipal Biosphere Reserve, Orissa, India, against a panel of Gram-positive and Gram-negative human pathogenic bacteria (e.g., Staphylococcus aureus MTCC 1144, B. licheniformis MTCC 7425, B. brevis MTCC 7404, B. subtilis MTCC 7164, S. epidermidis MTCC 3615, Streptococcus aureus (lab isolate), P. aeruginosa MTCC 1034, E. coli MTCC 1089, Vibrio cholerae (lab isolate), and Shigella flexneri (lab isolate)) and a fungal (e.g., C. krusei (lab isolate)). All extracts, in the volume of $200 \mu \mathrm{L}$ and in the concentration of $200 \mathrm{mg} / \mathrm{mL}$ each, were tested using the agar cup method. From the results obtained, AMML was considered to have an outstanding antimicrobial activity as indicated by the inhibition zones produced that are more than $20 \mathrm{~mm}$. The AMML was effective against B. brevis, V. cholerae, C. krusei, and B. subtilis, while the AMMBk was effective against $S$. aureus, B. brevis, and V. cholerae.

Johnny et al. [64] reported the antifungal activity of MMML, AcMML, and chloroform (CMML) extract of $M$. malabathricum leaves collected from Sarikei in the State of Sarawak, Malaysia, against Colletotrichum gloeosporioides, a plant pathogenic fungus isolated from mango. The antifungal activity was tested using agar-disc dilution assay followed by determination of minimum inhibition concentration (MIC) and the rate of sporulation assay. Benomyl was used as positive control. M. malabathricum extracts showed 40$55 \%$ antifungal activity against C. gloeosporioides at varying concentrations. The MMML exhibited antifungal activity of $53.09 \pm 0.75 \mathrm{~mm}$ at $10.00 \mu \mathrm{g} / \mathrm{mL}, 48.85 \pm 0.85 \mathrm{~mm}$ at $1.00 \mu \mathrm{g} / \mathrm{mL}, 44.94 \pm 0.66 \mathrm{~mm}$ at $0.10 \mu \mathrm{g} / \mathrm{mL}$, and $44.12 \pm$ $0.45 \mathrm{~mm}$ at $0.01 \mu \mathrm{g} / \mathrm{mL}$ against C. gloeosporioides, while the CMML exhibited antifungal activity of $49.45 \pm 0.32 \mathrm{~mm}$ at $10.00 \mu \mathrm{g} / \mathrm{mL}, 46.50 \pm 0.84 \mathrm{~mm}$ at $1.00 \mu \mathrm{g} / \mathrm{mL}, 42.55 \pm 0.71 \mathrm{~mm}$ at $0.10 \mu \mathrm{g} / \mathrm{mL}$, and $41.33 \pm 0.51 \mathrm{~mm}$ at $0.01 \mu \mathrm{g} / \mathrm{mL}$ against C. gloeosporioides. On the other hand, the AcMML exhibited antifungal activity of $48.54 \pm 0.41 \mathrm{~mm}$ at $10.00 \mu \mathrm{g} / \mathrm{mL}, 43.74 \pm$ $1.11 \mathrm{~mm}$ at $1.00 \mu \mathrm{g} / \mathrm{mL}, 39.43 \pm 0.96 \mathrm{~mm}$ at $0.10 \mu \mathrm{g} / \mathrm{mL}$, and $37.75 \pm 0.56 \mathrm{~mm}$ at $0.01 \mu \mathrm{g} / \mathrm{mL}$ against C. gloeosporioides. The MIC value recorded for the extracts was $20.00 \mu \mathrm{g} / \mathrm{mL}$. In the next studies to determine the inhibition of sporulation of C. gloeosporioides, the MMML exerted inhibition of sporulation $\left(\times 10^{5}\right)$ of $2.33 \pm 0.04$ at $10.00 \mu \mathrm{g} / \mathrm{mL}, 2.29 \pm 0.03$ at $1.00 \mu \mathrm{g} / \mathrm{mL}, 2.20 \pm 0.03$ at $0.10 \mu \mathrm{g} / \mathrm{mL}$, and $1.98 \pm 0.03$ at $0.01 \mu \mathrm{g} / \mathrm{mL}$ against $C$. gloeosporioides, while the CMML exerted inhibition of sporulation $\left(\times 10^{5}\right)$ of $2.27 \pm 0.04$ at $10.00 \mu \mathrm{g} / \mathrm{mL}, 1.89 \pm 0.03$ at $1.00 \mu \mathrm{g} / \mathrm{mL}, 1.80 \pm 0.03$ at $0.10 \mu \mathrm{g} / \mathrm{mL}$, and $1.77 \pm 0.03$ at $0.01 \mu \mathrm{g} / \mathrm{mL}$ against $C$. gloeosporioides. On the other hand, the AcMML exerted inhibition of sporulation $\left(\times 10^{5}\right)$ of $2.24 \pm 0.04$ at $10.00 \mu \mathrm{g} / \mathrm{mL}$ at $10.00 \mu \mathrm{g} / \mathrm{mL}$ against $1.76 \pm 0.03$ at $1.00 \mu \mathrm{g} / \mathrm{mL}, 1.75 \pm 0.02$ at $0.10 \mu \mathrm{g} / \mathrm{mL}$, and $1.76 \pm 0.03$ at $0.01 \mu \mathrm{g} / \mathrm{mL}$ against C. gloeosporioides.

Maji et al. [65] examined the antimicrobial efficiency of WMML, AcMML, and benzene (BMML) extracts of M. malabathricum leaves collected from Gurguripal forest, Midnapur, West Bengal, India, against seven human pathogens 


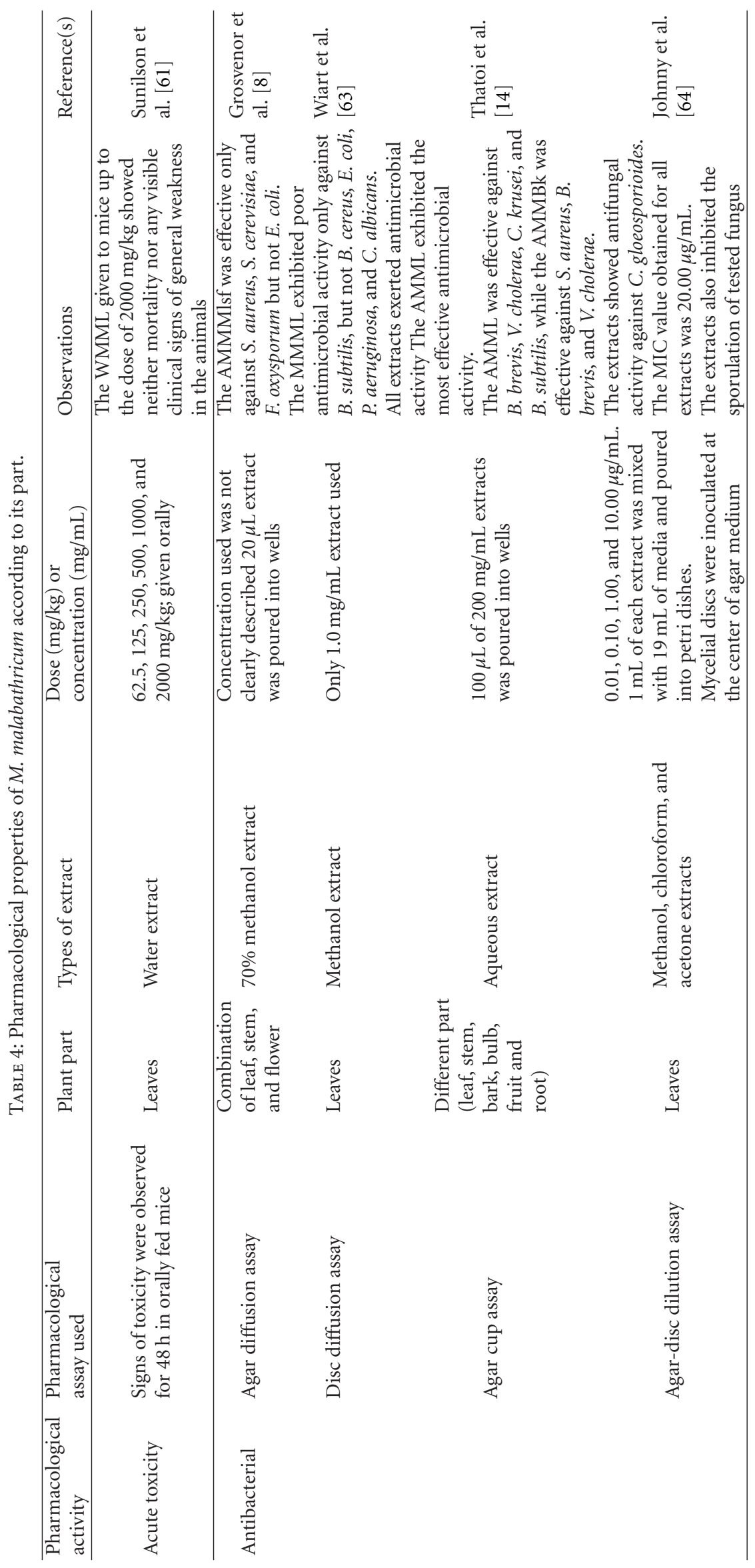




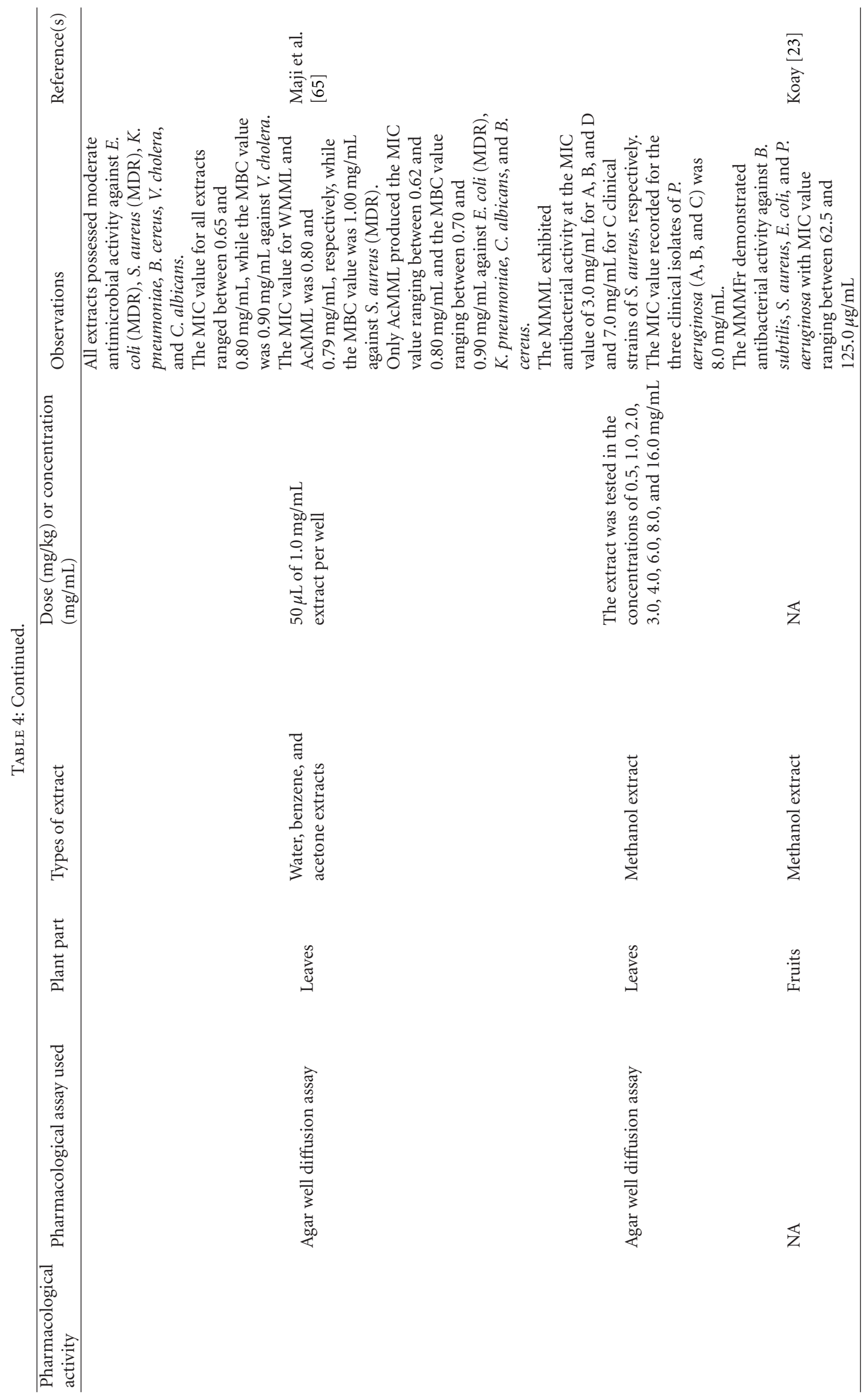




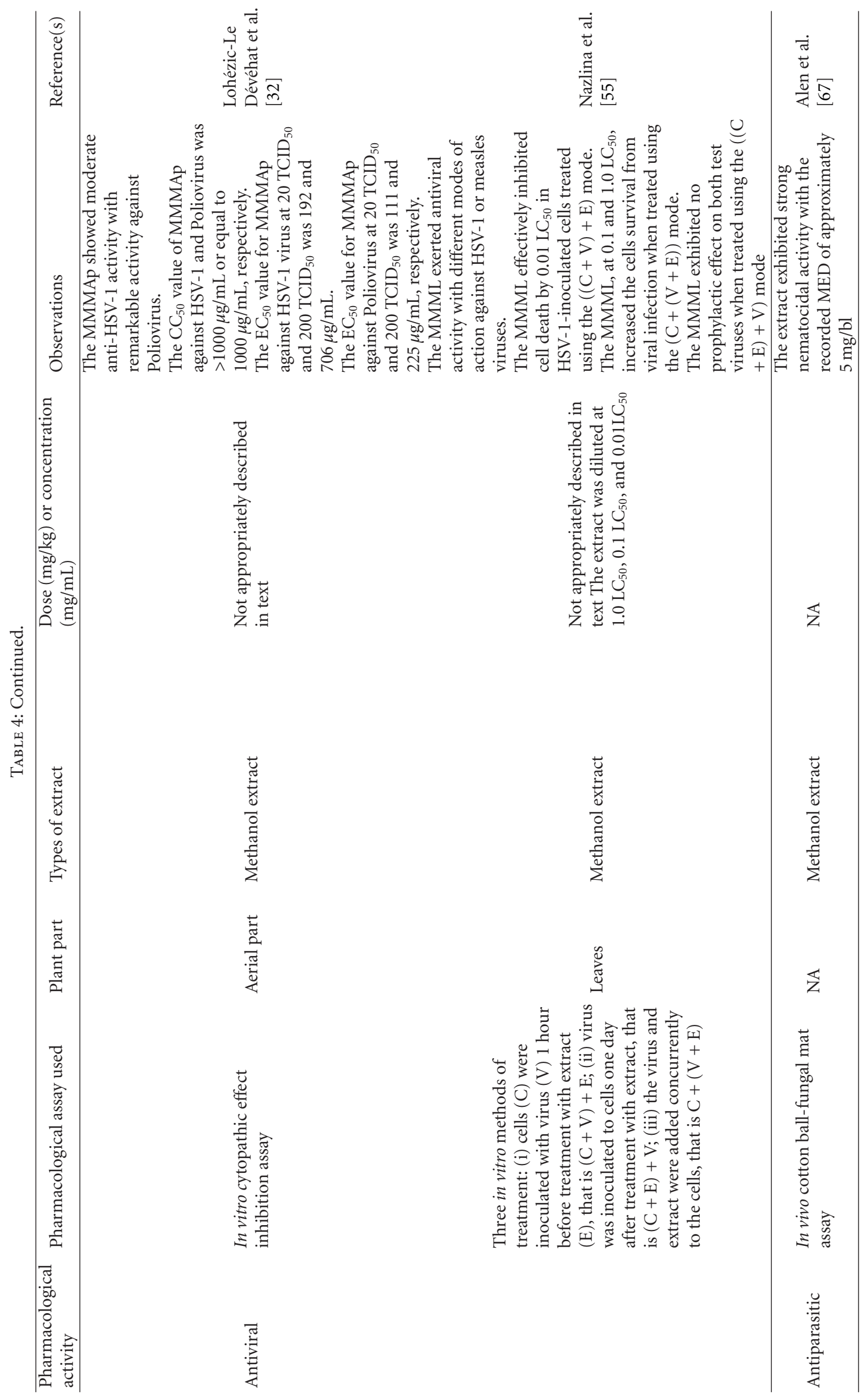




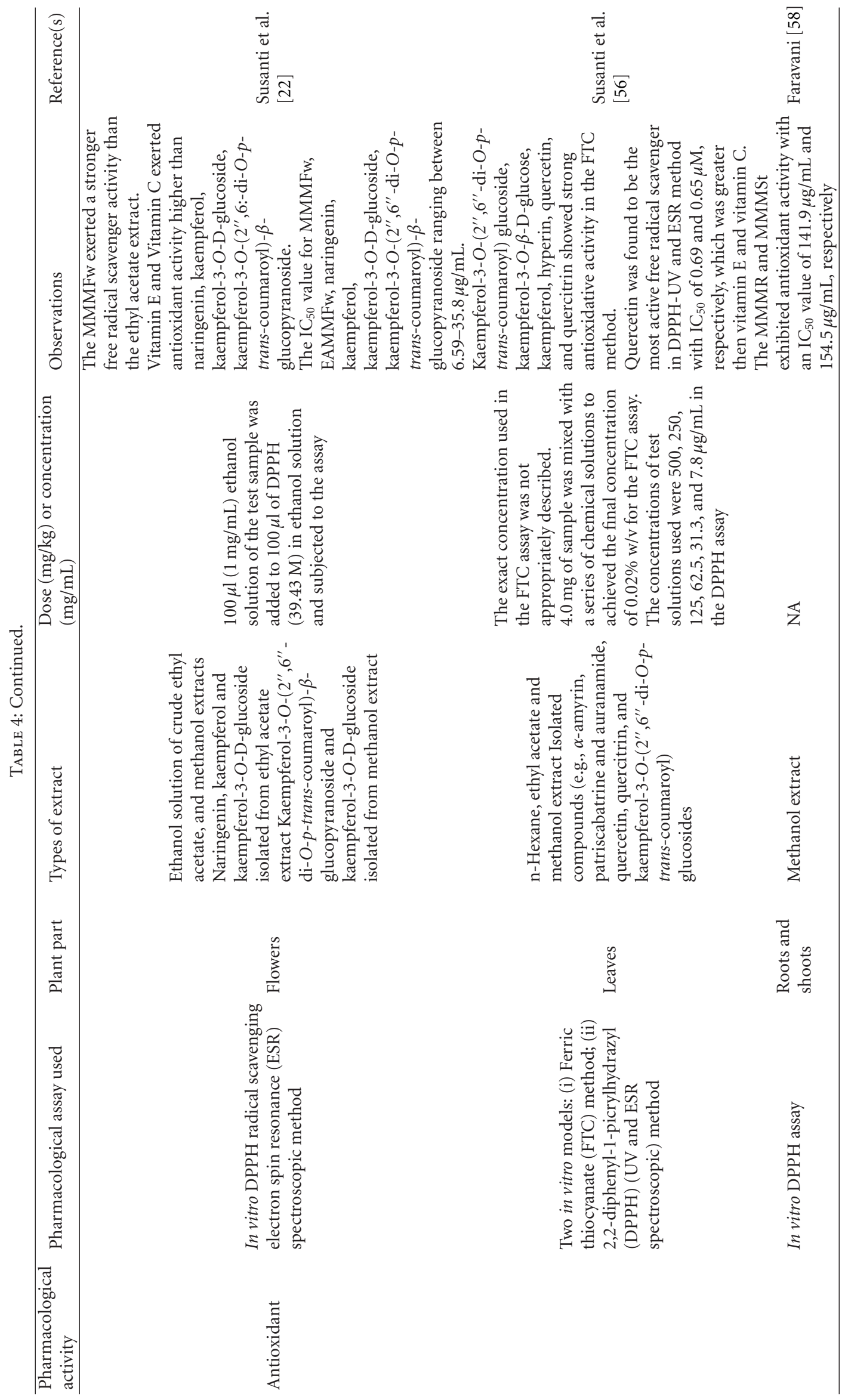




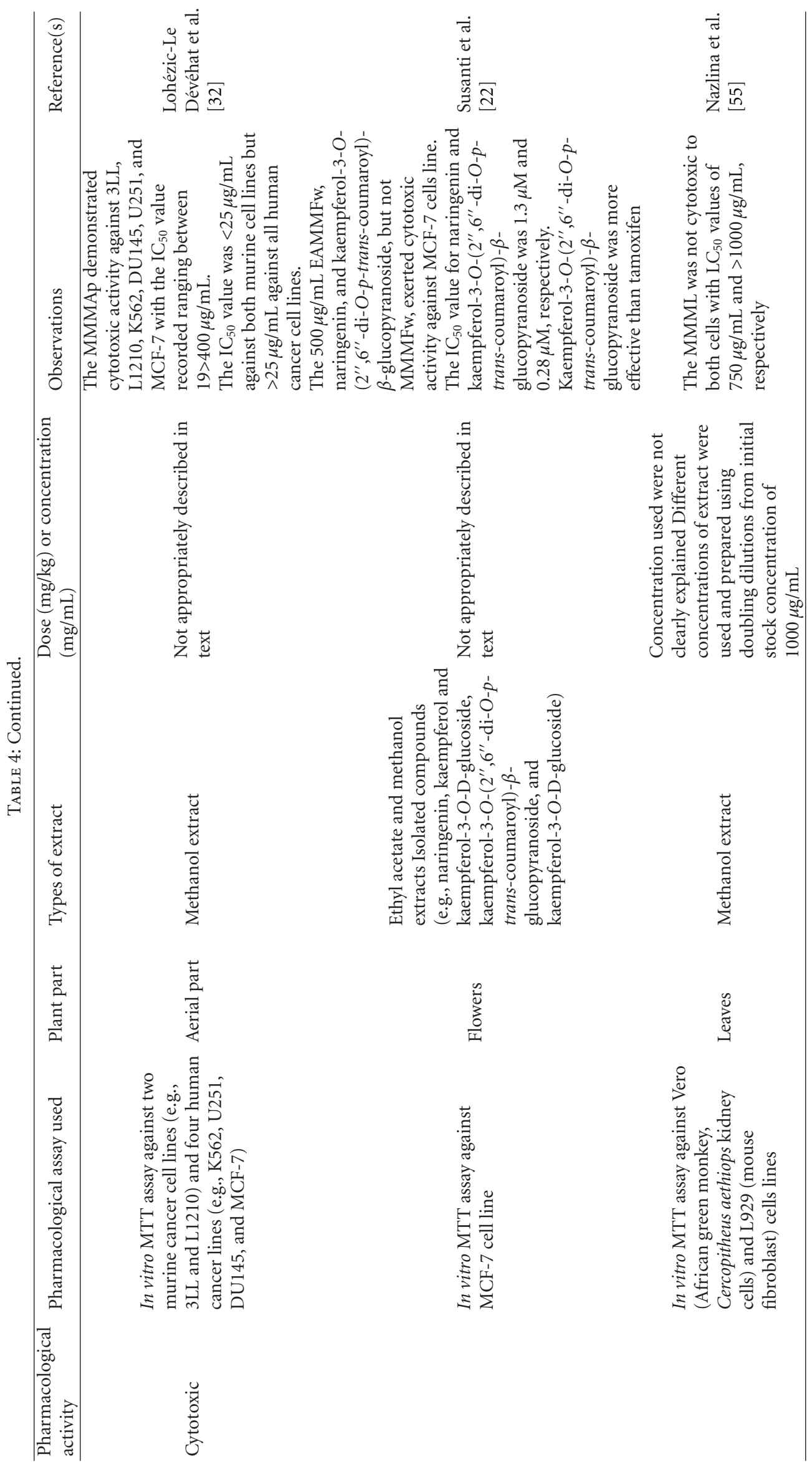




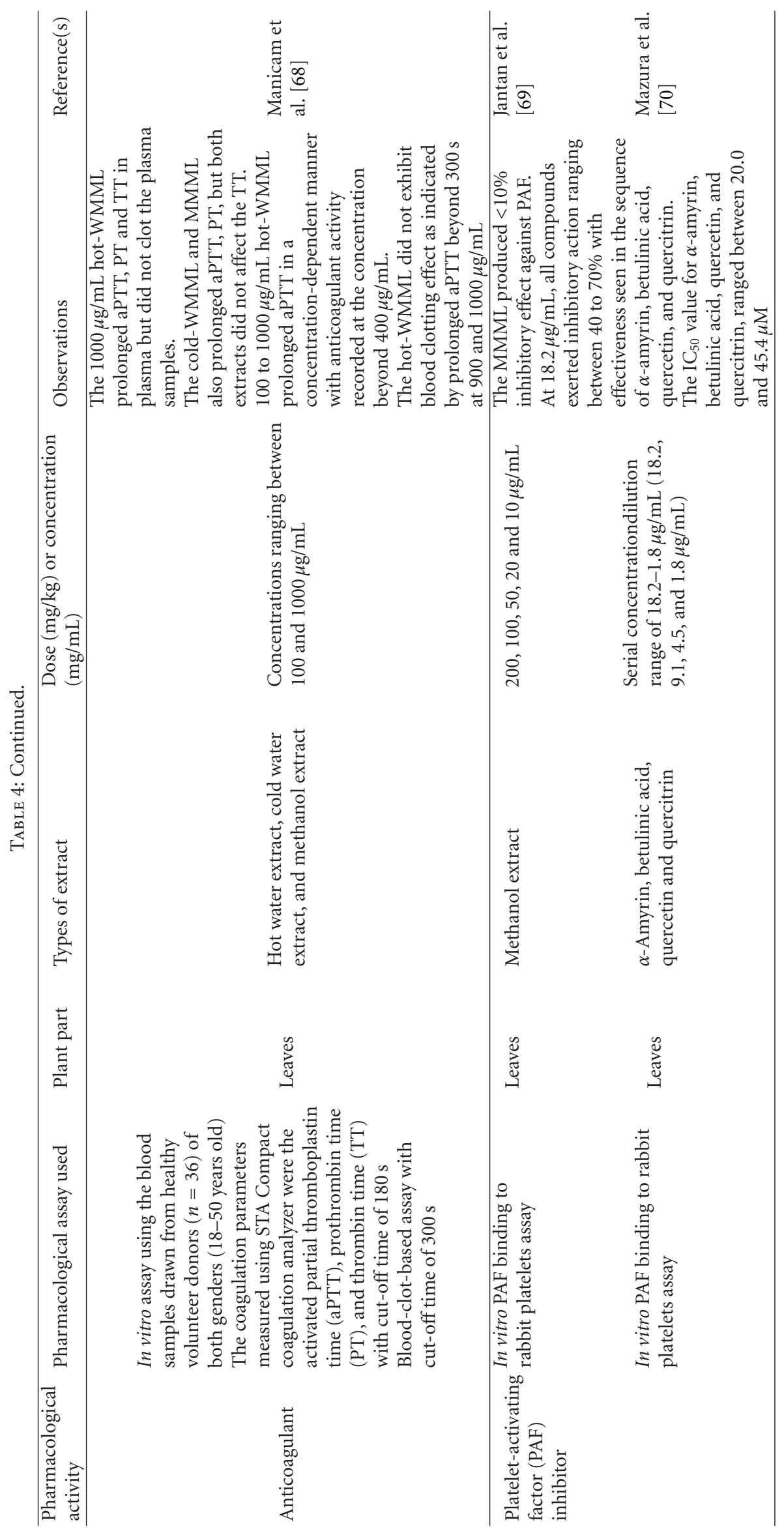




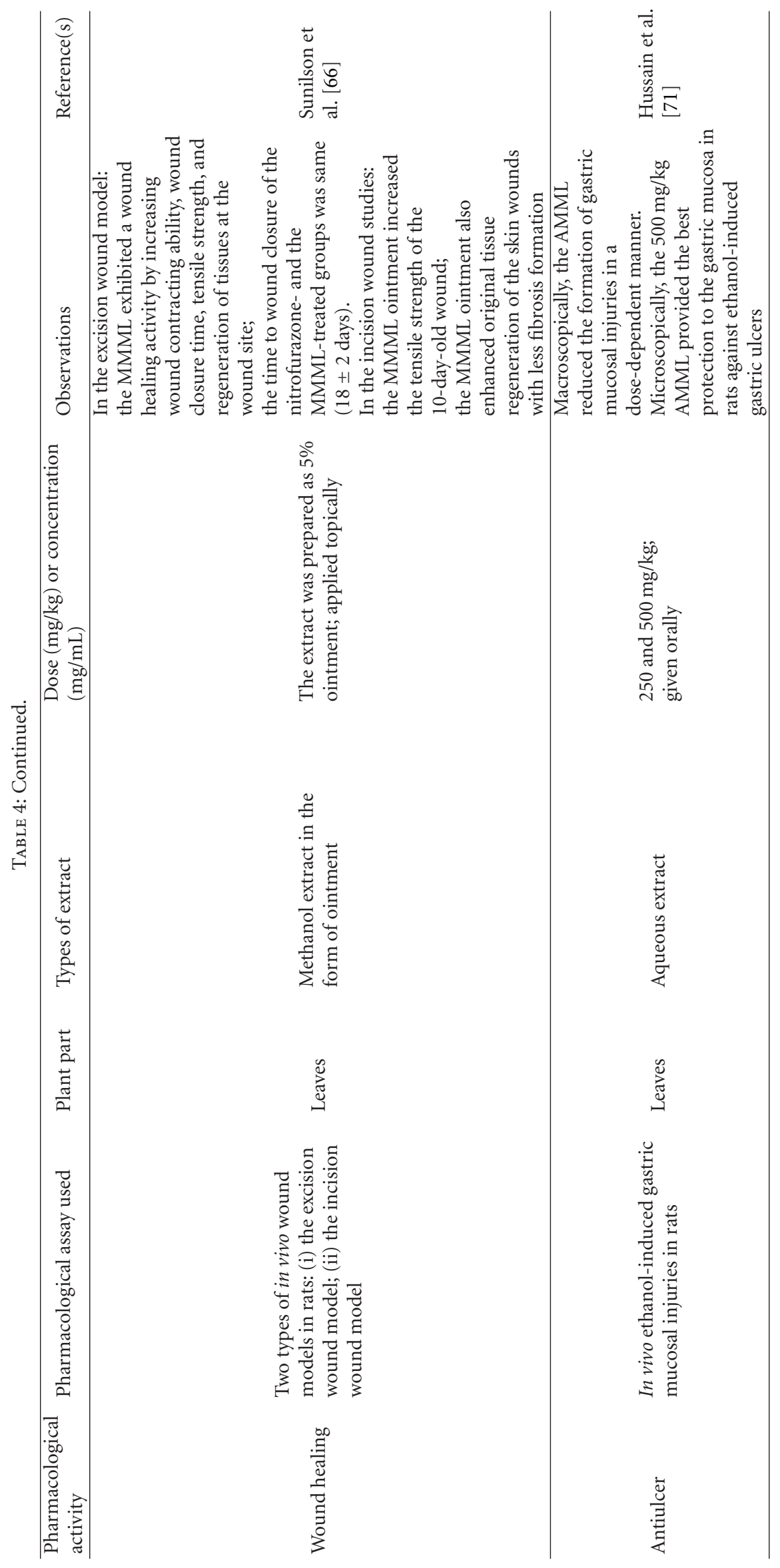




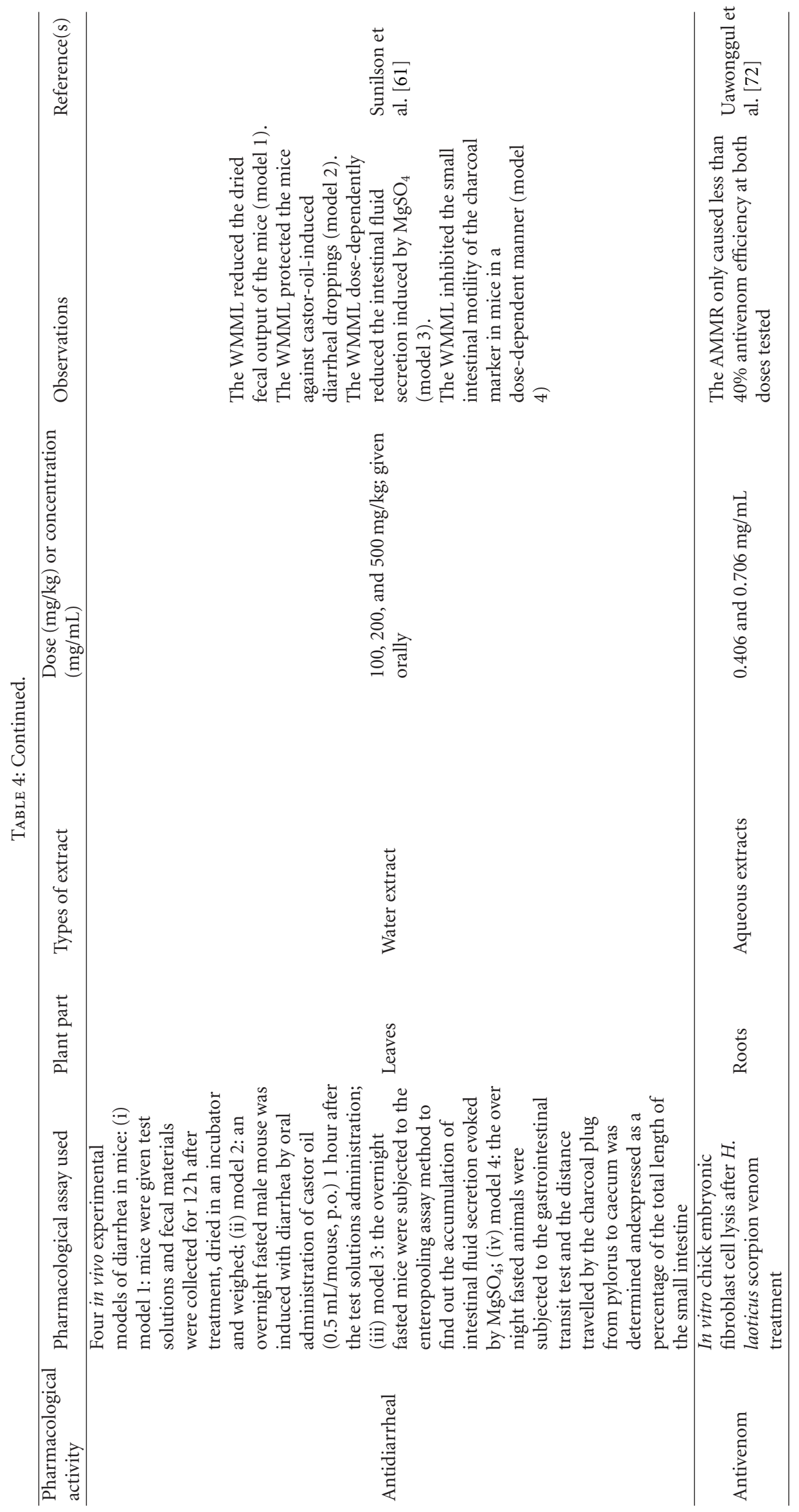




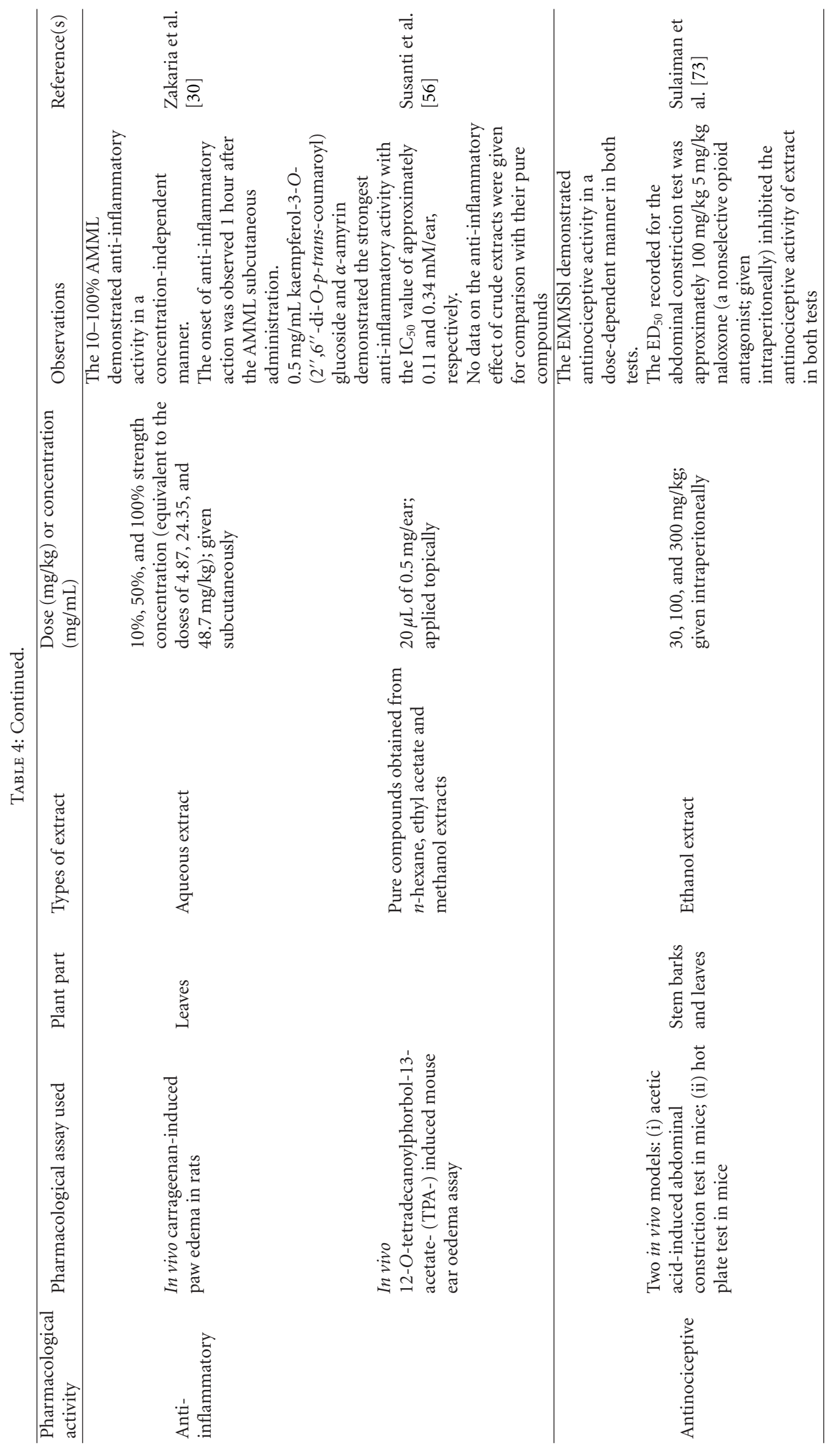




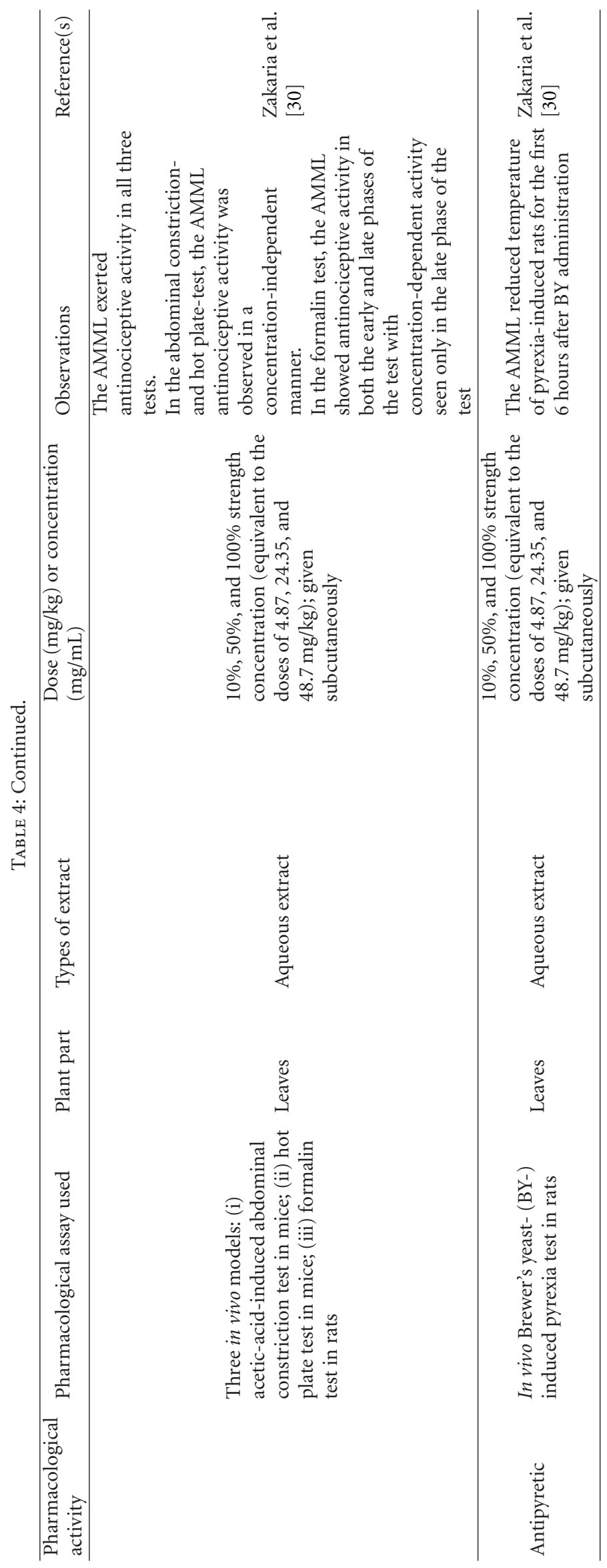


(e.g., E. coli (multi-drug-resistant (MDR)), S. aureus (MDR), $K$. pneumoniae, B. cereus, V. cholera, and C. albicans) using the agar well diffusion method with Ciprofloxacin $(50 \mu \mathrm{g} / \mathrm{mL})$ used as standard antibiotic. M. malabathricum, in the volume of $50 \mu \mathrm{L} /$ well and in the concentration of $1.00 \mathrm{mg} / \mathrm{mL}$, was considered to possess moderate antimicrobial activity as indicated by its ability to produce zone of inhibition ranging between 8 to $11 \mathrm{~mm}$ against all pathogenic microorganisms. In comparison, Ciprofloxacin produced the zone of inhibition ranging between 14 and $27 \mathrm{~mm}$. The MIC value for the WMML, BMML and AcMML against $V$. cholerae was $0.65,0.80$ and $0.80 \mathrm{mg} / \mathrm{mL}$ while the MIC value for the WMML and AcMML against S. aureus (MDR) was 0.80 and 0.79 , respectively. For E. coli (MDR), K. pneumoniae, C. albicans and B. cereus, only the AcMML produced MIC value, which was recorded at $0.62,0.79,0.80$ and $0.80 \mathrm{mg} / \mathrm{mL}$, respectively. In term of the $\mathrm{MBC}$ value, the three extracts of $M$. malabathricum caused bactericidal activity against $V$. cholera at the concentration of $0.90 \mathrm{mg} / \mathrm{mL}$ while the AcMML and BMML exerted bactericidal effect against $S$. aureus (MDR) at $1.00 \mathrm{mg} / \mathrm{mL}$. For E. coli (MDR), K. pneumoniae, $C$. albicans and $B$. cereus, the $\mathrm{MBC}$ value was recorded only for the AcMML extract, which is at 0.70, 0.95, 0.90 and $0.90 \mathrm{mg} / \mathrm{mL}$, respectively. However, the MIC and $\mathrm{MBC}$ value for Ciprofloxacin was not determined.

In an attempt to study the wound healing properties of the leaves of white M. malabathricum collected from the State of Selangor, Malaysia, Sunilson et al. [66] also carried out antibacterial study on the MMML against the four clinical isolates (A, B, C, and D) of S. aureus and 3 clinical isolates (A, $\mathrm{B}$, and $\mathrm{C}$ ) of $P$. aeruginosa obtained from sores of different patients using a modification of the agar well diffusion technique. Based on the data obtained, the extract, which was tested in the concentrations of $0.5,1.0,2.0,3.0,4.0,6.0,8.0$, and $16.0 \mathrm{mg} / \mathrm{mL}$, exhibited antibacterial activity at the MIC value of $3.0 \mathrm{mg} / \mathrm{mL}$ for $\mathrm{A}, \mathrm{B}$, and $\mathrm{D}$ and $7.0 \mathrm{mg} / \mathrm{mL}$ for $\mathrm{C}$ clinical strains of $S$. aureus, respectively. On the other hand, the MIC value recorded for the three clinical isolates of $P$. aeruginosa was $8.0 \mathrm{mg} / \mathrm{mL}$. However, no standard antibiotics were used as references.

4.3. Antiviral Activity. Lohézic-Le Dévéhat et al. [32] investigated the antiviral activity of ten methanolic extracts from eight Indonesian medicinal plants, which included $M$. malabathricum, against HSV-1 and Poliovirus. The virus titre was estimated from cytopathogenicity and expressed as 50\% tissue culture infectious doses per millilitre $\left(\mathrm{TCID}_{50} / \mathrm{mL}\right)$. The antiviral activity was assayed using the cytopathic effect inhibition assay, which was expressed as $\mathrm{EC}_{50}$. The effect of extract on uninfected Vero cells was given by cytotoxic concentration $50 \%\left(\mathrm{CC}_{50} ; \mu \mathrm{g} / \mathrm{mL}\right)$. The MMML together with several species from the Indonesian Loranthaceae, which was collected from Padang in the State of Andalas, Indonesia, was reported to exert moderate anti-HSV-1 activity with significant activity against Poliovirus. The MMML exhibited $\mathrm{CC}_{50}$ against HSV- 1 and Poliovirus with value greater than $1000 \mu \mathrm{g} / \mathrm{mL}$ ( $>1000 \mu \mathrm{g} / \mathrm{mL}$ ) or equal to $1000 \mu \mathrm{g} / \mathrm{mL}$, respectively. In terms of $\mathrm{EC}_{50}$, the value recorded for treatment of extract against HSV-1 virus at $20 \mathrm{TCID}_{50}$ and $200 \mathrm{TCID}_{50}$ was 192 and $706 \mu \mathrm{g} / \mathrm{mL}$, while, for treatment against Poliovirus, the $\mathrm{EC}_{50}$ value obtained at $20 \mathrm{TCID}_{50}$ and $200 \mathrm{TCID}_{50}$ was 111 and $225 \mu \mathrm{g} / \mathrm{mL}$, respectively.

Nazlina et al. [55] have studied the antiviral activity of MMML. The extract earlier subjected to the TLC assays resulted in the isolation and identification of rutin, quercitrin, and quercetin. The antiviral activity was screened against HSV-1 and vaccine strain of measles (Schwarz) wherein three methods of treatment to detect antiviral activity in each of the fraction were used (see Table 4). For the antiviral tests, the extract was diluted at $1.0 \mathrm{LC}_{50}, 0.1$ $\mathrm{LC}_{50}$, and $0.01 \mathrm{LC}_{50}$. The MMML exerted antiviral activity with different modes of action against HSV-1 or measles viruses. The extract was effective in inhibiting cell death by $0.01 \mathrm{LC}_{50}$ in HSV-1-inoculated cells using treatment mode $((\mathrm{C}+\mathrm{V})+\mathrm{E})$ suggesting that virus-inoculated cells were able to overcome viral infection when treated with the extract. Cells treated with simultaneous addition of measles virus and the extract at 0.1 and $1.0 \mathrm{LC}_{50}$ were found to survive from viral infection. The effect of MMML is probably due to the quercetin content that can inhibit reverse transcriptase which is the early part of the measles' replication process. Another possibility is that the MMML is capable of acting directly on viral particle such as modification of free viruses surfaces that inhibits viral attachment to host cells. This belief was supported by the fact that MMML was not capable of inhibiting virus-inoculated cells in treatment mode I. However, the most probable mode of infection can only be further confirmed by transcriptomic or proteomic studies. The extract was found not to have prophylactic effect on both test viruses as demonstrated in treatment mode $((\mathrm{C}+\mathrm{E})+\mathrm{V})$. As for control, guanidine hydrochloride is seen in this study to inhibit viral capability of infecting host cells when added simultaneously, which is believed to happen via blocking of the initiation step of viral RNA synthesis.

4.4. Antiparasitic Activity. Alen et al. [67] have screened 65 methanolic extracts of Sumatran rain forest plants, including M. malabathricum, for their nematocidal activity against Bursaphelenchus xylophilus using the in vivo cotton ball- (bl) fungal mat assay. The authors reported that the MMML, together with that of Allamanda cathartica, Ervatamia corymbosa, Hoya diversifolia, Bischofia javanica, Derris malaccensis, Ophiorrhiza konsteleary, and Brucea sumatrana, exhibited strong nematocidal activity with the recorded minimum effective dose (MED) of approximately $5 \mathrm{mg} / \mathrm{bl}$. However, the extracts of Bischofia javanica, Knema hookeriana and Areca catech $u$ were considered to be the most effective nematocidal agents with the recorded MED of approximately $0.7 \mathrm{mg} / \mathrm{bl}$.

4.5. Antioxidant Activity. Susanti et al. [22] have also studied the antioxidant activity of the ethanolic solution of the crude EAMMFw and MMMFw, as well as naringenin, kaempferol and kaempferol-3-O-D-glucoside isolated from the EAMMFw and kaempferol-3-O- $\left(2^{\prime \prime}, 6^{\prime \prime}\right.$-di-O-p-trans-coumaroyl)- $\beta$-glucopyranoside and kaempferol-3-O-D-glucoside isolated from the MMMFw. The antioxidant assay was carried out by the DPPH radical scavenging electron spin resonance (ESR) spectroscopic method with vitamin $\mathrm{E}$ and 
vitamin $\mathrm{C}$ used as standard positive control. The ethanolic solution of the test sample $100 \mu \mathrm{l}(1 \mathrm{mg} / \mathrm{mL})$ was added to $100 \mu \mathrm{l}$ of DPPH $(39.43 \mathrm{M})$ in ethanol solution and subjected to the assay. At the concentration of $7.8 \mu \mathrm{g} / \mathrm{mL}$, the MMMFw exerted a stronger free radical scavenger activity than the EAMMFw with the percentage of inhibition recorded at $59.3 \pm 1.4 \%$ and $53.2 \pm 1.3 \%$. Naringenin, kaempferol, kaempferol-3-O-D-glucoside, and kaempferol-3-O( $2^{\prime \prime}, 6$ :-di-O-p-trans-coumaroyl)- $\beta$-glucopyranoside, at the concentration of $7.8 \mu \mathrm{g} / \mathrm{mL}$, were found to produce $42.5 \pm$ $0.7 \%, 38.6 \pm 0.09 \%, 24.6 \pm 0.3 \%$, and $31.2 \pm 4.5 \%$ inhibition in comparison to vitamin $\mathrm{E}$ and vitamin $\mathrm{C}$, which produced $50.9 \pm 0.07 \%$ and $82.2 \pm 0.3 \%$ inhibition, respectively. The $\mathrm{IC}_{50}$ recorded for $\mathrm{MMMFw}$, EAMMFw, naringenin, kaempferol, kaempferol-3-O-D-glucoside, kaempferol-3-O-(2", $6^{\prime \prime}$-di-O-p-trans-coumaroyl)- $\beta$-glucopyranoside were $6.59 \pm$ $0.8 \mu \mathrm{g} / \mathrm{mL}, 7.21 \pm 0.5 \mu \mathrm{g} / \mathrm{mL}, 0.52 \pm 0.5 \mathrm{mM}, 81.5 \pm 0.7 \mu \mathrm{M}$, $1.07 \pm 0.4 \mathrm{mM}, 35.8 \pm 0.5 \mu \mathrm{M}$, respectively. According to Susanti et al. [22] kaempferol-3-O-(2" ,6:-di-O-p-transcoumaroyl)- $\beta$-glucopyranoside was a more active antioxidant than the other compounds and this pronounced radical-scavenging activity is due to the presence of two p-coumaroyl acid groups which are located at the 200 and 600 positions in the glucose ring. Thus, it is proposed that the presence of compound 4 contributed to the higher antioxidant activity of the MMMFw. Meanwhile the authors also suggested that naringenin exhibited a less active antioxidant activity when compared to kaempferol or kaempferol-3-O$\mathrm{D}$-glucoside due to the lack of an unsaturated heterocyclic ring (C-ring), which allows electron delocalization across the molecule for stabilization of the aryloxyl radical, as well as the lack of a $3-\mathrm{OH}$ group.

The antioxidant potential of HMML, EAMML, and MMML of white petals $M$. malabathricum, collected from Johor, Malaysia, together with the isolated compounds (e.g., $\alpha$-amyrin, patriscabatrine and auranamide, quercetin, quercitrin, and kaempferol-3-O- $\left(2^{\prime \prime}, 6^{\prime \prime}\right.$-di-O-p-trans-coumaroyl)glucoside), was determined using the ferric thiocyanate (FTC) and 2,2-diphenyl-1-picrylhydrazyl (DPPH) (UV and ESR spectroscopic) methods [56]. In the former assay, the final concentration of test solution was $0.02 \% \mathrm{w} / \mathrm{v}$, while, in the latter assay, the concentration of test solutions used were 500, 250, 125, 62.5, 31.3 and $7.8 \mu \mathrm{g} / \mathrm{mL}$. From the data obtained, kaempferol-3-O-(2", $6^{\prime \prime}$-di-O-p-trans-coumaroyl) glucoside, kaempferol-3-O- $\beta$-D-glucose, kaempferol, hyperin, quercetin, and quercitrin showed strong antioxidative activities than vitamin $\mathrm{E}$ with inhibition of more than $90 \%$ in the FTC method. Quercetin, quercitrin, and kaempferol-3$O$ - $\left(2^{\prime \prime}, 6^{\prime \prime}\right.$-di-O-p-trans-coumaroyl $)$ glucoside $)$ produced the respective percentage of linolenic acid peroxidation of $96.1 \%$, $94.1 \%$, and $92.2 \%$, which is greater than vitamin $\mathrm{E}(78.3 \%)$. In the DPPH assay, quercetin was found to be the most active free radical scavenger in DPPH-UV and ESR method with $\mathrm{IC}_{50}$ of 0.69 and $0.65 \mu \mathrm{M}$, respectively. The $\mathrm{IC}_{50}$ value of quercetin in the DPPH-UV method was greater than that of the positive control, vitamin $\mathrm{E}(17.1 \pm 2.5 \mathrm{mM})$ and vitamin $\mathrm{C}(8.3 \pm 1.2 \mu \mathrm{M})$ and the other flavonoids, namely, quercitrin $(74.1 \pm 0.4 \mu \mathrm{M})$ and kaempferol-3-O- $\left(2^{\prime \prime}, 6^{\prime \prime}\right.$-di-O-p-transcoumaroyl)glucoside) $(308.1 \pm 1.7 \mu \mathrm{M})$. The percent inhi- bition of quercetin, quercitrin, kaempferol-3-O- $\left(2^{\prime \prime}, 6^{\prime \prime}-\mathrm{di}-\right.$ $O$-p-trans-coumaroyl)glucoside), vitamin $\mathrm{E}$, and vitamin $\mathrm{C}$ at concentration $7.8 \mu \mathrm{g} / \mathrm{mL}$ was $57.60 \%, 15.4 \%, 7.5 \%, 7.4 \%$, and $30.8 \%$, respectively.

In addition, Faravani [58] also reported the antioxidant activity of crude MMMR and methanol extracts of M. malabathricum shoots (MMMSt) investigated using the DPPH assay. The MMMSt exhibited their radical scavenging activity as indicated by their ability to reduce the stable free-radical DPPH to the yellow-colored diphenylpicrylhydrazine with an $\mathrm{IC}_{50}$ recorded at approximately $141.9 \mu \mathrm{g} / \mathrm{mL}$ and $154.5 \mu \mathrm{g} / \mathrm{mL}$, respectively. However, the extracts antioxidant activity was considered to be lowered than that of the positive control, ascorbic acid, which produced an $\mathrm{IC}_{50}$ of approximately $28.6 \mu \mathrm{g} / \mathrm{mL}$.

4.6. Cytotoxic Activity. An attempt to determine the cytotoxic activity of MMML together with nine methanolic extracts from seven Indonesian medicinal plants was also made by Lohézic-Le Dévéhat et al. [32]. All plants were collected from Padang in the State of Andalas, Indonesia, and subjected to the cytotoxic study on two murine cancer cell lines (e.g., 3LL (Lewis lung carcinoma cells) and L1210 (leukaemic cells)) and four human cancer lines (e.g., K562 (chronic myeloid leukaemia), U251 (glioblastoma), DU145 (prostatic adenocarcinoma), and MCF-7 (mammary carcinoma)). The MMML exhibited cytotoxic activity against 3LL, L1210, K562, DU145, MCF-7, and U251 at the IC $_{50}$ values of 19, 21, $67,113,>400$, and $30 \mu \mathrm{g} / \mathrm{mL}$. Interestingly, MMML exhibited cytotoxic activity with $\mathrm{IC}_{50}$ value of $<25 \mu \mathrm{g} / \mathrm{mL}$ against both murine cell lines while the cytotoxicity activity against all human cancer cell lines was observed at an $\mathrm{IC}_{50}$ value that was $>25 \mu \mathrm{g} / \mathrm{mL}$.

Susanti et al. [22] have investigated cytotoxic activity of the crude EAMMFw and MMMFw and several compounds isolated from the respective crude extract (e.g., naringenin, kaempferol and kaempferol-3-O-D-glucoside, kaempferol3-O-( $2^{\prime \prime}, 6^{\prime \prime}$-di-O-p-trans-coumaroyl)- $\beta$-glucopyranoside, and kaempferol-3-O-D-glucoside) against a MCF-7 cell line using the 3-(4,5-dimethylthiazol-2-yl)-2,5-diphenyltetrazolium bromide (MTT) assay. DMSO (0.1\%) and tamoxifen were used as negative and positive controls, respectively. The $500 \mu \mathrm{g} / \mathrm{mL}$ EAMMFw caused a change in the cell morphology of MCF-7 cells line, while MMMFw, at the same concentration, did not display any activity. Naringenin and kaempferol-3-O-(2", $6^{\prime \prime}$-di-O- $p$-trans-coumaroyl $)$ - $\beta$-glucopyranoside demonstrated a significant anticancer effect against MCF-7 in a dose-dependent manner with $\mathrm{IC}_{50}$ values of $1.30 \pm 0.002 \mu \mathrm{M}$ and $0.28 \pm 0.004 \mu \mathrm{M}$, respectively. The anticancer activity of those compounds was demonstrated to involve cell proliferation and changes in the cell morphology. Thus, naringenin was suggested to contribute to the anticancer activity of the EAMMFw. The failure of MMMFw to exhibit its cytotoxicity effect suggested that the antagonist effects of the compounds present in the extract play an important role in not affecting the cell proliferation. Interestingly, the $\mathrm{IC}_{50}$ value of kaempferol-3-O- $\left(2^{\prime \prime}, 6^{\prime \prime}\right.$-di$O$-p-trans-coumaroyl)- $\beta$-glucopyranoside was lower than that of the positive control, tamoxifen (the $\mathrm{IC}_{50}$ value 
was $0.76 \pm 0.005 \mu \mathrm{M})$. Based on the cell morphology, it was proposed that kaempferol-3-O- $\left(2^{\prime \prime}, 6^{\prime \prime}-\mathrm{di}-\mathrm{O}-\mathrm{p}\right.$-transcoumaroyl)- $\beta$-glucopyranoside was active against human breast cell cancer by inhibiting cell proliferation. Meanwhile, naringenin inhibited cell proliferation, followed by cell lyses. Kaempferol-3-O-(2" $6^{\prime \prime}$-di-O-p-trans-coumaroyl $)-\beta$-glucopyranoside has a free hydroxyl group at position 3 and a parahydroxyl group in ring $B$, which probably increase the activity of this compound.

Nazlina et al. [55] have also studied the cytotoxic activity of MMML against Vero cell line (African green monkey, Cercopitheus aethiops kidney cells) and L929 cells (mouse fibroblast) whereby the cytotoxicity test was carried out according to the microculture method in, at least, two independent experiments in triplicates at different concentrations of MMML using doubling dilutions from initial stock concentration of $1000 \mu \mathrm{g} / \mathrm{mL}$. Cytotoxicity screening towards Vero and L929 cells showed that MMML was not cytotoxic to both cells with $\mathrm{LC}_{50}$ values of $750 \mu \mathrm{g} / \mathrm{mL}$ and $>1000 \mu \mathrm{g} / \mathrm{mL}$, respectively. As for gunaindine hydrochloride that was used as positive control, it was found not cytotoxic in Vero cells with the $\mathrm{LC}_{50}$ value of $100 \mu \mathrm{g} / \mathrm{mL}$ while the $\mathrm{LC}_{50}$ value for L929 cells was not determined.

4.7. Anticoagulant Activity. Manicam et al. [68] have reported on the anticoagulant property of the leaves of M. malabathricum collected from the area of Serdang in the state of Selangor, Malaysia. The hot- and cold-WMML and MMML were assayed for their anticoagulant property using the blood samples drawn from healthy volunteer donors $(n=36)$ of both genders (18-50 years old) after screening via questionnaire for familial history of cardiovascular diseases and other major coagulopathies. The coagulation parameters used to determine the extracts anticoagulant activity were the activated partial thromboplastin time (aPTT), prothrombin time (PT), and thrombin time (TT). These parameters were carried out in a STA Compact coagulation analyzer with the maximum cut-off time recorded by the coagulation analyzer set at $180 \mathrm{~s}$. Plasma samples were spiked with different concentrations of $M$. malabathricum extracts (ranging between 100 and $1000 \mu \mathrm{g} / \mathrm{mL}$ ), heparin (used as positive control), or deionized water (used as vehicle control). Based on the preliminary study, the hot-WMML, in the concentration of $1000 \mu \mathrm{g} / \mathrm{mL}$, significantly prolonged $(P<0.05)$ the three parameters, namely, aPTT, PT, and TT, in plasma when compared to the normal control plasma. The PT and TT measurements were $20.0 \pm 1.3 \mathrm{~s}$ and $43.2 \pm 0.1 \mathrm{~s}$ when compared to control group ( $13.3 \pm 0.5$ or $20.1 \pm 0.2 \mathrm{~s})$, respectively. Interestingly, the hot-WMML did not clot the plasma samples when tested for aPTT, as evidenced by the maximum cut-off time recorded at $180 \mathrm{~s}$. The cold-WMML and MMML also prolonged aPTT in a significant fashion $(P<0.05)$ with $120.0 \pm 0.9 \mathrm{~s}$ and $108.0 \pm 0.7 \mathrm{~s}$, respectively, in comparison to the $38.9 \pm 0.5 \mathrm{~s}$ of control plasma. Similar to the hotWMML, the PT of cold-WMML was prolonging significantly $(P<0.05)$ in comparison to the control. On the other hand, these extracts did not affect the TT significantly. Based on the anticoagulant activity demonstrated above, at the concentration of $1000 \mu \mathrm{g} / \mathrm{mL}$, Manicam et al. [68] selected the
hot-WMML for further study on its effect on clot-based assays. At the concentration ranging between 100 to $1000 \mu \mathrm{g} / \mathrm{mL}$, the hot-WMML caused prolongation of aPTT in a concentration-dependent manner with significant anticoagulant activity recorded at the concentration beyond $400 \mu \mathrm{g} / \mathrm{mL}$ in comparison with vehicle control. Interestingly, hot-WMML prolonged aPTT beyond $300 \mathrm{~s}$ at 900 and $1000 \mu \mathrm{g} / \mathrm{mL}$, which was comparable to that of $5-1000 \mu \mathrm{g} / \mathrm{mL}$ heparin. The cut-off time to measure clotting times was $300 \mathrm{~s}$; beyond which the plasma samples were rendered noncoagulable. The control plasma was found to record an aPTT of 64.3 and $60.7 \mathrm{~s}$ for females and males, respectively. On the other hand, the aPTT of normal pooled plasma (NPP) was 41.0 and $40.5 \mathrm{~s}$ for females and males, respectively, and was significantly different $(P<0.05)$ from that of the control plasma. In contrast to aPTT, hot-WMML caused no significant changes for PT and TT at the tested concentration range. However, PT was significantly $(P<0.001)$ prolonged at the highest contration of heparin $(1000 \mu \mathrm{g} / \mathrm{mL})$ while TT was significantly $(P<0.001)$ prolonged at the highest concentration of hot-WMML $(1000 \mu \mathrm{g} / \mathrm{mL})$ or at the range of $5-1000 \mu \mathrm{g} / \mathrm{mL}$. Overall, the PT assay recorded the lowest coagulation inhibitory activity for hot-WMML.

4.8. Platelet-Activating Factor Inhibitory Activity. Jantan et al. [69] investigated the anti-platelet-activating factor inhibitory property of 49 methanol extracts of 37 species of Malaysian medicinal plants, including $M$. malabathricum collected from Kepong, Shah Alam, Selangor, Malaysia. However, the MMML, at the concentrations of 200, 100, 50, 20 and $10 \mu \mathrm{g} / \mathrm{mL}$, produced $<10 \%$ inhibitory effect against platelet activating factor (PAF). Cedrol, a known PAF receptor antagonist and at the concentration of $18.2 \mu \mathrm{g} / \mathrm{mL}$, was used as a standard in the bioassay.

Mazura et al. [70], in their quest for natural anti-inflammatory agents, assessed the potential of $\alpha$-amyrin, betulinic acid, quercetin and quercitrin isolated from M. malabathricum to inhibit PAF binding to rabbit platelets using ${ }^{3} \mathrm{H}-\mathrm{PAF}$ as a ligand. At $18.2 \mu \mathrm{g} / \mathrm{mL}$, all compounds exerted 67.3, 64.3, 57.4 , and $45.4 \%$, while cedrol, as positive control, caused $79.6 \%$, respectively. The tested compounds, at the serial concentration dilution range of $18.2-1.8 \mu \mathrm{g} / \mathrm{mL}$, produced the percentage of inhibition (\%) of $17.9-70.4 \%, 11.8-65.1 \%$, $4.3-58.9 \%$, and $2.5-44.8 \%$, respectively. The results also indicated that quercetin, quercitrin, $\alpha$-amyrin, and betulinic acid showed inhibition of PAF receptor binding to rabbit platelets with $\mathrm{IC}_{50}$ values of $33.0,45.4,20.0$, and $22.2 \mu \mathrm{M}$, respectively. The $\mathrm{IC}_{50}$ values of these compounds were comparable to that of cedrol $(13.1 \mu \mathrm{M})$, which is a known PAF receptor antagonist.

4.9. Wound Healing Activity. Sunilson et al. [66] reported the wound healing potential of MMML, collected from the State of Selangor, Malaysia, in the form of ointment when examined in two types of wound model in rats: (i) the excision wound model and (ii) the incision wound model. The extract, prepared as 5\% ointment, exhibited a wound healing activity that was comparable with the standard drug, nitrofurazone, which was prepared as $0.2 \%$ ointment, in terms 
of wound contracting ability, wound closure time, tensile strength, and regeneration of tissues at the wound site. The time to wound closure of the nitrofurazone- and the extracttreated groups was the same $(18.0 \pm 2.0$ days $)$. In the incision wound studies, the extract ointment and nitrofurazone caused a significant increase in tensile strength of the 10day-old wound when compared with the control (418.0 \pm $13.8 \mathrm{~g})$. The tensile strength of the extract ointment- and the nitrofurazone-ointment-treated groups was almost the same $(551.0 \pm 16.9 \mathrm{~g}$ versus $576.0 \pm 12.5 \mathrm{~g})$. Interestingly, the extract ointment enhanced original tissue regeneration of the skin wounds much greater than nitrofurazone with the standard drug exerting more relative fibrosis of skin wounds when compared to the extract ointment. Although fibrosis was relatively less in the extract ointment-treated rats, the original tissue was regenerated much more in the animal wounds. The skin adrenal structures such as the Pilosebaceous glands and sweat glands were better presented in wounds treated with extract ointment compared to nitrofurazone-treated animal wounds.

4.10. Antiulcer Activity. Hussain et al. [71] studied the antiulcer activity of the AMML, collected around the University of Malaya campus in Petaling Jaya, Selangor, Malaysia, against ethanol-induced gastric mucosal injuries in rats. The extract, in the dose of 250 and $500 \mathrm{mg} / \mathrm{kg}$, and $20 \mathrm{mg} / \mathrm{kg}$ omeprazole, used as positive control, were administered orally followed 1 hour later by the oral administration of the ethanol. Macroscopically, the oral administration of the test solutions was found to significantly $(P<0.05)$ reduce the formation of gastric mucosal injuries in a dose-dependent manner when compared to the group that was pretreated with only distilled water. The ulcer area recorded for groups pretreated with distilled water, 250 and $500 \mathrm{mg} / \mathrm{kg}$ extract, and $20 \mathrm{mg} / \mathrm{kg}$ omeprazole was $845.00 \pm 52.17 \mathrm{~mm}^{2}, 210.00 \pm 8.17 \mathrm{~mm}^{2}$, $70.00 \pm 8.27 \mathrm{~mm}^{2}$ and $30.00 \pm 5.32 \mathrm{~mm}^{2}$, respectively. In terms of percentage of protection, the respective test solution was found to give approximately $75.15 \%, 91.72 \%$, and $96.45 \%$ protection. Microscopically, distilled-water-pretreated rats exhibited severe damage of the gastric mucosa, and induced submucosal edema and leucocytes infiltration while extractor omeprazole-received rats exerted marked reduction of gastric mucosal damage, reduction of oedema, and less leucocyte infiltration of submucosal layer. There were no significant differences between the cytoprotective abilities of the animals treated with $20 \mathrm{mg} / \mathrm{kg}$ omeprazole compared to the animals treated with $500 \mathrm{mg} / \mathrm{kg}$ AMML. Overall, the $500 \mathrm{mg} / \mathrm{kg}$ AMML was found to provide the best protection to the gastric mucosa in rats against ethanol-induced gastric ulcers.

4.11. Antidiarrheal Activity. The antidiarrheal activity of WMML, collected from the State of Selangor, Malaysia, was investigated using four experimental models of diarrhea in mice [61]. In model 1 , mice were given test solutions (e.g., 100,200 , and $500 \mathrm{mg} / \mathrm{kg}$ of extract or $5 \mathrm{mg} / \mathrm{kg}$ loperamide) and fecal materials were collected for $12 \mathrm{~h}$ after treatment, dried in an incubator, and weighed. The percentage reduction in the fecal output was determined. In model 2, an overnight fasted male mouse was induced with diarrhea by oral administration of castor oil $(0.5 \mathrm{~mL} /$ mouse, p.o. $) 1$ hour after the test solutions administration. The percentage protection from diarrhoeal droppings was calculated. In model 3 , overnight fasted mice were subjected to the enteropooling assay method wherein the animals received the test solutions and, 1 hour later, administered orally with a diarrheal agent, $10 \%$ aq $\mathrm{MgSO}_{4}(0.5 \mathrm{~mL} /$ mouse). Thirty min later, the animals were killed and the small intestines were collected and weighed to find out the accumulation of intestinal fluid secretion evoked by $\mathrm{MgSO}_{4}$. In model 4, the overnight fasted animals were subjected to the gastrointestinal transit test. The animals received test solutions, and, $5 \mathrm{~min}$ later, $0.5 \mathrm{~mL}$ of $3 \%$ charcoal suspended with tragacanth powder was administered orally to each mouse. Thirty min later, all the mice were killed by cervical dislocation and the distance travelled by the charcoal plug from pylorus to caecum was determined and expressed as a percentage of the total length of the small intestine. From the data obtained in model 1, 100,200 , and $500 \mathrm{mg} / \mathrm{kg}$ WMML significantly $(P<0.05)$ reduced the dried fecal output of the mice (dried fecal output per $100 \mathrm{~g}$ of mice) by $0.364 \pm 0.012(30.13 \%$ reduction $)$, $0.314 \pm 0.046$ (39.73\% reduction), and $0.296 \pm 0.023(43.19 \%$ reduction), respectively, while the reduction in the fecal output by loperamide $(5 \mathrm{mg} / \mathrm{kg})$ was noted to be $0.222 \pm$ 0.015 ( $57.39 \%$ reduction) when compared to the control group $(0.521 \pm 0.083)$. In model 2 , the WMML, at its respective dose, significantly $(P<0.05)$ protected the mice against castor-oil-induced diarrheal droppings by 60,80 and $80 \%$, while loperamide produced the $100 \%$ protection. In model 3 , the 100,200 , and $500 \mathrm{mg} / \mathrm{kg}$ WMML significantly $(P<0.05)$ and dose-dependently reduced the intestinal fluid secretion induced by $\mathrm{MgSO}_{4}$, with the weight of the small intestine per $100 \mathrm{~g}$ of mice recorded at $8.413 \pm 0.431,7.620 \pm 0.469$, and $7.314 \pm 0.261$ when compared to the control group $(9.362 \pm$ $0.518)$. Interestingly, $500 \mathrm{mg} / \mathrm{kg}$ WMML caused reduction in the intestinal fluid secretion that was almost comparable with that of $5 \mathrm{mg} / \mathrm{kg}$ loperamide $(6.416 \pm 0.514)$. In model 4 , the 100,200 and $500 \mathrm{mg} / \mathrm{kg}$ WMML significantly $(P<0.05)$ inhibited the small intestinal motility of the charcoal marker in mice in a dose-dependent manner by $8.10 \%, 25.15 \%$, and $32.97 \%$ inhibition in comparison to $5 \mathrm{mg} / \mathrm{kg}$ loperamide (57.42\% inhibition). The respective distance travelled by charcoal marker for each dose of extract presented as percentage of total length of small intestine was recorded at $63.63 \pm 3.71,51.82 \pm 4.11$ and $46.41 \pm 3.25$ when compared to the control group $(69.24 \pm 5.03)$ or $5 \mathrm{mg} / \mathrm{kg}$ loperamide $(29.48 \pm 2.69)$.

4.12. Antivenom Activity. Uawonggul et al. [72] reported the antivenom profile of the aqueous extracts of 64 plant species, including M. malabathricum, collected from northern and northeastern parts of Thailand and have been listed as animal- or insect-bite antidotes in old Thai drug recipes. The extracts, at the concentration of 0.406 and $0.706 \mathrm{mg} / \mathrm{mL}$, were screened for their activity against fibroblast cell lysis after Heterometrus laoticus scorpion venom treatment. $H$. laoticus scorpions were captured from suburban areas of Khon Kaen City, Khon Kaen Province, Thailand. Most of the 
plants, at the concetration of $0.706 \mathrm{mg} / \mathrm{mL}$, were found to give more than $40 \%$ efficiency following cell treatment with venom preincubated with the respective extract with Andrographis paniculata Nees (Acanthaceae) and Barringtonia acutangula (L.) Gaertn. (Lecythidaceae) given more than 50\% efficiency, indicating that they had a tendency to be scorpion venom antidotes. However, AMML only caused $39.86 \%$ efficiency at $0.706 \mathrm{mg} / \mathrm{mL}$ and $34.41 \%$ efficiency at $0.406 \mathrm{mg} / \mathrm{mL}$. The percentage of viable cells after $30 \mathrm{~min}$ treatment with 0.706 and $0.406 \mathrm{mg} / \mathrm{mL}$ AMML preincubated with $0.2 \mu \mathrm{g} / \mathrm{mL} H$. laoticus venom were $14.84 \pm 1.03$ and $14.11 \pm 1.03$ in comparison to their respective mock control, which is $37.23 \pm 0.34$ and $41.00 \pm 0.52$, respectively.

4.13. Anti-Inflammatory Activity. Zakaria et al. [30] reported on the anti-inflammatory activity of AMML, collected from Shah Alam, Selangor, Malaysia. The anti-inflammatory activity was determined using only the carrageenan-induced paw edema wherein the extract, at the concentration of $10 \%$, $50 \%$, and $100 \%$, was administered via subcutaneous route and measurement of paw thickness was carried out for 8 hours following the extract administration with 1-hour interval. The concentration of AMML used was equivalent to the doses of $4.87,24.35$, and $48.7 \mathrm{mg} / \mathrm{kg}$, respectively. The AMML was found to show significant $(P<0.05)$ anti-inflammatory activity in a concentration-independent manner wherein the activity was seen only at the $50 \%$ and $100 \%$ concentrations. In terms of the onset of action, the AMML exhibited the anti-inflammatory activity 1 hour after its subcutaneous administration and this activity was seen until the end of experiments. Interestingly, $100 \mathrm{mg} / \mathrm{kg}$ acetylsalicylic acid (ASA), used as positive control, exerted similar strength of anti-inflammatory when compared to the extract as indicated by the statistically insignificant data at the respective time interval.

Susanti et al. [56] investigated the anti-inflammatory activity of pure compounds obtained from HMML, EAMML and MMML using the 12-O-tetradecanoylphorbol-13-acetate- (TPA-) induced mouse ear oedema assay. The pure compound $(20 \mu \mathrm{L})$ was applied topically to the inner surface of the right ear of the mice with the left ear receiving only vehicle acting as negative control group. The pure compounds $(0.5 \mathrm{mg} / \mathrm{ear})$ and the standard drug indomethacin (0.5 mg/ear) were applied topically, simultaneous with TPA. From the results obtained, $0.5 \mathrm{mg} / \mathrm{mL}$ kaempferol-3-O$\left(2^{\prime \prime}, 6^{\prime \prime}\right.$-di-O-p-trans-coumaroyl) glucoside and $\alpha$-amyrin demonstrated the strongest activities in the anti-inflammatory assay with the $\mathrm{IC}_{50}$ of approximately $0.11 \pm 0.4$ and $0.34 \pm 1.1 \mathrm{mM} /$ ear, respectively as compared to the $0.5 \mathrm{mg} / \mathrm{mL}$ indomethacin $(2.10 \pm 0.5 \mathrm{mM} /$ ear $)$. However, no data on the anti-inflammatory effect of those crude extracts were given for comparison with their pure compounds.

4.14. Antinociceptive Activity. The ethanolic extract of $M$. malabathricum stem barks and leaves (EMMSBL), collected from Serdang, Selangor, Malaysia, was earlier studied its antinociceptive activity using the acetic-acid-induced abdominal constriction and hot plate test in mice [73]. The extract, administered intraperitoneally in the doses of 30, 100 and $300 \mathrm{mg} / \mathrm{kg}$, was found to exert potential $(P<0.05)$ antinociceptive activity in a dose-dependent manner in the former test with the percentage of nocicptive inhibition recorded at $23.0 \%, 50.0 \%$, and $84.4 \%$, respectively. The $\mathrm{ED}_{50}$ recorded was approximately $100 \mathrm{mg} / \mathrm{kg}$ when given intraperitoneally. ASA, at $100 \mathrm{mg} / \mathrm{kg}$ dose, produced $79.0 \%$ nocicptive inhibition. In the latter test, the extract significantly $(P<0.05)$ increased the response latency period to thermal stimuli in mice also in a dose-dependent manner. The antinociceptive activity of EMMSBL reached its peak approximately $60 \mathrm{~min}$ after the extract administration. Morphine, at $5 \mathrm{mg} / \mathrm{kg}$ dose, significantly $(P<0.05)$ prolonged the response latency period with maximum effect obtained approximately $1 \mathrm{~h}$ after treatment. In an attempt to determine the role of opioid receptors in mediating the EMMSBL antinociceptive activity, $5 \mathrm{mg} / \mathrm{kg}$ naloxone, a nonselective opioid antagonist given via intraperitoneal route $15 \mathrm{~min}$ before the extract, was found to inhibit the antinociceptive activity of the extract in both tests.

Zakaria et al. [30] reported on the antinociceptive activity of the AMML, collected from Shah Alam, Selangor, Malaysia. The antinociceptive activity of subcutaneously administered extract, at the concentration of $10 \%, 50 \%$, and $100 \%$ (which is equal to the dose of $4.87,24.35$, and $48.7 \mathrm{mg} / \mathrm{kg}$, resp.), was determined using the acetic acid-induced abdominal constriction, hot plate and formalin test. The AMML was found to show significant $(P<0.05)$ antinociceptive activity in all the three tests. In the acetic-acidinduced abdominal constriction test, all concentrations of AMML caused significant $(P<0.05)$ reduction in the number of abdominal constriction which occur in a concentration-independent manner. The 10\%, 50\%, and 100\% AMML exerted similar strength in antinociceptive activity when compared together or against $100 \mathrm{mg} / \mathrm{kg}$ ASA. In the hot plate test, all concentrations of AMML also exhibited a significant $(P<0.05)$ antinociceptive activity in a concentration-independent manner with only the $50 \%$ and $100 \%$ concentrations of AMML exerting an antinociceptive activity that lasted until the end of the experiment. In this test, $5 \mathrm{mg} / \mathrm{kg}$ morphine was used as a positive control and was more effective in increasing the latency to feel thermalinduced pain when compared to the extract. In the formalin test, the AMML at all concentrations used exerted antinociceptive activity in both the early and late phases of the test. The concentration-dependent activity was observed only in the late phase of the test.

4.15. Antipyretic Activity. Zakaria et al. [30] also reported on the antipyretic activity of AMML, collected from Shah Alam, Selangor, Malaysia. The antipyretic activity of subcutaneously administered AMML, at the concentration of $10 \%$, $50 \%$ and $100 \%$, was determined using the Brewer's Yeast(BY-) induced pyrexia test. The ability of M. malabathricum extract to reduce temperature of pyrexia induced rats was determined for 8 hours with 1-hour interval. The AMML was found to show significant $(P<0.05)$ antipyretic activity at all concentrations tested for the first 6 hours after BY administration. A rapid decrease in the antipyretic activity of the $100 \%$ concentration of AMML $3 \mathrm{~h}$ after BY administration 
when compared with the other concentrations of AMML, with completely diminished activity observed for the last $2 \mathrm{~h}$ of the experiment. The $100 \mathrm{mg} / \mathrm{kg}$ ASA demonstrated antipyretic activity only for the first 4 hours before the activity was gradually lost until the end of experiment.

\section{Discussion and Conclusion}

According to Mitchell and Ahmad [74], the wealth of a country resides to a large extent in its plant inheritance, regardless of whether the plants are endemic, naturalized, or recent introductions. Out of a total of more than 4000 species of Melastomataceae plants in the world, M. malabathricum has been one of the 22 species found in the Southeast Asian region alone [1] and one of the 12 species found in Malaysia. Considered as native to tropical and temperate Asia and the Pacific Islands [4], this commonly found small shrub has gained herbal status in the Malay folklore belief as well as the Indian, Chinese, and Indonesian folk medicines. Despite claims that this plant was one of the important herbs within the traditional Malay, Indian, and Chinese medicine, no proper documentation could be found to support them. For example, no documentation that provides proofs for the claims of the importance of M. malabthricum in traditional Chinese medicine could be found when the authors carried out thorough search via university or public libraries, as well as the internet. Various parts of this shrub have been claimed to be used in the treatment of various types of ailments and diseases (e.g., diarrhoea, dysentery, leucorrhoea, hemorrhoids, cuts and wounds, infection during confinement, toothache, stomachache, flatulence, sore legs, and thrush) with most of them not yet proven via clinical studies [23]. Despite the lack of clinical studies related to this plant, several attempts have been made to elucidate the pharmacological properties of $M$. malabathricum using the standard and scientific in vitro and in vivo techniques of biological evaluations and to finally confirm those folklore claims.

Present interests towards the medicinal benefits of herbal medicines have been increasing worldwide as can be seen with increased laboratory investigation into the pharmacological properties of various medicinal plants. Scientists have also been involved in the isolation, identification, and determination of the bioactive ingredients with specific ability to treat various diseases [75]. Various drugs have entered the international market as a result of scientifically in-depth and systematic exploration of ethnopharmacology and traditional medicine. Despite the increase in scientific study towards medicinal plants all over the world, a smaller number of phytochemical entities or drugs have entered the local or international market due to their evidence-based therapeutics [74]. Due to the latter market trend, efforts are needed to ascertain and confirm evidence regarding safety and practices of plant-based medicines. Furthermore, plantbased medicines are erroneously considered safe because they are regarded as naturally occurring and of plant origin. According to Yob et al. [76], the lack of scientific and clinical data has led to poor understanding of the efficacy and safety of the herbal drugs, which in turn contributes to major impediment in the use of plant-based medicinal pre- parations. The only attempt to establish acute toxicity profile of M. malabathricum was performed by Sunilson et al. [61]. The authors reported the nontoxic effect of WMML up to the dosage of $2000 \mathrm{mg} / \mathrm{kg}$ when given to mice. This indicates that the WMML is safe for consumption even at the highest dosage $(2000 \mathrm{mg} / \mathrm{kg})$ tested and justifies the traditional uses of M. malabathricum.

The dosage range used for in vivo study was very important to corroborate with the dosages used in traditional medicine and the selection of dosage range should not exceed the maximum tolerated dose (MTD) of $1000 \mathrm{mg} / \mathrm{kg} / \mathrm{day}$ suggested for in vivo studies [77]. Based on MTD, the dosage range used for in vivo antiulcer, antidiarrheal, antinociceptive, anti-inflammatory, and antipyretic activities, which is between 4 and $500 \mathrm{mg} / \mathrm{kg}$, was considered acceptable. In the in vitro studies, the pharmacological activities shown have to be interpreted cautiously depending on the $\mathrm{EC}_{50}$ or $\mathrm{IC}_{50}$ value obtained for the respective study [76]. According to Meyer et al. [78] for any compounds/extracts to be considered active, they need to exhibit the respective activity at $\mathrm{EC}_{50}$ or $\mathrm{IC}_{50}$ value of less than or equal to $30 \mu \mathrm{g} / \mathrm{mL}(\leq 30 \mu \mathrm{g} / \mathrm{mL})$. Based on this suggestion, the antibacterial, antiviral, antiparasitic, and antivenom activities were observed at $\mathrm{EC}_{50}$ or $\mathrm{IC}_{50}$ values that are unrealistic and greater than $30 \mu \mathrm{g} / \mathrm{mL}$, and, thus, should be ignored. Some of the potential activities of M. malabathricum, as indicated by $\mathrm{EC}_{50}$ or $\mathrm{IC}_{50}$ value of $\leq 30 \mu \mathrm{g} / \mathrm{mL}$, include antifungal, antioxidant, and cytotoxic activities. The MMML, CMML, and AcMML exhibited antifungal activity against C. gloeosporioides with MIC of $20 \mu \mathrm{g} / \mathrm{mL}$ [64]. The MMMFw and EAMMFw exerted antioxidant activity in the DPPH assay at the $\mathrm{IC}_{50}$ of $6.59 \pm$ $0.8 \mu \mathrm{g} / \mathrm{mL}$ and $7.21 \pm 0.5 \mu \mathrm{g} / \mathrm{mL}$, respectively [22]. The MMMFw was also reported to show cytotoxic effect against 3LL, L1210, and U251 cell lines at the $\mathrm{IC}_{50}$ values of 19 , 21 , and $30 \mathrm{mg} / \mathrm{mL}$, respectively [32]. Another major flaw in some of the reports cited above was failure of the authors to provide proper comparison with reference drug [76]. The importance and reason for choosing certain routes of administration and in vitro rather than in vivo assays in some of the studies have been discussed by Yob et al. [76].

In this paper, we intended to briefly summarize the in vitro and in vivo assays applied in the discovery of possibly new pharmacological agents from M. malabathricum. In addition, various literatures pertinent to the pharmacological investigation of $M$. malabathricum were reviewed to gather all information related to the ethnobotanical, phytochemical, and pharmacological properties of M. malabathricum. Although various scientific papers were published on pharmacological properties of M. malabathricum, detailed and careful analysis revealed that $M$. malabathricum only exhibited promising antiulcer, antidiarrheal, antinociceptive, antiinflammatory, and antipyretic activities as measured via the various in vivo assays and antifungal, antioxidant, and cytotoxic activities as measured by the in vitro assays.

Despite the various medicinal uses of M. malabathricum as described in the ethnobotanical section, the therapeutics efficacy of this plant has not been fully studied indepth. Even though there are various types of bioactive compounds isolated and identified from M. malabathricum as 
highlighted in the phytochemical section, their contribution towards the plant claimed medicinal uses or demonstrated pharmacological activities were also not fully studied. Thus, the quest for new compounds from M. malabathricum with specific pharmacological activity remains unsolved. It is suggested that researches should be increased to isolate, identify, and collect most of the reported new compounds from $M$. malabathricum so that their pharmacological potential could be investigated thoroughly if they were to be developed as candidates for new drug development in the future. In conclusion, it is hoped that this paper will serve as an encouragement for others to further explore the pharmacological potentials of $M$. malabathricum with hope of developing it as a new therapeutic agents as it is considered as one of the important herbs, particularly in the Malay folklore medicine.

\section{Acknowledgments}

The authors thank the Faculty of Medicine and Health Sciences, Universiti Putra Malaysia for providing the necessary support for this study. This research was supported by a Research University Grant Scheme 2010 (04/02/10/0925RU) from the Universiti Putra Malaysia.

\section{References}

[1] M. T. Rajenderan, "Ethno medicinal uses and antimicrobial properties of Melastoma malabathricum," SEGi Review, vol. 3, pp. 34-44, 2010.

[2] K. Meyer, "Revision of the Southeast Asian genus Melastoma (Melastomataceae)," Blumea: Journal of Plant Taxonomy and Plant Geography, vol. 46, no. 2, pp. 351-398, 2001.

[3] J. L. C. H. van Valkenberg and N. Bunyapraphatsara, "Melastoma malabathricum L.," in Plant Resources of South-East Asia No. 12(2): Medicinal and Poisonous Plants 2, J. L. C. H. van Valkenburg and N. Bunyapraphatsara, Eds., pp. 365-366, Backhuys, Leiden, The Netherlands, 2001.

[4] K. H. Ling, C. T. Kian, and T. C. Hoon, A Guide to Medicinal Plants. An Illustrated, Scientific and Medicinal Approach, World Scientific, Singapore, 2009.

[5] W. Wong, Melastoma malabathricum: Too Beautiful to Be Called $a$ Weed, Green Culture, Singapore, 2008.

[6] F. A. Abdul Majid and L. Y. Ting, "Basic in vitro studies of human skin culture: Melastoma malabathricum extract on fibroblasts growth," February 2011, http://eprints.utm.my/ 2850/1/75127.pdf.

[7] A. S. M. Fazlin, Z. Ahmad, and H. H. Lim, Compendium of Medicinal Plants Used in Malaysia, vol. 2, Herbal Medicine Research Centre, Institute for Medical Research, Kuala Lumpur, Malaysia, 2002.

[8] P. W. Grosvenor, P. K. Gothard, N. C. McWilliam, A. Supriono, and D. O. Gray, "Medicinal plants from Riau Province, Sumatra, Indonesia. Part 1: uses," Journal of Ethnopharmacology, vol. 45, no. 2, pp. 75-95, 1995.

[9] G. Umali-Stuart and A. Stiuart-Santiago, "Phillippine Medicinal Plants: Family Melastomaceae," February 2010, http:// www.stuartxchange.org/Malatungaw.html.

[10] W. Zhengyi, P. H. Raven, and D. Y. Hong, Flora of China (Vol. 13) (Clusiaceae through Araliaceae), Missouri Botanical Garden Press, St. Louis, Mo, USA, 2007.
[11] H. K. Sharma, L. Chhangte, and A. K. Dolui, "Traditional medicinal plants in Mizoram, India," Fitoterapia, vol. 72, no. 2, pp. 146-161, 2001.

[12] A. D. Khumbongmayum, M. L. Khan, and R. S. Tripathi, "Ethnomedicinal plants in the sacred groves of Manipur," Indian Journal of Traditional Knowledge, vol. 4, pp. 21-32, 2005.

[13] C. Pattanaik, C. Sudhakar Reddy, and M. S. R. Murthy, "An ethnobotanical survey of medicinal plants used by the Didayi tribe of Malkangiri district of Orissa, India," Fitoterapia, vol. 79, no. 1, pp. 67-71, 2008.

[14] H. N. Thatoi, S. K. Panda, S. K. Rath, and S. K. Dutta, "Antimicrobial activity and ethnomedicinal uses of some medicinal plants from Similipal Biosphere Reserve, Orissa," Asian Journal of Plant Sciences, vol. 7, no. 3, pp. 260-267, 2008.

[15] C. L. Ringmichon, S. N. Shimpi, and B. Gopalkrishnan, "Ethnomedicinal investigations of Melastoma malabathricum Linn. from Manipur," Journal of Herbal Medicine and Toxicology, vol. 4, pp. 141-144, 2010.

[16] R. Kagyung, P. R. Gajurel, P. Rethy, and B. Singh, "Ethnomedicinal plants used for gastro-intestinal diseases by Adi tribes of Dehang-Debang Biosphere Reserve in Arunachal Pradesh," Indian Journal of Traditional Knowledge, vol. 9, no. 3, pp. 496-501, 2010.

[17] N. S. Jamir, Takatemjen, and Limasemba, "Traditional knowledge of Lotha-Naga tribes in Wokha district, Nagaland," Indian Journal of Traditional Knowledge, vol. 9, no. 1, pp. 4548, 2010.

[18] M. Rahmatullah, M. S. Hossain, A. Hanif et al., "Ethnomedicinal applications of plants by the traditional healers of the Marma tribe of Naikhongchhari, Bandarban district, Bangladesh," Advances in Natural and Applied Sciences, vol. 3, pp. 392-401, 2009.

[19] M. Rahmatullah, I. J. Mukti, A. K. M. Fahmidul Haque et al., "An ethnobotanical survey and pharmacological evaluation of medicinal plants used by the Garo tribal community living in Netrakona district, Bangladesh," Advances in Natural and Applied Sciences, vol. 3, pp. 402-418, 2009.

[20] M. Rahmatullah, R. Jahan, M. S. Hossan et al., "A comparative analysis of medicinal plants used by three tribes of Chittagong hill tracts region, Bangladesh to treat leukorrhea," Advances in Natural and Applied Sciences, vol. 4, no. 2, pp. 148-152, 2010.

[21] M. Zakaria and M. A. Mohd, Traditional Malay Medicinal Plants, Fajar Bakti Sdn. Bhd., Kuala Lumpur, Malaysia, 1994.

[22] D. Susanti, H. M. Sirat, F. Ahmad, R. M. Ali, N. Aimi, and M. Kitajima, "Antioxidant and cytotoxic flavonoids from the flowers of Melastoma malabathricum L," Food Chemistry, vol. 103, no. 3, pp. 710-716, 2007.

[23] S. S. Koay, Establishment of cell suspension culture of Melastoma malabathricum L. for the production of anthocyanin, Ph.D. thesis, Universiti Sains Malaysia, Pulau Pinang, Malaysia, 2008.

[24] I. H. Burkill, A Dictionary of Economic Products of Malay Peninsular, Ministry of Agriculture and Cooperatives, Kuala Lumpur, Malaysia, 1966.

[25] I. B. Jaganath and L. T. Ng, Herbs: The Green Pharmacy of Malaysia, Vinpress Sdn. Bhd., Kuala Lumpur, Malaysia, 2000.

[26] D. Begum and S. C. Nath, "Ethnobotanical review of medicinal plants used for skin diseases and related problems in Northeastern India," Journal of Herbs, Spices and Medicinal Plants, vol. 7, no. 3, pp. 55-93, 2000.

[27] S. Bharadwaj and S. K. Gakhar, "Ethnomedicinal plants used by tribals of Mizorum to use cuts and wounds," Indian Journal of Traditional Knowledge, vol. 4, pp. 75-80, 2005. 
[28] T. W. Hugh Tan and C. K. Yeo, The Potential of Native Woody Plants for Enhancing the Urban Waterways and Waterbodies Environment in Singapore, Raffles Museum of Biodiversity Research and Singapore-Delft Water Alliance, National University Singapore, Singapore, 2009.

[29] A. Latiff and A. H. Zakri, "Protection of Traditional Knowledge, Innovations and Practices: The Malaysian Experience," in the UNCTAD Expert Meeting on Systems and National Experiences for Protecting Traditional Knowledge, Innovations and Practices, Geneva, Switzerland, October-November 2000.

[30] Z. A. Zakaria, M. N. R. N. S. Raden, G. Hanan Kumar et al., "Antinociceptive, anti-inflammatory and antipyretic properties of Melastoma malabathricum leaves aqueous extract in experimental animals," Canadian Journal of Physiology and Pharmacology, vol. 84, no. 12, pp. 1291-1299, 2006.

[31] A. L. Sajem and K. Gosai, "Traditional use of medicinal plants by the Jaintia tribes in North Cachar Hills district of Assam, northeast India," Journal of Ethnobiology and Ethnomedicine, vol. 2, article no. 33, 2006.

[32] F. Lohézic-Le Dévéhat, A. Bakhtiar, C. Bézivin, M. Amoros, and J. Boustie, "Antiviral and cytotoxic activities of some Indonesian plants," Fitoterapia, vol. 73, no. 5, pp. 400-405, 2002.

[33] K. W. Lin, "Ethnobotanical study of medicinal plants used by the Jah Hut peoples in Malaysia," Indian Journal of Medical Sciences, vol. 59, no. 4, pp. 156-161, 2005.

[34] S. K. Jain and R. A. De Filipps, Medicinal Plants of India, Reference Publication Inc., Algonac, Mich, USA, 1991.

[35] S. Mohandoss and P. Ravindran, "Flavonoids from Melastoma melabathricum," Fitoterapia, vol. 64, no. 3, pp. 277-278, 1993.

[36] L. M. Perry, Medicinal Plants of East and Southeast Asia, Harvard University, Cambridge, Mass, USA, 1980.

[37] S. Elliott and J. Brimacombe, "The medicinal plants of Gunung Leuser National Park, Indonesia," Journal of Ethnopharmacology, vol. 19, no. 3, pp. 285-317, 1987.

[38] H. C. Ong and M. Nordiana, "Malay ethno-medico botany in Machang, Kelantan, Malaysia," Fitoterapia, vol. 70, no. 5, pp. 502-513, 1999.

[39] H. C. Ong and J. Norzalina, "Malay herbal medicine in Gemencheh, Negri Sembilan, Malaysia," Fitoterapia, vol. 70, no. 1, pp. 10-14, 1999.

[40] K. Roosita, C. M. Kusharto, M. Sekiyama, Y. Fachrurozi, and R. Ohtsuka, "Medicinal plants used by the villagers of a Sundanese community in West Java, Indonesia," Journal of Ethnopharmacology, vol. 115, no. 1, pp. 72-81, 2008.

[41] J. B. Lowry, "The distribution and potential taxonomic value of alkylated ellagic acids," Phytochemistry, vol. 7, no. 10, pp. 1803-1813, 1968.

[42] J. B. Lowry, "Anthocyanins of the Melastomataceae, Myrtaceae and some allied families," Phytochemistry, vol. 15, no. 4, pp. 513-516, 1976.

[43] M. Manzoor-I-Khuda, S. A. Chowdhury, T. Reza, and A. K. Chowdhury, "Chemical Investigation on Melastoma Malabathricum. Part 1: Isolation of Melastomic Acid and Betasitosterol from the Roots," Journal of the Bangladesh Academy of Sciences, vol. 5, pp. 55-59, 1981.

[44] B. Dinda and M. K. Saha, "Aliphatic compounds from Melastoma malabathricum," Journal of the Indian Chemical Society, vol. 63, pp. 764-766, 1986.

[45] B. Dinda and M. K. Saha, "Fatty acid sterols from Melastoma malabathricum," Journal of the Indian Chemical Society, vol. 63, pp. 144-145, 1986.

[46] K. K. Dass and J. J. Kotoky, "A new aliphatic constituent of Melastoma malabathricum Linn.," Journal of the Indian Chemical Society, vol. 65, pp. 385-386, 1988.
[47] B. Dinda and M. K. Saha, "A flavonol-diglycoside from Melastoma malabathricum," Journal of the Indian Chemical Society, vol. 65, pp. 209-211, 1988.

[48] T. Yoshida, F. Nakata, K. Hosotani, A. Nitta, and T. Okuda, "Dimeric hydrolysable tannins from Melastoma malabathricum," Phtochemistry, vol. 31, pp. 2829-2833, 1992.

[49] T. Yoshida, F. Nakata, K. Hosotani, A. Nitta, and T. Okuda, "Tannins and related polyphenols of melastomataceous plants. V. Three new complex tannins from Melastoma malabathricum L," Chemical and Pharmaceutical Bulletin, vol. 40, no. 7, pp. 1727-1732, 1992.

[50] N. Pongprom, C. Khanapan, and P. Tosert, "Chemical constituents of Melastoma malabathricum Linn," in the 29th Congress on Science and Technology of Thailand, p. 130, Khon Kaen, Thailand, October 2003.

[51] S. Nuresti, S. H. Baek, and A. Asari, "Chemical components of Melastoma malabathricum," ACGC Chemical Research Communications, vol. 16, pp. 28-33, 2003.

[52] D. M. H. Ali, K. C. Wong, and L. P. Boey, Triterpenoids, Glycolipids and Flavonoids of Melastoma malabathricum: Isolation, Spectrometric Characterization and Antibacterial Activity, VDM, Saarbrücken, Germany, 2010.

[53] K. C. Wong, P. L. Boey, and D. M. H. Ali, "Phytochemical and biological study of Melastoma malabathricum L., a local plant used in traditional medicine," MIDAS Bulletin, vol. 32, p. 8, 2004.

[54] D. M. H. Ali, K. C. Wong, and L. P. Boey, "Flavonoids from the Flowers of Melastoma malabathricum," Working Paper. Universiti Sains Malaysia, March 2001, http://eprints.usm.my/ 8175/1/Flavonoids_from_the_flowers_of_Melastoma_malabathricum_(PPSKimia).pdf.

[55] I. Nazlina, S. Norha, A. W. Noor Zarina, and I. B. Ahmad, "Cytotoxicity and antiviral activity of Melastoma malabathricum extracts," Malaysian Journal of Applied Biology, vol. 37, pp. 53$55,2008$.

[56] D. Susanti, H. M. Sirat, F. Ahmad, and R. Mat Ali, "Bioactive constituents from the leaves of Melastoma malabathricum L.," Jurnal Ilmiah Farmasi, vol. 5, pp. 1-8, 2008.

[57] M. Simanjuntak, Ekstraksi and fraksinasi komponen ekstrak daun tumbuhan senduduk (Melsatoma malabathricum) serta pengujian efek sediaan krim terhadap penyembuhan luka bakar, M.S. thesis, Universitas Sumatera Utara, Sumatera, Indonesia, 2008, http://repository.usu.ac.id/bitstream/123456789/14472/1/09E01171.pdf.

[58] M. Faravani, The population biology of Straits Rhododendron (Melastoma malabathricum L.), Ph.D. thesis, University of Malaya, Kuala Lumpur, Malaysia, 2009.

[59] B. Dinda and M. K. Saha, "Free amino acids of Melastoma malabathricum," Journal of the Indian Chemical Society, vol. 62, pp. 789-790, 1985.

[60] H. H. Yeoh, Y. C. Wee, and L. Watson, "Leaf protein contents and amino acid patterns of dicotyledonous plants," Biochemical Systematics and Ecology, vol. 20, no. 7, pp. 657-663, 1992.

[61] J. A. J. Sunilson, K. Anandarajagopal, A. V. A. G. Kumari, and S. Mohan, "Antidiarrhoeal activity of leaves of Melastoma malabathricum linn," Indian Journal of Pharmaceutical Sciences, vol. 71, no. 6, pp. 691-695, 2009.

[62] P. W. Grosvenor, A. Supriono, and D. O. Gray, "Medicinal plants from Riau Province, Sumatra, Indonesia. Part 2: antibacterial and antifungal activity," Journal of Ethnopharmacology, vol. 45, no. 2, pp. 97-111, 1995. 
[63] C. Wiart, S. Mogana, S. Khalifah et al., "Antimicrobial screening of plants used for traditional medicine in the state of Perak, Peninsular Malaysia," Fitoterapia, vol. 75, no. 1, pp. 68-73, 2004.

[64] L. Johnny, U. K. Yusuf, and R. Nulit, "The effect of herbal plant extracts on the growth and sporulation of Colletotrichum gloeosporioides," Journal of Applied Biosciences, vol. 34, pp. 2218-2224, 2010.

[65] S. Maji, P. Dandapat, D. Ojha et al., "In vitro antimicrobial potentialities of different solvent extracts of ethnomedicinal plants against clinically isolated human pathogens," Journal of Phytology, vol. 2, pp. 57-64, 2010.

[66] J. A. J. Sunilson, J. James, J. Thomas, P. Jayaraj, R. Varatharajan, and M. Muthappan, "Antibacterial and wound healing activities of Melastoma malabathricum Linn.," African Journal of Infectious Disease, vol. 2, pp. 68-73, 2008.

[67] Y. Alen, S. Nakajima, T. Nitoda, N. Baba, H. Kanzaki, and K. Kawazu, "Antinematodal activity of some tropical rainforest plants against the pinewood nematode Bursaphelenchus xylophilus," Zeitschrift fur Naturforschung C, vol. 55, no. 3-4, pp. 295-299, 2000.

[68] C. Manicam, J. O. Abdullah, E. R. Mohd Tohit, Z. Seman, C. C. Sieo, and M. Hamid, "In vitro anticoagulant activities of Melastoma malabathricum Linn. aqueous leaf extract: a preliminary novel finding," Journal of Medicinal Plants Research, vol. 4, pp. 1464-1472, 2010.

[69] I. Jantan, I. A. A. Rafi, and J. Jalil, "Platelet-activating factor (PAF) receptor-binding antagonist activity of Malaysian medicinal plants," Phytomedicine, vol. 12, no. 1-2, pp. 88-92, 2005.

[70] M. P. Mazura, D. Susanti, and M. A. Rasadah, "Anti-inflammatory action of components from Melastoma malabathricum," Pharmaceutical Biology, vol. 45, no. 5, pp. 372-375, 2007.

[71] F. Hussain, M. A. Abdulla, S. M. Noor, S. Ismail, and H. M. Ali, "Gastroprotective effects of Melastoma malabathricum aqueous leaf extract against ethanol-induced gastric ulcer iin rats," American Journal of Biochemistry and Biotechnology, vol. 4, no. 4, pp. 438-441, 2008.

[72] N. Uawonggul, A. Chaveerach, S. Thammasirirak, T. Arkaravichien, C. Chuachan, and S. Daduang, "Screening of plants acting against Heterometrus laoticus scorpion venom activity on fibroblast cell lysis," Journal of Ethnopharmacology, vol. 103, no. 2, pp. 201-207, 2006.

[73] M. R. Sulaiman, M. N. Somchit, D. A. Israf, Z. Ahmad, and S. Moin, "Antinociceptive effect of Melastoma malabathricum ethanolic extract in mice," Fitoterapia, vol. 75, no. 7-8, pp. 667-672, 2004.

[74] S. A. Mitchell and M. H. Ahmad, "A review of medicinal plant research at the University of the West Indies, Jamaica, 19482001," West Indian Medical Journal, vol. 55, no. 4, pp. 243-269, 2006.

[75] W. J. Craig, "Phytochemicals: guardians of our health," Journal of the American Dietetic Association, vol. 97, no. 10, pp. S199204, 1997.

[76] N. J. Yob, S. Mohd. Joffry, M. M. R. Meor. Mohd. Affandi, L. K. Teh, M. Z. Salleh, and Z. A. Zakaria, "Zingiber zerumbet (L.) Smith: a review of its ethnomedicinal, chemical and pharmacological uses," Evidence-Based Complimentary and Alternative Medicine, vol. 2011, Article ID 543216, 12 pages, 2011.

[77] USEPA, "Points for discussion in the selection of dose levels for mammalian in vivo Tier 1 assays," December 2010, http:// www.epa.gov/endo/pubs/edmvs/tier1doseselectionptsv2.pdf.
[78] B. N. Meyer, N. R. Ferrigni, and J. E. Putnam, "Brine shrimp: a convenient general bioassay for active plant constituents," Planta Medica, vol. 45, no. 1, pp. 31-34, 1982. 


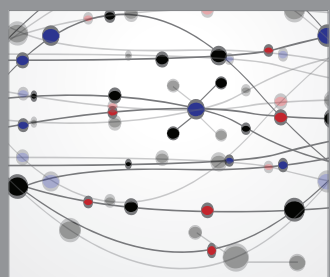

The Scientific World Journal
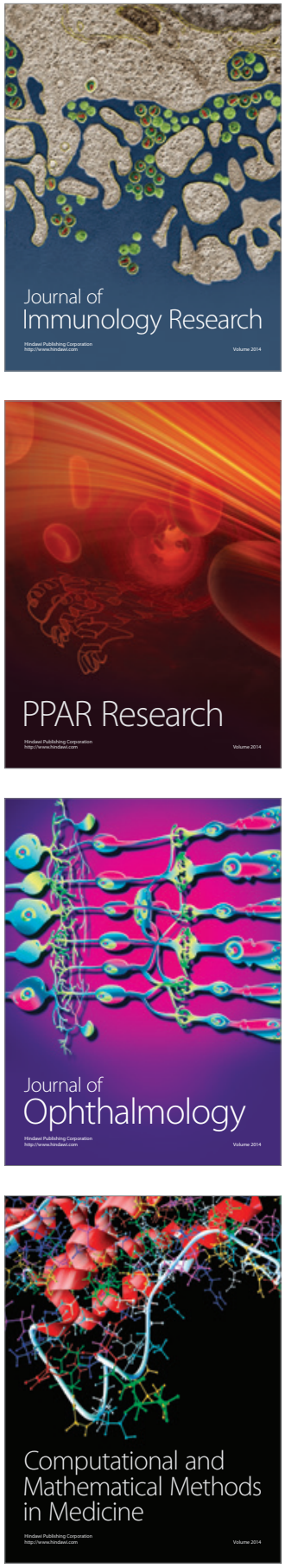

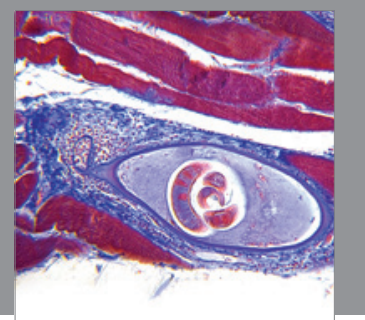

Gastroenterology

Research and Practice
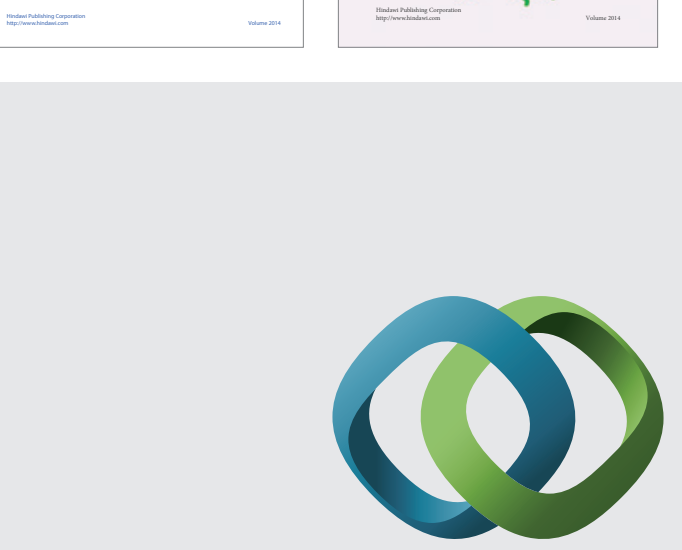

\section{Hindawi}

Submit your manuscripts at

http://www.hindawi.com
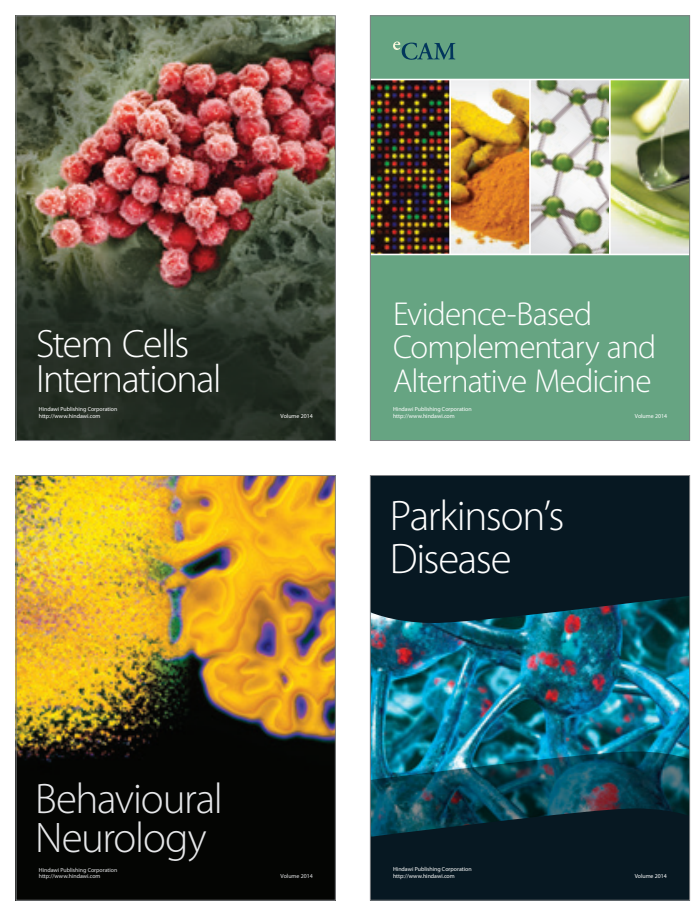

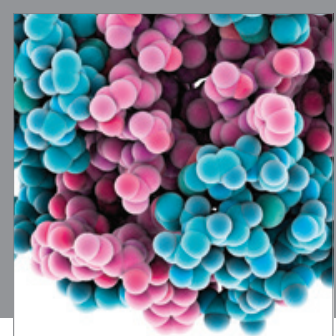

Journal of
Diabetes Research

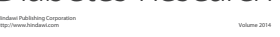

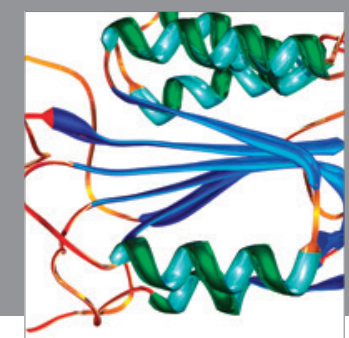

Disease Markers
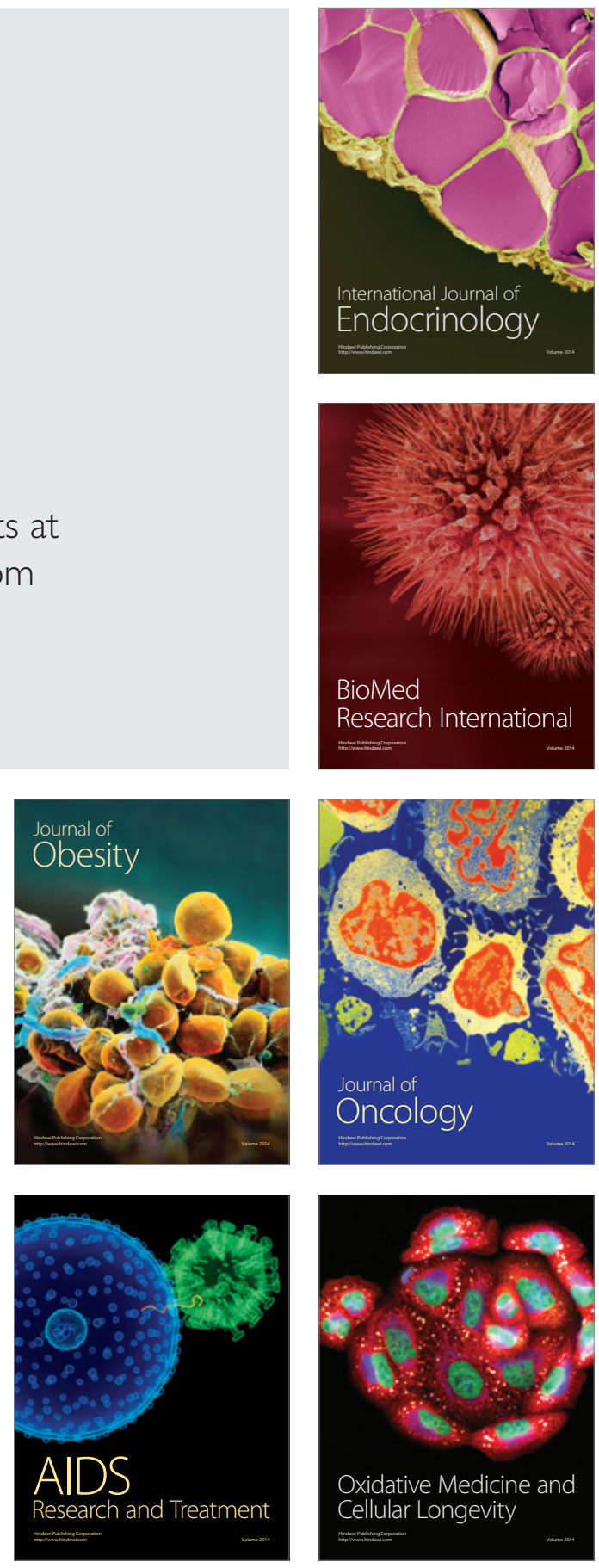